MAÑALICH, Juan Pablo, “Tentativa, error y dolo. Una reformulación normológica de la

distinción entre tentativa y delito putativo".

Polít. crim. Vol. 14, No 27 (Julio 2019), Art. 10, pp. 296-375.

[http://politcrim.com/wp-content/uploads/2019/05/Vol14N27A10.pdf]

\title{
Tentativa, error y dolo \\ Una reformulación normológica de la distinción entre tentativa y delito putativo*
}

\section{Attempt, mistake and mens rea. \\ A norm-logical reformulation of the distinction between attempted and putative offenses}

\author{
Juan Pablo Mañalich R. \\ Doctor en derecho \\ Profesor titular del Departamento de Ciencias Penales, Universidad de Chile \\ jpmanalich@derecho.uchile.cl
}

\section{Resumen}

El artículo explora algunas conexiones fundamentales que existen entre la dogmática de la tentativa y la dogmática del dolo. El punto de partida para ello se obtiene de la caracterización general de la tentativa de delito como una estructura de imputación constituida sobre un error fundante-de-dolo. Ello exige clarificar la noción misma de dolo, que resulta desacoplada de la noción de conocimiento, así como examinar el mérito del así llamado "argumento de la inversión". El paso siguiente consiste en la impugnación de la tradicional distinción entre las categorías de tentativa idónea y tentativa inidónea, para luego reconstruir detalladamente la distinción entre las categorías de tentativa y delito putativo, en referencia a los casos de causalidad putativa y los casos de error invertido acerca de un elemento normativo del tipo. El trabajo se cierra con un análisis del problema de la así llamada "tentativa subjetivamente inidónea", que lleva a su identificación como una constelación ulterior de delito putativo.

Palabras clave: tentativa, dolo, error invertido, idoneidad e inidoneidad de la tentativa, delito putativo

\begin{abstract}
The paper explores some fundamental connections that exist between the doctrines of attempts and of means rea. The starting point is provided by the general characterization of the concept of attempt as an imputation structure built upon a dolus-grounding mistake. This imposes the need of both clarifying the very notion of dolus, which becomes disengaged from the notion of knowledge, and examining the merit of the so called "inversion argument". The next step consists in a rejection of the traditional distinction between the categories of possible and impossible attempts, in order to carefully reconstruct

\footnotetext{
* El presente artículo se enmarca en el Proyecto Fondecyt $\mathrm{N}^{\circ} 1160147$ (regular), del cual el autor es investigador responsable. Por sus comentarios, observaciones y correcciones, agradezco a Flavia Carbonell, Javier Contesse, Gissella López, Juan Pablo Montiel y Alejandra Olave. A Julio Cortés y Felipe Bonzi, ayudantes ad honorem del Departamento de Ciencias Penales, debo gratitud por su generosa colaboración en la edición del borrador.
} 
the distinction between attempted and putative offenses, with reference to the cases of putative causation and of an inverted mistake concerning a normative element of the definition of an offense. The paper closes with an analysis of the problem of so called "subjectively impossible attempts", that leads to their assessment as a constellation of putative offense.

Keywords: attempt, means rea, inverted mistake, possibility and impossibility of attempts, putative offense

\section{La tentativa como error}

En su tan fundamental como soslayado Strafrecht nach logisch-analytischer Methode observaba Hruschka que, en cuanto estructuras de imputación, la tentativa y la imprudencia muestran un paralelismo no suficientemente advertido. ${ }^{1}$ Lo que ambas estructuras tienen en común se vuelve reconocible a partir de la constatación de su respectiva divergencia frente al paradigma del delito doloso consumado. La constitución de un delito doloso consumado depende de que la realización no-justificada del respectivo tipo-de-delito resulte imputable a título de dolo. Frente a este paradigma, tanto la tentativa del delito respectivo como el correspondiente delito imprudente exhiben un determinado déficit, que se ve compensado a través de un respectivo criterio de subrogación. En el caso del delito imprudente, la falta de dolo se ve compensada por la posibilidad y exigibilidad de que el agente se representara las circunstancias que objetivamente constituyeron la correspondiente instancia de realización no-justificada del tipo en cuestión. ${ }^{2}$ En el caso de la tentativa de delito, en cambio, el déficit en cuestión está constituido por la falta de realización no-justificada del tipo, el cual se vería compensado por el "principio de ejecución" del hecho. ${ }^{3}$

Lo anterior significa que la tentativa y la imprudencia tienen en común una discrepancia entre las circunstancias efectivamente existentes y las circunstancias que el agente se representa como existentes. Esto determina que tanto la tentativa como la imprudencia puedan ser entendidas como estructuras de imputación que, al descansar en la existencia de tal discrepancia, se distinguen por consistir en sendas formas de error. En lo específicamente concerniente a la estructura de la tentativa, este hallazgo fue claramente documentado por Hälschner, quien ya en 1881 observaba que la tentativa conlleva, en todos los casos, "un error del agente" como un elemento conceptual necesario. ${ }^{4}$ Sobre la base de una concepción general de la tentativa de delito como delito imperfecto, desarrollada a partir de un determinado modelo de teoría de las normas, ${ }^{5}$ este trabajo buscará sustentar la caracterización de la tentativa de delito como una estructura de imputación construida sobre la noción de error, para así corroborar la hipótesis de que la clave para la elaboración de la dogmática de la tentativa se encuentra en la dogmática del dolo.

\footnotetext{
${ }^{1}$ HRUSCHKA, Joachim, Strafrecht nach logisch-analytischer Methode, $2^{\mathrm{a}}$ ed, Berlín: Walter de Gruyter, 1988 , pp. 185 ss.

${ }^{2}$ En detalle al respecto MAÑALICH, Juan Pablo, "La imprudencia como estructura de imputación", Revista de Ciencias Penales XLII, no 3, 2015, pp. 13-35, pp. 15 ss., 21 ss.

${ }^{3}$ HRUSCHKA, Strafrecht, cit. nota no 1 , p. 188.

${ }^{4}$ HÄLSCHNER, Hugo, Das Gemeine Deutsche Strafrecht, vol. I., Bonn: Adolph Marcus, 1881, p. 344.

${ }^{5}$ Véase MAÑALICH, Juan Pablo, "La tentativa como hecho punible. Una aproximación analítica", Revista Chilena de Derecho 44, n 2, 2017, pp. 461-493, passim.
} 
La afirmación de que es constitutiva de toda tentativa la existencia de un error fundante-dedolo ha sido tradicionalmente validada por los partidarios de una concepción subjetivista del fundamento de punibilidad de la tentativa. ${ }^{6}$ Pero el modelo teórico aquí desplegado se distancia críticamente de los postulados subjetivistas, aun cuando de una manera que no conduce a la validación, como contrapartida, de una concepción ortodoxamente objetivista. Pues mientras el común denominador de las — por lo demás muy heterogéneas - versiones de una concepción objetivista ha tendido a quedar asociado a alguna exigencia de peligrosidad del respectivo comportamiento como presupuesto de su punibilidad qua tentativa, la concepción aquí favorecida identifica la objetividad de la constitución de una tentativa como hecho punible con la objetividad de la fundamentación del dolo. Una consecuencia fundamental que se sigue de la aproximación así delineada consiste en la superación de la tradicional distinción entre las categorías de tentativa idónea y tentativa inidónea, sea que la distinción quede vinculada a la adopción de una perspectiva ex post $\mathrm{o}$ a una perspectiva ex ante.

El artículo procurará demostrar, adicionalmente, que el recurso al así llamado "principio de inversión" no es apto para hacer operativa la irrenunciable distinción entre casos de tentativa y casos de delito putativo, en la medida en que, según cómo se lo formule, el argumento apoyado en semejante principio resulta ser o bien lógicamente vicioso o bien tautológico. Antes bien, la distinción en cuestión queda determinada por el hecho de que una adecuada reconstrucción teórica de la organización de los presupuestos de punibilidad de un comportamiento cualquiera conduce a que se vea operativamente descartada, de entrada, la posible tematización de tal cosa como un delito putativo. ${ }^{7}$ Esta última consideración es decisiva, al mismo tiempo, para la presentación de un argumento, construido sobre la base del ya referido modelo de teoría de las normas, conducente a demostrar que los casos de una así llamada "tentativa subjetivamente inidónea", en los cuales un extraneus erróneamente se tiene por destinatario de una norma cuyo quebrantamiento es constitutivo de un delito especial, resultan ser casos de delito putativo.

\section{El "error-sobre-el-delito" y su inversión}

\subsection{La antinormatividad como propiedad superveniente}

La tesis según la cual la estructura de toda tentativa de delito se corresponde con la de un error de cierta clase puede ser más precisamente formulada como sigue: es constitutivo de la estructura de toda tentativa que el potencial autor haga o deje de hacer algo bajo la creencia predictiva de que su comportamiento habrá de exhibir las propiedades que objetivamente lo harían ejemplificar el correspondiente género de comportamiento

\footnotetext{
${ }^{6}$ Véase ya VON BURI, Maximilian, “Über die sog. untauglichen Versuchshandlungen”, Zeitschrift für die gesamte Strafrechtswissenschaft 1, 1881, pp. 185-210, p. 185. Para un enérgico rechazo de esta proposición, véase ya BINDING, Karl, Die Normen und ihre Übertretung, tomo III, Léipzig: Felix Meiner, 1918, pp. 407 ss., $421 \mathrm{ss.}$

${ }^{7}$ Así recientemente KINDHÄUSER, Urs, "Versuch und Wahn. Zum Irrtum über Rechtstatsachen", en: SAFFERLING, Christoph et al. (coords.), Festschrift für Franz Streng zum 70. Geburtstag, Heidelberg: C.F. Müller, 2017, pp. 325-342, p. 325.
} 
antinormativo, en circunstancias de que esa creencia resulta ser, ex post, falsa. ${ }^{8}$ Pero sostener que, en este preciso sentido, la estructura de toda tentativa es la de un error no equivale a sostener que la fundamentación sustantiva de su punibilidad pueda ser reducida a una argumentación construida a partir de algunas premisas extraídas de la dogmática del error. Como se explicará más abajo, esto último es lo que distingue, empero, a algunas de las versiones más célebres del recurso (falaz) al así llamado "argumento de inversión" para intentar sustentar una fundamentación subjetivista de la punibilidad de la tentativa. ${ }^{9}$

La noción de "error invertido" fue originariamente acuñada por Binding, con el propósito de designar la forma de error que representaría — valga la redundancia - la inversión de un "error-sobre-el-delito" (Deliktsirrtum). ${ }^{10}$ Este último consistiría en el desconocimiento de la antinormatividad —entendida aquí como el carácter objetivamente delictivo- del respectivo comportamiento. ${ }^{11}$ Tal error-sobre-el-delito podría derivar, por un lado, del desconocimiento de que el respectivo comportamiento satisface uno o más de los "elementos de la acción en sentido estricto", esto es, que exhibe aquellas propiedades primarias o "básicas" de cuya instanciación por el respectivo comportamiento depende que

\footnotetext{
${ }^{8}$ MAÑALICH, "La tentativa", cit. nota $n^{0}$ 5, pp. 475 ss., 483 ss. Nótese que la verdad o la falsedad de la respectiva creencia predictiva depende de que el estado de cosas al que ella se encuentra referida llegue o no a ser el caso; el grado de probabilidad que acompañe la representación del agente acerca de que el estado de cosas en cuestión llegará a ser el caso es extrínseco a ese mismo estado de cosas, de manera tal que la verdad o falsedad de la creencia en cuestión es insensible a la probabilidad que la modaliza. Al respecto, véase el análisis de la noción de predicción que, como categoría de acto de habla, se ofrece en SEARLE, John; VANDERVEKEN, Daniel, Foundations of illocutionary logic, Cambridge: Cambridge University Press, 1985, pp. 53 ss., 63 ss., 186, quienes la identifican con una específica fuerza ilocutiva de carácter asertivo, operada sobre un contenido proposicional relativo al futuro (desde la perspectiva del punto de tiempo en que tiene lugar la predicción).

${ }^{9}$ Véase infra, 4.

${ }^{10}$ BINDING, Die Normen, cit. nota $\mathrm{n}^{\circ}$ 6, pp. 401 ss.; anticipatoriamente ya BINDING, Karl, Handbuch des Strafrechts, Léipzig: Felix Meiner, 1885, pp. 691 ss., en referencia a la "acción erróneamente delictiva". Al respecto y más sintéticamente, BINDING, Karl, La culpabilidad en el derecho penal, Trad. CANCIO, Manuel, Buenos Aires y Montevideo: BdF, 2009, pp. 105 ss. Sobre ello, y detalladamente, ENGISCH, Karl, "Der ,umgekehrte Irrtum" und das ,Umkehrprinzip", en: LÜTTGER, Hans (coord.), Festschrift für Ernst Heinitz zum 70. Geburtstag, Berlín: Walter de Gruyter, 1972, pp. 185-205, pp. 185 ss.

${ }^{11}$ Véase BINDING, Die Normen, cit. nota ${ }^{\circ}$ 6, pp. 131 ss.; también BINDING, Karl, Strafrechtliche und strafprozessuale Abhandlungen, tomo I, Múnich y Léipzig: Duncker \& Humblot, 1915, pp. 406 ss. Además de semejante "error-sobre-el-delito", al cual atribuye la condición de "error jurídico-penal principal" (strafrechtlicher Hauptirrum), Binding tematiza un "error jurídico-penal colateral" (strafrechtlicher Nebensirrtum), consistente en la falta de representación de circunstancias que, en cuanto conocidas por el autor, operan como una "marca de altura de la punibilidad" sobre el respectivo delito genérico, dando forma a un hecho punible calificado o privilegiado; se trata, en tal medida, de un error conducente a la falta de satisfacción de un "elemento de la punibilidad" que integraría una exigencia cognitiva (en contraposición, por ejemplo, a una mera condición objetiva de la punibilidad). Véase BINDING, Die Normen, cit. nota $\mathrm{n}^{\circ}$ 6, $\mathrm{pp}$. 184 ss.; también BINDING, Abhandlungen, cit. nota $\mathrm{n}^{\circ} 11$, pp. 430 ss. Acerca de la correspondiente distinción entre "elementos de antinormatividad" y "elementos de punibilidad", véase BINDING, Karl, Die Normen und ihre Übertretung, tomo I, $4^{\mathrm{a}}$ ed., Léipzig: Felix Meiner, 1922, pp. 194 ss.; también BINDING, Handbuch, cit. nota $\mathrm{n}^{\circ}$ 10, pp. 507 ss. La importancia de la distinción, en lo que aquí interesa, radica en que, por esa vía, Binding podía sostener que un error colateral por definición deja intacto el dolo respectivo, en la medida en que el objeto de referencia de éste debe entenderse constituido por (nada más que) las circunstancias que realizan los correspondientes elementos de la antinormatividad. Para una aplicación de este punto de vista al problema del desconocimiento de las circunstancias fundantes de una relación interpersonal con relevancia típica sub specie parricidio, véase MAÑALICH, Juan Pablo, "iIncompatibilidad entre frustración y dolo eventual?”, Revista de Estudios de la Justicia 27, 2017, pp. 171-182, pp. 172 ss.
} 


\section{Polít. crim. Vol. 14, No 27 (Julio 2019), Art. 10, pp. 296-375. [http://politcrim.com/wp-content/uploads/2019/05/Vol14N27A10.pdf]}

éste sea antinormativo bajo una determinada norma de prohibición o de requerimiento, susceptibles de ser designadas "propiedades fundantes-de-antinormatividad". Pero un errorsobre-el-delito también podría consistir, por otro lado, en un desconocimiento directo de la antinormatividad del respectivo comportamiento, en cuanto propiedad secundaria, o "superveniente", exhibida por ese comportamiento en virtud de su instanciación de aquellas propiedades básicas. ${ }^{12}$ A partir de tal noción de error-sobre-el-delito, entonces, Binding proponía definir la noción obtenida a través de la inversión de aquélla de la siguiente manera, a saber: como la noción de un error en el que incurre un agente que se representa como jurídicamente prohibida o requerida la acción que se dispone a ejecutar o a omitir, sin que esa acción en efecto exhiba tal carácter. ${ }^{13}$

\subsection{La impotencia modificativa del error}

El axioma sobre el cual Binding articuló su indagación en el estatus jurídico-penal del error invertido sobre-el-delito consiste en que "el error es impotente sobre su objeto". ${ }^{14}$ Así, mientras "[e]l error-sobre-el-delito de aquel que ha desconocido la antijuridicidad de su acción no es en absoluto capaz de modificar esta antijuridicidad", así también

"el revés de este error-sobre-el-delito, más precisamente el error de aquel que considera prohibida una acción no prohibida, en cuanto hecho psicológico en el alma del que yerra, no está en posición, similarmente, de transformar la naturaleza jurídica de la acción ejecutada". ${ }^{15}$

El problema está, sin embargo, en que Binding hacía suya una concepción general de la tentativa que le llevaba a desconocer que ésta se corresponde, estructuralmente, con un error que en efecto es incapaz de alterar la falta de antinormatividad del comportamiento imputable a ese mismo título. Y esto se debe a que Binding sistemáticamente confundía dos categorías que él pretendía designar bajo el sustantivo "antinormatividad", a saber: la propiedad superveniente que se corresponde con el estatus deóntico exhibido por un comportamiento consistente o bien en la ejecución de una acción que ejemplifica un tipo de acción sometido a una norma de prohibición, o bien en la omisión de una acción que ejemplifica un tipo de acción sometido a una norma de requerimiento, por un lado; y el constructo interpretativo consistente en una instancia particular de quebrantamiento de una norma semejante, por otro. ${ }^{16}$ Sostener que un comportamiento constitutivo de una instancia

\footnotetext{
${ }^{12}$ Detalladamente BINDING, Die Normen, cit. nota $\mathrm{n}^{\circ}$ 6, pp. 131 ss.; también BINDING, Abhandlungen, cit. nota $\mathrm{n}^{\circ} 11$, pp. 406 ss., 420 ss.; véase también, y más sintéticamente, BINDING, La culpabilidad, cit. nota $\mathrm{n}^{\circ}$ 10, pp. 83 ss. Para la reformulación terminológica, favorecida en el texto principal, de la distinción entre las dos "fuentes" de error-sobre-el-delito tematizadas por Binding, véase MAÑALICH, Juan Pablo, "El delito como injusto culpable. Sobre la conexión funcional entre el dolo y la consciencia de la antijuridicidad", Revista de Derecho de la Universidad Austral de Chile 24, 2011, pp. 87-115, pp. 99 ss., con referencias ulteriores; acerca de la caracterización de la antinormatividad como propiedad superveniente, véase MAÑALICH, "La tentativa", cit. nota n ${ }^{\circ} 5$, pp. 463 ss., también con referencias ulteriores.

${ }^{13}$ BINDING, Die Normen, cit. nota ${ }^{\circ}$ 6, p. 403.

${ }^{14}$ BINDING, Die Normen, cit. nota n ${ }^{\circ}$ 6, p. 409.

${ }^{15}$ BINDING, Die Normen, cit. nota n ${ }^{\circ}$ 6, p. 409.

${ }^{16}$ Esto se muestra en el hecho de que, ocasionalmente, Binding usara las expresiones "antinormatividad" (Normwidrigkeit) y "delito" (Delikt) como sinónimas; véase KAUFMANN, Armin, Lebendiges und Totes in Bindings Normentheorie, Gotinga: Otto Schwarz \& Co, 1954, pp. 144 s.
} 
de tentativa de delito resulta antinormativo bajo la norma $\mathrm{Nx}$ en virtud de que ese comportamiento resulta imputable como quebrantamiento de $\mathrm{Nx},{ }^{17}$ constituye una confusión categorial. ${ }^{18} \mathrm{Y}$ esta confusión categorial se manifiesta prístinamente en la conceptualización de la tentativa de delito como un "delito parcial", que Binding ofreciera al poner en relación la noción de tentativa con su peculiar concepción de la causación del respectivo resultado como un "proceso divisible" en fases o etapas. ${ }^{19}$ Que esto último no puede llevar, empero, a la conclusión de que el correspondiente tipo-de-delito, en cuanto descripción que especifica los "elementos de la antinormatividad" que son definitorios del respectivo género delictivo, ${ }^{20}$ pudiera verse parcialmente realizado, ${ }^{21}$ se sigue de que la comprobación de la antinormatividad de un comportamiento, en cuanto juicio de subsunción, tiene carácter binario, en el sentido de que su resultado sólo puede corresponder, en el sentido de una disyunción excluyente, a los valores " 1 " o " 0 ".

La deficiencia fundamental que aqueja al planteamiento de Binding radica, en tal medida, en su desconocimiento de la estricta "relatividad-a-la-descripción" que exhibe la antinormatividad de un comportamiento cualquiera, entendida como propiedad superveniente. Pues sólo desconociendo la superveniencia de la antinormatividad de un comportamiento respecto de la conjunción de las propiedades básicas especificadas a través de la descripción en la que consiste el tipo del respectivo delito genérico podría llegar a sostenerse que, "[p]uesto que prohibida se encuentra la completa acción de causación, se encuentra ipso jure prohibida cada una de sus partes". ${ }^{22}$

Esto último supone pasar por alto, crasamente, que el hecho de que la descripción que especifica las respectivas propiedades fundantes-de-antinormatividad resulte verdadera del comportamiento atribuible a un agente no significa otra cosa que el hecho de que en referencia a ese mismo agente, resulte verdadera la oración predicativa que le adscribe no haber omitido o bien no haber ejecutado una acción de cierto tipo. ${ }^{23} \mathrm{Y}$ no tiene sentido

\footnotetext{
${ }^{17}$ Véase BINDING, Handbuch, cit. nota $\mathrm{n}^{\circ}$ 10, p. 173: "La prohibición siempre reza, antes bien, de manera tan general que ella abarca tanto la contravención dolosa como la culposa, prohíbe tanto la consumación como la tentativa".

${ }^{18}$ Nótese que Binding mismo advertía la necesidad de tematizar una "antinormatividad objetiva" — véase BINDING, Abhandlungen, cit. nota $\mathrm{n}^{\mathrm{o}} 11$, pp. 140 s., con nota 20-, que en ciertos pasajes coincide con lo que Binding denomina “antijuridicidad” (Rechtswidrigkeit) —-véase BINDING, Die Normen, cit. nota $n^{\circ} 11$, pp. 291 ss., 298 ss.; BINDING, Karl, Die Normen und ihre Übertretung, tomo II-1, 2a ed., Léipzig: Felix Meiner, 1914, pp. 228 ss._, lo cual se ve corroborado por su aserto de que el agente que padece un "errorsobre-el-delito" actúa antijurídicamente; así BINDING, Die Normen, cit. nota n 6, p. 169.

${ }^{19}$ BINDING, Die Normen, cit. nota n ${ }^{\circ}$ 6, pp. 421 ss., 427 ss. Acertadamente en la denuncia de la confusión de la noción de delito imperfecto con la noción de "la fracción de un delito", JIMÉNEZ DE ASÚA, Luis, Tratado de Derecho Penal, tomo VII, $3^{\text {a }}$ ed., Buenos Aires: Losada, 1985, p. 396.

${ }^{20}$ BINDING, Die Normen, cit. nota $\mathrm{n}^{\circ}$ 6, p. 426; latamente al respecto BINDING, Die Normen, cit. nota $\mathrm{n}^{\mathrm{o}}$ 11, pp. 190 ss.; también BINDING, Handbuch, cit. nota n 10, pp. 504 ss.

${ }^{21}$ Así empero BINDING, Die Normen, cit. nota $n^{\circ}$ 6, pp. 427 ss., 441 ss., llegando a sostener que la tentativa de delito sería "tan delito como el consumado - sólo que uno más pequeño" (BINDING, Die Normen, cit. nota $\mathrm{n}^{\circ} 6$, p. 428).

${ }^{22}$ Así BINDING, Die Normen, cit. nota nº 6, p. 430.

${ }^{23}$ Véase MAÑALICH, Juan Pablo, Norma, causalidad y acción, Madrid, Barcelona, Buenos Aires y San Pablo: Marcial Pons, 2014, pp. 17 ss., 27 s. Valga la precisión de que lo sostenido en el texto principal se encuentra exclusivamente referido al quebrantamiento de normas de comportamiento que prohíben o requieren acciones de cierto tipo, y no así al quebrantamiento de normas que prohíben o requieren actividades
} 


\section{Polít. crim. Vol. 14, No 27 (Julio 2019), Art. 10, pp. 296-375. [http://politcrim.com/wp-content/uploads/2019/05/Vol14N27A10.pdf]}

alguno pensar que la comprobación de la verdad de semejante oración predicativa pudiera representar el resultado agregativo de la comprobación de la verdad de diferentes partes de esa misma oración. Pues no tiene sentido alguno asumir que los componentes "suboracionales" que constituyen una oración predicativa atómica pudieran exhibir, a su vez, valor-de-verdad. Sólo la oración en cuestión, en cuanto expresiva de una determinada proposición, es susceptible de ser verdadera o falsa. ${ }^{24}$ En esto consiste la base semántica de lo que cabría llamar la "irreductibilidad de la realización del tipo-de-delito": del hecho de que un tipo-de-delito cualquiera pueda ser descompuesto en múltiples elementos, y del hecho de que tenga sentido la sugerencia de que alguno de esos elementos puede verse aisladamente realizado, no se sigue que la realización de una o varias de esas partes del tipo-de-delito pueda identificarse con una realización parcial del mismo tipo.

Que todo comportamiento imputable a título de tentativa se distinga por no ejemplificar el conjunto de propiedades respectivamente fundantes-de-antinormatividad, determina que su imperfección delictiva justamente consista en que se trata de un comportamiento susceptible de ser interpretado como un quebrantamiento de la norma respectiva, a pesar de no resultar antinormativo bajo esa misma norma. ${ }^{25}$ Esto muestra que el axioma de la impotencia de todo error para modificar el estatus deóntico del respectivo objeto de la imputación, acertadamente asentado por Binding, se extiende también — pace Binding —a la propia tentativa.

\subsection{La invariabilidad de la extensión del tipo-de-delito}

Una consideración del todo coincidente con lo aquí sostenido aparece en la objeción que Kindhäuser recientemente dirigiera contra el intento de Burkhardt por sustentar la -en todo caso correcta - "solución del delito putativo", en contra de la "solución de la tentativa", en referencia a los casos de error acerca de "hechos jurídicos", esto es, de error acerca del sentido o alcance de algún elemento normativo del tipo respectivo. ${ }^{26} \mathrm{Al}$ respecto, Burkhardt sostiene que, en este contexto, sería definitorio de todo delito putativo que éste suponga una "ampliación de la extensión de elementos normativos del tipo" y con ello una "ampliación del ámbito de aplicación del tipo respectivo". 27 Pero como observa Kindhäuser, esto desconoce que la extensión del tipo-de-delito, y con ésta el ámbito de

\footnotetext{
o aun estados de cierto tipo, cuya consideración exigiría introducir algunas alteraciones en la formulación del argumento, que aquí pueden ser pasadas por alto.

${ }^{24}$ En esto consiste lo que en la filosofía analítica del lenguaje usualmente se tematiza como el problema de "la unidad de la proposición”. Véase al respecto la pormenorizada revisión ofrecida por DAVIDSON, Donald, Truth and Predication, Cambridge (Mass.) y Londres: The Belknap Press, 2005, pp. 76 ss., 120 ss., 141 ss. Una metodología de la subsunción jurídica que asume el postulado según el cual es recién una oración lo que puede tener valor de verdad debe favorecer la reformulación operativa de la descripción abstracta en la que consiste el supuesto de hecho de la norma de cuya aplicabilidad se trata como una "función oracional", cuyas variables individuales puedan verse "llenadas" por las constantes individuales que integran el estado de cosas que provee el objeto de la respectiva subsunción; al respecto MAÑALICH, Norma, cit. nota n 23, pp. 63 ss., con referencias ulteriores.

${ }^{25}$ En detalle MAÑALICH, "La tentativa", cit. nota n ${ }^{\circ}$ 5, pp. 462 ss., 475 ss.

${ }^{26}$ Al respecto en detalle infra, 6.3.

${ }^{27}$ BURKHARDT, Björn, "Nachschlag zum Wahndelikt", Goltdammer's Archiv für Strafrecht, 2013, pp. 346359, p. 356; ya BURKHARDT, Björn, "Rechtsirrtum und Wahndelikt", Juristenzeitung, 1981, pp. 681-688, pp. $685 \mathrm{~s}$.
} 
aplicación de la norma de comportamiento cuyo quebrantamiento es delictivo, queda determinada por la intensión del tipo en cuestión, que en tal medida fija el contenido semántico de la norma respectiva. ${ }^{28}$

Ello no se ve alterado por el hecho de que, en defensa de su "argumento de la extensión", Burkhardt sostenga que tratándose de una tentativa el respectivo error tendría por objeto un "hecho singular" (por ejemplo, el hecho de que el objeto en contra del cual el agente dispara no sea un ser humano, sino un espantapájaros), en tanto que el error constitutivo de un delito putativo tendría por objeto un "hecho general", concerniente al alcance de un concepto que expresa un elemento del tipo correspondiente (por ejemplo, el hecho de que un ser humano no nacido no cuente como un "otro" bajo el tipo del homicidio). ${ }^{29}$ Pues aun cuando ella tiene importancia para la demarcación de las nociones de tentativa y delito putativo, ${ }^{30}$ esta diferencia no logra modificar el hecho de que en uno y otro caso el comportamiento del agente no realiza el tipo en cuestión, precisamente porque la extensión de éste no es subjetivamente alterable por las representaciones del agente.

Antes bien, y como sugiere Kindhäuser, sólo el "ámbito de aplicación hipotético de la norma, bajo la pregunta de si la norma sería objetivamente aplicable si la representación del hechor sobre la satisfacción de las condiciones bajo las cuales el tipo sería realizado fuera correcta", logra verse ampliado por la representación del agente sobre la cual descansa una imputación a título de tentativa, en razón de que esa representación resulta ser errónea. ${ }^{31}$ Con ello, la noción de tentativa admite ser más precisamente definida como una instancia de quebrantamiento de una norma $\mathrm{Nx}$, constituida por un comportamiento atribuible a un destinatario de Nx que, de haber sido acertada la creencia predictiva de éste en cuanto a las propiedades básicas que ese mismo comportamiento hubiera de haber exhibido, habría resultado antinormativo bajo $\mathrm{Nx}$.

\section{El dolo como creencia predictiva acerca de la satisfacción de las condiciones de aplicación de la norma de comportamiento}

\subsection{El dolo como representación de las circunstancias realizadoras de las propiedades fundantes-de-antinormatividad}

Lo anterior sugiere, a su vez, que la noción bindingiana de error invertido resulta ser demasiado indiferenciada, justamente porque ella no discrimina entre las dos "fuentes" que puede tener un error-sobre-el-delito, precedentemente distinguidas, a saber: un desconocimiento de las circunstancias que determinan que un comportamiento objetivamente exhiba las respectivas propiedades fundantes-de-antinormatividad, por un lado, y un desconocimiento de la antinormatividad del comportamiento que exhibe tales propiedades, por otro. Esta última distinción es puramente analítica, en la medida en que

\footnotetext{
${ }^{28}$ KINDHÄUSER, "Versuch", cit. nota $n^{\circ}$ 7, p. 331. En la misma dirección ya NEUMANN, Ulfrid, "Regel und Sachverhalt in der strafrechtlichen Irrtumsdogmatik", en: PAEFFGEN, Hans-Ullrich et al. (coords.), Strafrechtswissenschaft als Analyse und Konstruktion. Festschrift für Ingeborg Puppe zum 70. Geburtstag, Berlín: Duncker \& Humblot, 2011, pp. 171-187, pp. 183 ss.

${ }^{29}$ BURKHARDT, "Nachschlag", cit. nota ${ }^{\circ}$ 27, p. 357.

${ }^{30}$ Véase infra, 6.2.3.

${ }^{31}$ KINDHÄUSER, "Versuch", cit. nota no 7, p. 332.
} 


\section{Polít. crim. Vol. 14, № 27 (Julio 2019), Art. 10, pp. 296-375. [http://politcrim.com/wp-content/uploads/2019/05/Vol14N27A10.pdf]}

diferencia dos especies de actitud doxástica que condicionan la fundamentación de responsabilidad jurídico-penal, pertenecientes a niveles de imputación que han de ser diferenciados. Que el agente se represente las circunstancias de cuya efectividad depende que el comportamiento en cuestión satisfaga la descripción que fija las propiedades respectivamente fundantes-de-antinormatividad es, trivialmente, condición necesaria, mas no suficiente, de que el agente se represente la antinormatividad de ese comportamiento, en cuanto comportamiento especificado bajo esa misma descripción. En esta representación de la antinormatividad del comportamiento, en cuanto especificado a través de la descripción en la que consiste el tipo (y no modificada por la descripción consistente en el supuesto de hecho de alguna causa de justificación), consiste a su vez la consciencia de su ilicitud, la cual queda definida, en esa misma medida, por una "referencia-al-tipo". 32

$\mathrm{Si}$, con arreglo a la terminología impuesta por la así llamada "teoría de la culpabilidad", el primero de estos dos presupuestos "cognitivos" de la imputación se identifica con el dolo, ${ }^{33}$ en tanto que el segundo, con la consciencia de la antijuridicidad, entonces cabe reconocer la existencia de una conexión funcional entre aquél y éste, en el sentido de que la función del primer presupuesto es posibilitar la satisfacción del segundo. ${ }^{34} \mathrm{El}$ carácter analítico de la distinción así trazada determina que ella no prejuzgue si, en cuanto a las consecuencias jurídicas de la falta de satisfacción del segundo presupuesto, deba favorecerse la solución asociada a la así llamada "teoría del dolo" o bien la solución asociada a la ya referida "teoría de la culpabilidad". 35

Bajo la concepción "informacional" aquí favorecida, el dolo puede ser entendido como un título de imputación fundamentado a través de la adscripción de una determinada creencia predictiva, cuyo objeto de referencia está constituido por circunstancias que de ser existentes determinarían que el comportamiento que se imputa al agente exhiba el respectivo conjunto de propiedades fundantes-de-antinormatividad. ${ }^{36}$ En cuanto especie de actitud proposicional, y según ya se anticipara, lo distintivo de una creencia es que ésta tiene el carácter de una actitud doxástica. ${ }^{37}$ Así, que $S$ crea que $p$ equivale a que $S$ tenga

\footnotetext{
${ }^{32}$ En contra de lo sostenido por NEUMANN, "Regel", cit. nota ${ }^{\circ} 28$, pp. 174 ss., esto quiere decir que la consciencia de la ilicitud no puede ser definida como el "conocimiento de la norma". Pues la exigencia de la "referencia-al-tipo" que ha de satisfacer la consciencia de la ilicitud se ve salvaguardada si al destinatario de la norma sólo pueda ser atribuida la representación de la antinormatividad de su comportamiento, en la medida en que le sea atribuible la representación de que su comportamiento exhibe las propiedades específicamente fundantes de su posible antinormatividad. Así ya MAÑALICH, "El delito", cit. nota n 12, pp. 99 s., con nota 38.

${ }^{33}$ Stricto sensu, con la dimensión cognitiva del título de imputación ordinaria en el que consiste el dolo; véase al respecto MAÑALICH, Norma, cit. nota $\mathrm{n}^{\circ} 23$, pp. 25 s., con nota 32.

${ }^{34}$ Detalladamente al respecto MAÑALICH, "El delito", cit. nota n ${ }^{\circ} 12, \mathrm{pp} .102 \mathrm{ss}$.

${ }^{35}$ Véase ya MAÑALICH, "El delito", cit. nota $\mathrm{n}^{\circ} 12$, pp. 105 ss.

${ }^{36}$ Supra, 2.1. El carácter predictivo de la creencia en cuestión queda determinado por una consideración pragmática, concerniente a la función de la respectiva norma de comportamiento como razón (externa) para la acción. Pues una creencia fundante-de-dolo debe entenderse referida a circunstancias de cuya efectividad depende que del comportamiento del agente haya de resultar verdadera la descripción que especifica las respectivas propiedades fundantes-de-antinormatividad, de manera tal que un destinatario de la norma que reconozca ésta como premisa vinculante pueda, sobre la base de esa creencia, formarse la intención de omitir o ejecutar la acción en cuestión, para así ajustar su comportamiento a la norma.

${ }^{37}$ Véase al respecto HACKER, P.M.S., The Intellectual Powers. A Study of Human Nature, Malden (Mass.), Oxford y Chichester (West Sussex): Wiley-Blackwell, 2013, pp. 196 ss.
} 
una determinada actitud acerca del estado de cosas identificado como $p$, el cual a su vez se corresponde con el "contenido proposicional" de la creencia en cuestión. Lo distintivo de esa actitud consiste en que $\mathrm{S}$ tiene por existente el estado de cosas en cuestión, lo cual equivale a decir que $\mathrm{S}$ tiene por verdadera la proposición que especifica ese mismo estado de cosas.

En cuanto actitud proposicional de naturaleza doxástica, una creencia necesariamente exhibe una dirección de ajuste "mente-a-mundo" (mind-to-world direction of fit). Esto quiere decir que su contenido proposicional fija condiciones de satisfacción que se corresponden con un determinado estado de cosas que debe darse en el mundo para que la creencia en cuestión sea verdadera. ${ }^{38}$ En tal medida, que una determinada creencia resulte ser verdadera o falsa depende exclusivamente de si el estado de cosas que se corresponde con su contenido proposicional resulta ser existente o no. De ahí que toda creencia exhiba aquella propiedad que es en general característica de las actitudes proposicionales, conocida como "intencionalidad", consistente en que el correspondiente estado mental —en tal medida: "intencional" - se encuentre referido a algo que puede existir o no existir, o que puede ser el caso o no ser el caso, sin que ello comprometa la existencia del estado mental en cuestión. ${ }^{39}$ Así por ejemplo, si X experimenta el así llamado "temor de Dios", cabría decir que el temor de $\mathrm{X}$ es un estado intencional cuyo respectivo objeto intencional es denotado por la palabra "Dios", con total independencia de que con el uso de esta palabra se logre o no hacer referencia a objeto extensional alguno. En la medida en que, en cuanto estado intencional que exhibe un contenido propiamente proposicional, una creencia se encuentre referida a un estado de cosas que puede o no ser el caso, cabe decir que ese estado de cosas cuya existencia o inexistencia determina la verdad o la falsedad de la creencia en cuestión configura el "objeto (de referencia) intencional" — en un sentido extremadamente lato de "objeto"_ de esa misma creencia. ${ }^{40}$

\subsection{Las circunstancias objetivamente realizadoras de los elementos del tipo como objeto de referencia de la creencia predictiva fundante-de-dolo}

Hay dos aspectos de la noción de dolo así presentada que es necesario considerar pormenorizadamente. El primer aspecto concierne a la identificación precisa del contenido representacional del dolo, entendido éste como un título de imputación (ordinaria) constituido por la representación de las circunstancias de cuya efectividad depende la realización no-justificada del correspondiente tipo-de-delito. ${ }^{41}$ La pregunta así planteada

\footnotetext{
${ }^{38}$ De ahí que el equivalente lingüístico de la creencia de que $p$ es el caso sea la aserción de que $p$ es el caso; véase SEARLE, John, Intentionality, Cambridge: Cambridge University Press, 1983, pp. 7 ss.

${ }^{39}$ Fundamental HACKER, Powers, cit. nota $n^{\circ} 37$, pp. 60 ss., 66 ss. Al respecto, véase también SEARLE, Intentionality, cit. nota $\mathrm{n}^{\circ}$ 38, pp. 6 ss.; SEARLE, John, Mind. A Brief Introduction, Oxford y Nueva York: Oxford University Press, 2004, pp. 112 ss.; SEARLE, John, Making the Social World, Oxford y Nueva York: Oxford University Press, 2010, pp. 25 ss. Ambos autores acertadamente problematizan el uso del sustantivo "objeto" para tematizar el contenido de la respectiva actitud proposicional.

${ }^{40}$ En este contexto, "intencional" no significa "con una intención", en el sentido ordinario del término, sino que designa la propiedad distintiva de determinados estados mentales, consistente en su cualidad de ser "acerca-de-algo" (about-ness). Véase las referencias ofrecidas supra, nota 39.

${ }^{41}$ Para la distinción entre los modos ordinario y extraordinario de la imputación jurídico-penal, véase MAÑALICH, Juan Pablo, Nötigung und Verantwortung, Baden-Baden: Nomos, 2009, pp. 46 ss., 67 ss.; MAÑALICH, Norma, cit. nota $\mathrm{n}^{\circ}$ 23, pp. 25 ss., con múltiples referencias ulteriores.
} 


\section{Polít. crim. Vol. 14, No 27 (Julio 2019), Art. 10, pp. 296-375. [http://politcrim.com/wp-content/uploads/2019/05/Vol14N27A10.pdf]}

adquiere virulencia, ante todo, tratándose de la adscripción del dolo de cualquier delito cuyo tipo integre algún elemento normativo. ${ }^{42}$ Pues justamente en tal contexto se vuelve problemática la asunción de que el objeto del dolo respectivo, en lo tocante a la representación de la satisfacción del correspondiente elemento normativo, podría consistir, en efecto, en el conjunto de circunstancias de cuya efectividad depende la satisfacción del elemento normativo en cuestión.

Precisamente la negación de que la sola representación de las respectivas circunstancias sea suficiente para una adscripción de dolo, en lo tocante a la satisfacción del correspondiente elemento normativo del tipo, es defendida por el todavía muy nutrido sector doctrinal que, en la senda de Mezger, entiende necesario hacer depender la adscripción del dolo, en tal contexto, de la pregunta de si el potencial autor ha "captado", aunque sólo sea aproximativamente, el sentido del elemento normativo en cuestión con arreglo al criterio de la así llamada "valoración paralela en la esfera del lego". "Como habrá de demostrarse a continuación, este método debe ser desechado, por cuanto resulta incompatible con la distinción de los dos niveles de representación que, en cuanto presupuestos doxásticos de la imputación, adquieren relevancia para la fundamentación de la responsabilidad jurídicopenal.

Para ilustrar el problema, considérese el siguiente caso, construido por vía de adaptación (al derecho sucesorio chileno) de un caso sugerido por Kindhäuser:

(1) Entre las cosas comprendidas por la masa hereditaria adquirida en propiedad por $\mathrm{H}$ como único heredero figuran tres jarrones de porcelana, uno de los cuales debe ser traspasado por $\mathrm{H}$ al legatario (de género) $\mathrm{L}$, en virtud del legado a tal efecto instituido por el causante $\mathrm{C}$ al momento de otorgar el testamento. Bajo la creencia errónea de que $\mathrm{H}$ pretendería sustraerse al cumplimiento de la obligación de dar por él contraída al aceptar la herencia, para en cambio vender los tres jarrones al tercero $\mathrm{T}$, y bajo la creencia asimismo errónea de que en su condición de legatario él se habría hecho dueño de uno (cualquiera) de los tres jarrones a consecuencia del solo fallecimiento de C, L destruye uno de los jarrones, para así —a lo menos-impedir la plena materialización del negocio que L cree habría de tener lugar, en su perjuicio, entre $\mathrm{H}$ y $\mathrm{T}^{44}$

Los partidarios del criterio de la valoración paralela sujetarían la imputación a L de la realización no-justificada del tipo del daño, a título de dolo, a que $\mathrm{L}$ haya entendido encontrarse, respecto del jarrón por él destruido, en una relación suficientemente similar a la de alguien que, jurídicamente, no sería propietario del jarrón. El problema radica, sin

\footnotetext{
${ }^{42}$ Detalladamente acerca del problema, véase FAKHOURI, Yamila, El objeto del dolo en derecho penal, Bogotá: Universidad Externado de Colombia, 2012, pp. 143 ss., 185 ss.

${ }^{43}$ MEZGER, Edmund, Tratado de Derecho Penal, tomo II, Trad. RODRÍGUEZ, José, $3^{\text {a }}$ ed., Madrid: Editorial Revista de Derecho Privado, 1957, pp. 145 ss., 148 s., precisando el requisito en cuestión como consistente en "una apreciación de la característica del tipo en el círculo de pensamientos de la persona individual y en el ambiente del autor, que marche en la misma dirección y sentido que la valoración legaljudicial". Al respecto véase sólo FAKHOURI, El objeto, cit. nota n ${ }^{\circ} 42$, pp. 155 ss. El antecedente más preclaro para la fórmula acuñada por Mezger se encuentra en BINDING, Die Normen, cit. nota ${ }^{\circ}$ 6, pp. 146 ss.

${ }^{44}$ Véase KINDHÄUSER, "Versuch”, cit. nota no 7, p. 326.
} 
embargo, en que desde el punto de vista del derecho alguien o bien es propietario de una cosa o bien no es propietario de esa misma cosa: tertium non datur. Frente a la pregunta de si, en cuanto destinatario de la prohibición de dañar cosa ajena, L habría podido formarse la intención de evitar destruir el jarrón en cuestión sobre la base de su representación de la situación, para así dar seguimiento a esa misma norma, la respuesta sólo podría ser afirmativa bajo la hipótesis de que L se hubiera representado correctamente el sentido de la prohibición del daño de cosa ajena. Ello dependerá de que L dominara, y en tal medida hubiera sido capaz de, aplicar correctamente el concepto de ajenidad (de una cosa corporal), concepto que especifica la propiedad expresada por el respectivo elemento del tipo de daño. Y por definición, toda valoración "paralela" a la fijación jurídica del sentido - esto es, de la intensio - de tal concepto es una valoración discrepante de la correspondiente fijación jurídica del concepto en cuestión, y en tal medida irrelevante para la fundamentación del dolo. ${ }^{45}$

Antes bien, la formulación precedente trae consigo la identificación del método adecuado para determinar si el potencial autor contó, en la oportunidad pertinente, con una representación fundante-de-dolo. ${ }^{46} \mathrm{El}$ método consiste en reconstruir la pregunta bajo la hipótesis de un exacto conocimiento de la norma - y así, de una exacta captación de la intensio de los elementos del respectivo tipo-de-delito- por parte de quien funge, situacionalmente, como su destinatario, en los términos siguientes: ¿habría podido el potencial autor, sobre la base de las circunstancias que tuvo por existentes en el momento relevante para la decisión, formarse la intención de omitir la acción prohibida o ejecutar la acción requerida por la norma respectiva, en caso de que él hubiese tenido una representación exacta del alcance de la norma? Concretando la pregunta en referencia al caso (1): ¿habría podido L, en consideración de las circunstancias que tuvo por existentes en el momento relevante para su decisión (de romper el jarrón), formarse la intención de omitir la acción destructiva del jarrón, de haber L tenido una representación exacta del alcance de la prohibición del daño de cosa ajena?

En contra del parecer de un sector amplio de la doctrina alemana, ${ }^{47}$ la respuesta es afirmativa. Para advertirlo es conveniente reparar en que, como lo ha mostrado Kindhäuser, la demarcación del objeto de referencia del dolo se corresponde con un reflejo subjetivo de la comprobación de la adecuación típica del comportamiento del potencial autor. ${ }^{48}$ Esa comprobación tiene lugar en la forma de un esquema (o argumento) de subsunción, cuya premisa mayor formula la descripción abstracta en la que consiste el respectivo tipo-dedelito, mientras su premisa menor enuncia el conjunto de circunstancias en las que consisten el comportamiento del agente y la situación en la que éste tiene lugar, cuya descripción habría de encontrarse conceptualmente contenida en la descripción abstracta en

\footnotetext{
${ }^{45}$ KINDHÄUSER, Urs, “Zur Unterscheidung von Tat- und Rechtsirrtum”, Goltdammer's Archiv für Strafrecht, 1990, pp. 407-423, pp. 417 ss.; véase también, aunque desde una perspectiva radicalmente diferente, PUPPE, Ingeborg, Strafrechtsdogmatische Analyse, Gotinga: Vandenhoeck \& Ruprecht, 2006, pp. 279 ss.

${ }^{46}$ Fundamental KINDHÄUSER, “Zur Unterscheidung”, cit. nota n 45, pp. 408 ss., 413 ss.; véase también MAÑALICH, "El delito", cit. nota no 12, pp. 104 s.

${ }^{47}$ Véase en este sentido, aun cuando desde perspectivas diferentes, PUPPE, Analyse, cit. nota n ${ }^{\circ} 45$, pp. 265 ss., 270 ss.; JAKOBS, Günther, Strafrecht Allgemeiner Teil, 2ª ed., Berlín: Walter de Gruyter, 1991, 8/48 ss., ${ }^{48}$ KINDHÄUSER, "Versuch", cit. nota n 7, pp. 334 s.
} 


\section{Polít. crim. Vol. 14, No 27 (Julio 2019), Art. 10, pp. 296-375. [http://politcrim.com/wp-content/uploads/2019/05/Vol14N27A10.pdf]}

la que consiste el tipo. Si se constata la existencia de tal relación de satisfacción semántica entre la descripción abstracta en la que consiste el tipo y la descripción concreta que resulta verdadera del comportamiento del potencial autor, entonces la conclusión rezará que el comportamiento atribuible al agente es típicamente adecuado.

La premisa mayor del esquema de subsunción reproduce, al mismo tiempo, el contenido semántico de la norma de cuya posible aplicación se trata, sobre la base de la correspondiente definición de los elementos conceptuales que la integran, según su respectiva formulación lingüística, ${ }^{49}$ fijando así su ámbito de aplicación. Por su parte, el concreto estado de cosas enunciado en la premisa menor identifica nada más que una posible situación de aplicabilidad de la norma. Con ello, la conclusión del argumento subsuntivo, que declara la subsunción del comportamiento bajo la norma en cuestión, expresa que el estado de cosas enunciado en la premisa menor representa un caso de aplicación de esa norma, que como tal queda comprendido en la extensión de ésta. ${ }^{50}$

Lo anterior vuelve fácil advertir que la premisa mayor del esquema de subsunción especifica aquello que alguien conoce cuando puede correctamente atribuírsele el conocimiento de la norma en cuestión. Como observa Kindhäuser: "La norma es conocida por la persona $\mathrm{P}$, y comprendida, por ésta, si $\mathrm{P}$ está en posición de aplicar correctamente los elementos del tipo a casos que están comprendidos en el contenido de la norma". ${ }^{1}$ Frente a ello, el objeto de referencia del dolo queda constituido por el estado de cosas enunciado en la premisa menor, en cuanto satisfactorio de una descripción conceptualmente contenida en la descripción abstracta formulada en la premisa mayor. De ello se sigue que sólo es posible adscribir dolo a quien tiene por existente un estado de cosas que objetivamente satisface (en caso de ser existente) o satisfaría (en caso de no ser existente) las condiciones de aplicación de la norma, con independencia de que la representación que tiene por existente ese mismo estado de cosas resulte ser acertada o no. Volviendo al caso (1), esto lleva a sustentar una adscripción del dolo de daño a L. Pues una persona que hubiese tenido una representación exacta del alcance de esa norma prohibitiva habría advertido, en la situación de L, que la acción que éste se disponía a ejecutar, bajo una descripción de esa misma acción que el propio L tenía por verdadera, era una acción que resultaría subsumible bajo la prohibición en cuestión, teniendo que ser omitida esa acción, entonces, en pos del seguimiento de esta misma norma. ${ }^{52}$

\footnotetext{
${ }^{49}$ Acerca de la relevancia de las definiciones para las operaciones de subsunción, véase PUPPE, Ingeborg, Kleine Schule des juristischen Denkens, 2a ed., Gotinga: Vandenhoeck \& Ruprecht, 2011, pp. 61 ss., distinguiendo entre operaciones de subsunción consistentes en la construcción de "cadenas de subsunción horizontal" y de "cadenas de subsunción vertical", según si, respectivamente, cada uno de los elementos de la descripción que funge como contenido semántico de la norma en cuestión recibe una definición autosuficiente, o bien el concepto expresado por aquella descripción es objeto de una o varias definiciones progresivamente especificadoras.

${ }^{50}$ KINDHÄUSER, "Versuch", cit. nota no 7, p. 335.

${ }^{51}$ KINDHÄUSER, "Versuch", cit. nota no 7, p. 335.

${ }^{52}$ Esta es la solución que se sigue de lo sostenido en KINDHÄUSER, "Zur Unterscheidung”, cit. nota n ${ }^{\circ} 45$, pp. 417 ss. Véase sin embargo KINDHÄUSER, "Versuch", cit. nota no 7, pp. 329, 331, donde para una exclusión del dolo del correspondiente delito contra la propiedad se entiende suficiente "el mero desconocimiento de la (efectiva) ajenidad", con independencia de que ese desconocimiento esté condicionado "por una representación errónea acerca de las reglas de la legación". Esta última solución descansa, en tal medida, en una consideración de "erróneas representaciones conceptuales" del potencial autor en el nivel de
} 


\subsection{Error extensional versus error intensional}

Que L en efecto no haya alcanzado prácticamente esta última conclusión, se explica por el hecho de que L no contaba con una representación correcta del sentido de (a lo menos) uno de los elementos conceptuales que integran esa prohibición, y que como tal se corresponde con uno de los elementos del tipo del delito de daño, a saber: el elemento consistente en la ajenidad de la cosa que funge como objeto del comportamiento en cuestión. La correspondiente definición del elemento de la ajenidad de la cosa determina que la propiedad institucional (y relacional) de una cosa, ${ }^{53}$ consistente en ser ajena para el destinatario de la norma, fuera exhibida por el jarrón destruido por L. Y que L no se haya representado estar destruyendo una cosa ajena se explica por su errónea creencia de que el legatario de una especie indeterminada de un género podría hacerse dueño, a consecuencia de la sola apertura de la respectiva sucesión, de alguna de las especies del género en cuestión, comprendidas en la masa hereditaria. Con ello, el error padecido por L es un error exclusivamente concerniente al alcance de uno de los elementos conceptuales de la prohibición de dañar una cosa ajena, que como tal sólo compromete la consciencia de la ilicitud de su comportamiento. ${ }^{54}$

Lo anterior descansa en una reformulación de la distinción entre las nociones de error excluyente del dolo y error excluyente de la consciencia de la antijuridicidad, a saber, como la distinción entre las nociones de un error-de-referencia (o "error extensional") y un error-de-sentido (o "error intensional"), en lo concerniente a la satisfacción de las condiciones de aplicación de la norma de comportamiento respectiva. ${ }^{55}$ Quien padece un error de la primera clase se representa erróneamente como existentes circunstancias que, de ser existentes, satisfarían semánticamente las condiciones de aplicación de una norma existente; esto es, se representa como existente un estado de cosas cuya existencia haría verdadera la aserción de que se satisfacen las condiciones de aplicación de esa norma. En cambio, quien padece un error de la segunda clase tiene erróneamente por existente una norma cuyas condiciones de aplicación no se corresponden con las condiciones de aplicación de norma existente alguna. El error padecido por L en el caso ya considerado es, en estos términos, un error-de-sentido, pues él atribuyó a la expresión "ajena" un sentido

\footnotetext{
la imputación a título de dolo, lo cual, como se observara en KINDHÄUSER, "Zur Unterscheidung”, cit. nota $\mathrm{n}^{\circ} 45$, p. 420, resulta incompatible con una adopción consistente de la distinción entre las categorías de errorde-referencia y error-de-sentido; sobre esto último véase infra, nota 55.

${ }^{53} \mathrm{Al}$ respecto, y en detalle, véase infra, 6.3.

${ }^{54}$ Véase MAÑALICH, "El delito", cit. nota no 12, pp. 104 s.

55 Fundamental KINDHÄUSER, "Zur Unterscheidung", cit. nota ${ }^{\circ}$ 45, pp. 409 ss., recurriendo a la expresión "error-de-verdad" para lo que aquí se denomina "error-de-referencia". Véase también, RENZIKOWSKI, Joachim, "Wahnkausalität und Wahndelikt — zur Strafbarkeit des untauglichen Versuchs", KAUFMANN, Matthias (coord.), Wahn und Wirklichkeit - Multiple Realitäten, Fráncfort del Meno: Peter Lang, 2003, pp. 309-322, pp. 311 s., 319 ss., quien tematiza lo que aquí se ha denominado "error-de-verdad" como un "error sobre el estado de cosas" (Sachverhaltsirrtum), en tanto que lo que aquí se ha denominado "error-de-sentido" como un "error sobre la regla" (Regelirrtum); en sentido ya JOERDEN, Jan, "Wesentliche und unwesentliche Abweichungen zurechnungsrelevanter Urteile des Täters von denen des Richters", Jahrbuch für Recht und Ethik 2, 1994, pp. 307-325, pp. 310 s. Aun cuando Renzikowski tematiza, como una tercera categoría potencialmente relevante, la del "error de subsunción", como una que identificaría la especie de error consistente en la errónea aplicación de una regla a un determinado estado de cosas, él acertadamente sostiene, en definitiva, que esta última es enteramente reducible a las dos primeras.
} 


\section{Polít. crim. Vol. 14, Nº 27 (Julio 2019), Art. 10, pp. 296-375. [http://politcrim.com/wp-content/uploads/2019/05/Vol14N27A10.pdf]}

diferente de aquel que efectivamente exhibe el correspondiente elemento (de la formulación) de la prohibición del daño de cosa ajena. Ese error se traduce en que L tiene por existente una prohibición divergente de la norma de comportamiento efectivamente aplicable en las circunstancias que $\mathrm{L}$ tuvo por existentes.

\subsection{La irrelevancia de la justificación epistémica de la creencia predictiva}

Pero hay un segundo aspecto de la noción de dolo aquí examinada que también necesita ser explicitada. Ya fue observado, a propósito de la demarcación entre dolo y consciencia de la antijuridicidad, que el primero tiene por objeto de referencia un estado de cosas que - de existir - quedaría objetivamente comprendido en el ámbito de aplicación de la norma. Lo crucial ahora es insistir en que la adscripción del dolo no se ve alterada por el hecho de que el estado de cosas, tenido por existente por el potencial autor, en efecto no exista. Antes bien, ello sólo tiene impacto en si, desde el punto de vista de lo que resulta imputable al agente a título de dolo, éste podrá resultar autor de un delito consumado o sólo de la correspondiente tentativa de delito. Pues nuevamente en palabras de Kindhäuser: "Tratándose de una tentativa, el estado de cosas que el autor se representa tiene que ser uno que se presentaría irrestrictamente como un caso de aplicación de la norma, si aquél efectivamente se diera" ${ }^{56}$ precisamente porque "[u]na tentativa presupone que aquello que el autor se representa se deja subsumir bajo un tipo, esto es, satisfaría las condiciones de aplicación de una norma, si esa representación fuera acertada".

La consecuencia fundamental que es posible extraer de esto es la siguiente: aun bajo una concepción pretendidamente "cognitivista" del dolo, éste no puede ser definido como un título de imputación constituido por el conocimiento de las circunstancias que realizan (injustificadamente) el tipo. Pero a favor de esta toma de posición habla, desde ya, una consideración relativa a la definición general del concepto de dolo, prescindente de la especificidad de la adscripción de dolo para la configuración de una tentativa punible. El problema se refiere a la concepción más generalizada de lo que se entiende, ordinariamente, por "conocimiento" o "saber" — en el sentido de un saber-que, y no de un saber-cómo ${ }^{58}$-, delineada por el así llamado "enfoque tripartito". ${ }^{59}$ De acuerdo con éste, una oración del tipo "S sabe que $p$ ", donde "S" designa un sujeto cualquiera y " $p$ " ocupa el lugar de una proposición cualquiera, es semánticamente equivalente a una oración del tipo "S cree justificadamente que $p$, y es verdad que $p$ ". Esta identificación de la noción de conocimiento con la noción de creencia justificada y verdadera, que se remonta a la filosofía de Platón,${ }^{60}$ resulta poco afortunada en el contexto de la definición del concepto jurídico-penal de dolo, a lo menos por dos razones diferentes.

\footnotetext{
${ }^{56}$ KINDHÄUSER, "Versuch", cit. nota no 7, p. 335.

${ }^{57}$ KINDHÄUSER, "Versuch", cit. nota $n^{\circ}$ 7, p. 337; véase también MAÑALICH, "La tentativa", cit. nota ${ }^{\circ}$ 5, pp. 483 ss.

${ }^{58}$ Fundamental al respecto RYLE, Gilbert, The Concept of Mind, Chicago: The University of Chicago Press, 1949, pp. 27 ss.; véase también HACKER, Powers, cit. nota nº 37, pp. 175 ss., 186 ss.

${ }^{59}$ Véase STARK, Findlay, Culpable Carelessness. Recklessness and Negligence in the Criminal Law, Cambridge: Cambridge University Press, 2016, pp. 128 s.

${ }^{60}$ Véase al respecto AUDI, Robert, Epistemology. A contemporary introduction to the theory of knowledge, $2^{\mathrm{a}}$ ed., Nueva York y Londres: Routledge, 2003, pp. 220 ss.; también RESCHER, Nicholas, Epistemology. An Introduction to the Theory of Knowledge, Nueva York: Universidad del Estado de Nueva York, 2003, pp. 3 ss.
} 
La primera dificultad que enfrenta el enfoque tripartito es de naturaleza epistemológica y se la asocia, en la literatura filosófica, con los así llamados "casos Gettier", en honor a quien articulara la objeción más célebre a tal enfoque, imaginando situaciones en las cuales sería intuitivamente inadecuado decir que $\mathrm{S}$ sabe que $p$, a pesar de que $\mathrm{S}$ cree justificadamente que $\mathrm{p}$, siendo verdad que $p .{ }^{61}$ Considérese la siguiente variación de uno de los ejemplos ofrecidos por Stark:

(2) El padre P detecta un salpullido en el brazo de su hijo $\mathrm{H}$, tomándolo como un posible síntoma de meningitis, sobre la base de información contenida en mensajes gubernamentales en el marco de una campaña sanitaria referida a la prevención y el tratamiento de la meningitis. No obstante formarse esta creencia, P prescinde de llevar a $\mathrm{H}$ a consulta médica, pues prefiere mantener el plan de ver el partido de fútbol del club de sus amores por televisión. Contra lo que $\mathrm{P}$ cree, el salpullido ha sido generado a consecuencia de una reacción alérgica al detergente usado para lavar la ropa de $\mathrm{H}$, quien efectivamente ha contraído meningitis, a pesar de que todavía no muestra síntomas de ello. ${ }^{62}$

En el caso así construido, a $\mathrm{P}$ es atribuible la creencia (epistémicamente) justificada y verdadera de que $\mathrm{H}$ está enfermo de meningitis, pareciendo intuitivamente implausible, empero, sostener que $\mathrm{P}$ sabe que $\mathrm{H}$ está enfermo de meningitis. Que la creencia de $\mathrm{P}$ es verdadera resulta simplemente del hecho de que $\mathrm{H}$ ha contraído meningitis. Que esa misma creencia se encuentra justificada resulta de que ella se apoya en información epistémicamente adecuada para la formación de semejante creencia. Como es obvio, lo que vuelve problemática la afirmación de que $\mathrm{P}$ sabe que $\mathrm{H}$ está enfermo de meningitis es la intuición de que la verdad y la justificación de la creencia de $\mathrm{P}$ no se encuentran apropiadamente conectadas.

Si bien los epistemólogos siguen debatiendo acerca de cómo habría que modificar la definición del concepto de conocimiento, favorecida por el enfoque tripartito, para hacer frente a los "casos Gettier", 63 ello no es algo que nos deba ocupar aquí. Pues de cara a la definición del concepto jurídico-penal de dolo, el enfoque tripartito plantea una dificultad adicional, consistente ya en la inadecuación de la exigencia de justificación de la creencia

\footnotetext{
${ }^{61}$ GETTIER, Eduard, “Is Justified True Belief Knowledge?”, Analysis 23, no 6, 1963, pp. 121-123, passim, quien ofreciera dos casos como objeto de análisis para impugnar la definición de "conocimiento" como creencia justificada y verdadera. Considérese sólo el primer caso, que involucra a dos personas, A y B, que han postulado a una misma posición laboral, creyendo A que B habrá de conseguir el trabajo, pues así se lo ha asegurado el presidente de la compañía, y creyendo también A que B tiene diez monedas en su bolsillo, puesto que el propio A las ha contado, sobre la base de lo cual cabría inferir, entonces, que A cree que la persona que obtendrá el trabajo tiene diez monedas en su bolsillo, estando esta última creencia justificada por la evidencia de la que A dispone. Si en definitiva resulta ser A quien obtenga el trabajo, y es asimismo el caso que, siendo ello desconocido por A, éste tiene diez monedas en su bolsillo, ello implicaría que la creencia de A en cuanto a que la persona que habría de obtener el trabajo tenía diez monedas en su bolsillo era una creencia verdadera, y al mismo tiempo una creencia justificada, sin que parezca correcto, empero, sostener que, por el hecho de tener esa creencia, A sabía que la persona que habría de obtener el trabajo tenía diez monedas en su bolsillo.

${ }^{62}$ STARK, Carelessness, cit. nota n ${ }^{\circ} 59$, pp. 135 s.

${ }^{63}$ Véase sólo AUDI, Epistemology, cit. nota ${ }^{\circ}$ 60, pp. 222 ss.
} 


\section{Polít. crim. Vol. 14, Nº 27 (Julio 2019), Art. 10, pp. 296-375. [http://politcrim.com/wp-content/uploads/2019/05/Vol14N27A10.pdf]}

respectiva. ${ }^{64}$ En efecto, para la fundamentación de una imputación jurídico-penal a título de dolo debería resultar irrelevante la corrección epistémica de la creencia predictiva en cuestión. Esto último se traduce en que, como observa Kindhäuser, actúa con dolo de homicidio, por ejemplo, quien acertadamente cree estar disparando un arma de fuego en contra de un ser humano (vivo), aun cuando su identificación de la víctima qua objeto del disparo haya estado condicionada por un error de percepción. ${ }^{65}$

Para sustentar la tesis de la irrelevancia de la justificación —sub specie corrección epistémica - de la creencia predictiva cuya adscripción pudiera ser fundante-de-dolo, es útil considerar una variación del célebre "caso del camarero", propuesto por Jakobs para intentar demostrar la supuesta indisponibilidad de un filtro de imputación objetiva, previo al juicio de imputación subjetiva, en las constelaciones en las cuales el potencial autor cuenta con "conocimientos especiales" ${ }^{66} \mathrm{El}$ caso originalmente construido por Jakobs es el siguiente:

(3) Un estudiante de biología que se desempeña como camarero auxiliar descubre, gracias a sus conocimientos adquiridos a través del estudio universitario, un fruto venenoso en la ensalada exótica, pese a lo cual la sirve al cliente. ${ }^{67}$

El argumento de Jakobs para negar que el condicionamiento del desenlace lesivo para el cliente sea "ya" objetivamente imputable al camarero se funda en una reformulación del criterio del así llamado "riesgo permitido". De acuerdo con esta reformulación, la predicación de la generación de un riesgo jurídicamente desaprobado del comportamiento del potencial autor depende de la circunstancia de que la base epistémica desde la cual se enjuicia la creación del riesgo en cuestión esté internamente conectada con el rol social desempeñado por aquél. Esto se traduce en que, para que el riesgo realizado en el resultado en cuestión pueda entenderse como un riesgo jurídicamente desaprobado, la activación de la respectiva base de conocimientos en pos de la evitación del condicionamiento del correspondiente resultado tendría que resultar "normativamente esperable" del agente en razón del rol situacionalmente desempeñado por éste. De esta manera, y a contrario sensu, el nexo objetivo de imputabilidad tendría que fallar cuando la posibilidad de que el agente dispusiera de esa misma base de conocimientos aparece fundada en el azar.

Lo anterior quiere decir que, según Jakobs, el así llamado "azar epistémico" involucrado en la circunstancia más o menos fortuita de que el camarero encargado de servir el plato de ensalada haya resultado ser un estudiante de biología capacitado para detectar - como de hecho lo hiciera - la presencia de un hongo venenoso en el plato, debería quedar desprovisto de relevancia para fundamentar, a su respecto, la imputabilidad de la

\footnotetext{
${ }^{64}$ A propósito de la categoría anglosajona de knowledge como forma de mens rea, véase STARK, Carelessness, cit. nota ${ }^{\circ} 59$, pp. 129 ss.

${ }^{65}$ KINDHÄUSER, "Versuch", cit. nota n ${ }^{\circ}$ 7, p. 339.

${ }^{66}$ Véase JAKOBS, Günther, "Tätervorstellung und objektive Zurechnung”, en: DORNSEIFER, Gerhard et al. (coords.), Gedächtnisschrift für Armin Kaufmann, Colonia, Berlín, Bonn y Múnich: Carl Heymanns Verlag, 1989 , pp. 271-288, pp. 272 s., 283 ss.

${ }^{67}$ JAKOBS, “Tätervorstellung", cit. nota $\mathrm{n}^{\circ}$ 66, p. 273; véase también JAKOBS, Günther, La imputación objetiva en derecho penal, Trad. CANCIO, Manuel, Buenos Aires: Ad-Hoc, 1996, pp. 62 ss.; JAKOBS, Günther, "Altes und Neues zum strafrechtlichen Vorsatzbegriff”, Rechtswissenschaft, 2010, pp. 283-315, pp. 310 ss.
} 
producción del desenlace lesivo. ${ }^{68}$ Pero en contra de lo sugerido por Jakobs, ${ }^{69}$ no basta con echar mano a adjetivos como "subjetivo" o "psicológico" para poner en cuestión, fundadamente, toda validación del azar epistémico.

En efecto, Jakobs se precipita en demasía a sostener, más bien apodícticamente, que de un camarero no cabría esperar, de modo jurídicamente relevante, la activación de conocimientos extrínsecos al rol social así tematizado. Es claro, desde luego, que ningún cliente de un restaurante podría esgrimir, ceteris paribus, razones jurídicamente garantizadas para confiar en que quien habrá de atenderlo durante su visita a aquél contará con conocimientos de biología avanzada. Pero extraer de esto la conclusión a la que arriba Jakobs supone confundir el objeto de referencia de las expectativas cuya frustración puede estar involucrada en la fundamentación de una imputación jurídico-penal.

La expectativa cuya defraudación puede sustentar un reproche de culpabilidad jurídicopenal no es otra que la expectativa puesta en el seguimiento de la norma en cuestión por cada uno de sus destinatarios, en la medida en que el respectivo destinatario de la norma haya contado con la capacidad de darle seguimiento, o bien - tratándose de una eventual imputación extraordinaria - con la capacidad de asegurar su capacidad de darle seguimiento. ${ }^{70}$ Con arreglo al principio ultra posse nemo obligatur, nadie queda obligado por tal norma más allá de su propia capacidad, a menos que el aseguramiento de la capacidad faltante, en la forma de la adopción de una medida de precaución, haya sido esperable del agente, de manera tal que el quebrantamiento de la norma le sea imputable a título de imprudencia, esto es, en virtud de la correspondiente falta de cuidado. De ahí que, en caso de que el camarero no hubiese llegado a advertir la presencia del fruto venenoso en el plato, simplemente por no haber prestado atención a lo que éste contenía, habría que tener por descartada una imputación de la producción del desenlace lesivo a título de imprudencia, en la medida en que la activación de sus conocimientos de biología no haya formado parte de su "rol" como camarero. Pero en contra de lo sugerido por Jakobs, ${ }^{71}$ ello no prejuzga cuál deba ser la solución del caso original, definido por la circunstancia de que el camarero sí advirtiera la presencia del ingrediente venenoso.

Quien, siendo destinatario de la norma, efectivamente cuenta con la capacidad de darle seguimiento no puede pretender inmunizarse frente a la imputación de su quebrantamiento aduciendo que su posesión de alguna habilidad, destreza o información situacionalmente requerida para dar seguimiento a la norma habría sido azarosa. ${ }^{72}$ Pues la pregunta misma de si para alguien que sabe algo en un rol pudiera ser permisible no saber eso mismo en otro

\footnotetext{
${ }^{68}$ En detalle acerca del así llamado "azar epistémico", véase VILLAR, Mario, Suerte penal. Un estudio acerca de la interferencia de la suerte en los sistemas de imputación, Buenos Aires: ediciones Didot, 2016, pp. 32 s., 91 ss., con múltiples referencias ulteriores.

${ }^{69}$ JAKOBS, La imputación, cit. nota n 67, p. 64; JAKOBS, “Vorsatzbegriff”, cit. nota nº 67, p. 311.

${ }^{70} \mathrm{Se}$ trata - en ambos casos - de una capacidad intencionalmente compleja, en el sentido de una capacidad de intencionalidad recursiva; véase en detalle KINDHÄUSER, Urs, Gefährdung als Straftat, Fráncfort del Meno: Vittorio Klostermann, 1989, pp. 41 ss.

71 JAKOBS, “Vorsatzbegriff”, cit. nota n 67, pp. $311 \mathrm{s.}$

${ }^{72}$ Fundamental KINDH ̈̈USER, Urs, "Der subjektive Tatbestand im Verbrechensaufbau. Zugleich eine Kritik der Lehre von der objektiven Zurechnung”, Goltdammer's Archiv für Strafrecht, 2007, pp. 447-468, pp. 456 ss., 462 s.
} 


\section{Polít. crim. Vol. 14, No 27 (Julio 2019), Art. 10, pp. 296-375. [http://politcrim.com/wp-content/uploads/2019/05/Vol14N27A10.pdf]}

rol, ${ }^{73}$ carece de sentido: si alguien sabe algo, lo sabe simpliciter, lo cual quiere decir: lo sabe a través de los diversos roles que pudiera corresponderle desempeñar. Con ello, y en la medida en que el ámbito de aplicación de la norma en cuestión no se encuentre delimitado mediante una cláusula que restrinja el universo de sus destinatarios a quienes satisfagan alguna cualidad personal especial — verbigracia, a quienes desempeñen un rol (institucional) determinado-,${ }^{74}$ entonces nadie podría pretender no quedar vinculado por esa misma norma por el hecho de haber adquirido de manera azarosa - esto es, no situacionalmente controlable - alguna información que lo haya puesto en posición de prestarle seguimiento.

\subsection{La irrelevancia de la verdad de la creencia predictiva}

Para reforzar la conclusión precedente, considérese ahora la siguiente variación del caso del camarero:

(4) Todo lo demás siendo igual al caso (3), el camarero $\mathrm{C}_{1}$, estudiante universitario de biología, observa cómo el camarero $\mathrm{C}_{2}$, estudiante de derecho, se dispone a servir un plato de ensalada al cliente que lo ha ordenado. Antes de que $\mathrm{C}_{2}$ alcance la mesa en la cual debe dejar el plato, $\mathrm{C}_{1}$ le dice, al oído, que el plato que está ad portas de servir contiene un hongo venenoso, que con toda probabilidad generará una fuerte indigestión en quien los ingiera.

En este caso, cabría decir, la creencia que se forma $\mathrm{C}_{2}$ en cuanto al contenido venenoso del plato que se dispone a servir se muestra como doblemente azarosa. Pues al azar asociado al hecho de que su colega $\mathrm{C}_{1}$ posea conocimientos avanzados de biología se añadiría la circunstancia azarosa, en cuanto no controlable por $\mathrm{C}_{2}$, de que aquél se haya resuelto a hacerle la advertencia en cuestión. ¿Habría que concluir, por esto, que si $\mathrm{C}_{2}$, no obstante esa misma advertencia, en definitiva sirve el plato al cliente, sin efectuar advertencia alguna, la eventual producción del desenlace lesivo, consistente en una intoxicación constitutiva de lesión corporal, no habría de serle ya "objetivamente" imputable? ${ }^{75} \mathrm{En}$ la medida en que para alguien que se encuentra en la posición de $\mathrm{C}_{2}$ sea mínimamente racional confiar en la información que le provee $\mathrm{C}_{1}$, no hay razón alguna para no atribuir relevancia a esa información a la hora de determinar si el agente en cuestión no ha extraído la conclusión práctica que tendría que haber extraído a partir de su reconocimiento de la prohibición de lesionar corporalmente a otra persona como premisa vinculante. ${ }^{76} \mathrm{Y}$ nótese que la valoración de la situación no debería variar en un ápice si ahora asumiéramos, introduciendo una nueva variación del caso, que la información provista por $C_{1}$ a $C_{2}$ hubiera sido falsa. Pues siendo factible adscribir a $\mathrm{C}_{2}$ una $d u d a$ racionalmente fundada en

\footnotetext{
${ }^{73}$ JAKOBS, “Tätervorstellung”, cit. nota $n^{\circ} 66$, p. 273.

${ }^{74}$ Acerca del problema de las así llamadas "normas especiales" en cuanto normas cuyo quebrantamiento es constitutivo de un delito especial, así como de la constitución de la respectiva tentativa en caso de quebrantamiento imperfecto de una norma tal, véase infra, 7.2. y 7.3.

${ }^{75}$ Nótese que, en tal caso, la imputación en cuestión tendría que ajustarse a la estructura de una autoría mediata "por autolesión del instrumento"; véase en detalle al respecto MAÑALICH, Nötigung, cit. nota n 41 , pp. 167 y ss.; MAÑALICH, Juan Pablo, "La estructura de la autoría mediata", Revista de Derecho de la Pontificia Universidad Católica de Valparaíso 34, 2010, pp. 385-414, pp. 405 ss.

${ }^{76}$ Acerca del modelo del así llamado "silogismo práctico", véase MAÑALICH, Norma, cit. nota n 23, pp. 17 ss., 23 ss.; MAÑALICH, "La tentativa”, cit. nota nº 5, pp. 469 ss., con múltiples referencias ulteriores.
} 
cuanto a si el plato de ensalada que está ad portas de servir al cliente contiene un ingrediente venenoso, cabría adscribirle dolo de lesión corporal aun cuando la creencia implicada en esa misma duda - de que el plato servido al cliente eventualmente contiene un ingrediente venenoso resulte ser falsa.

La inadecuación funcional tanto de la exigencia de justificación epistémica como de la exigencia de verdad de la respectiva creencia habla determinantemente a favor de renunciar a definir la noción de dolo a partir de la noción de conocimiento. Esto resulta de importancia una vez que la pregunta se especifica ulteriormente en atención a la particularidad que exhibe la adscripción de dolo en la constitución — por vía de imputación - de una tentativa de delito. Esta particularidad consiste en que, tratándose de toda tentativa de delito, la creencia predictiva atribuible al agente resulta ser desacertada, esto es, falsa, ${ }^{77}$ que es justamente lo que ocurría en la última versión propuesta del caso del camarero: la falsedad de la creencia de $\mathrm{C}_{2}$, determinada por la falsedad de la información que le ha provisto $\mathrm{C}_{1}$, deja intacta la adscripción de dolo de lesión corporal al primero, en términos tales que, de llegar el cliente a dar inicio a la ingesta de la ensalada, se habrá constituido una tentativa de lesión corporal, imputable a $\mathrm{C}_{2}$ en la forma de una autoría mediata por "autolesión del instrumento". 78

En la medida en que el concepto de dolo queda desacoplado de la noción de conocimiento, es enteramente adecuado identificar la creencia predictiva fundante de una eventual imputación a título de tentativa con el componente "cognitivo" —o más precisamente: informacional - de la capacidad de evitación intencional de la realización no-justificada del tipo-de-delito, que asociamos a la noción general de dolo. En estos términos, la

\footnotetext{
${ }^{77}$ Precisamente esta consideración lleva a Streng, en dirección opuesta al argumento aquí presentado, a sostener que en referencia a los presupuestos subjetivos de una tentativa no cabría hablar, stricto sensu, de dolo; véase STRENG, Franz, "Der Irrtum beim Versuch - ein Irrtum?", Zeitschrift für die gesamte Strafrechtswissenschaft 109, 1997, pp. 862-899, pp. 868 ss., 872 ss., quien apoya su argumento en el tenor del apartado $1^{\circ}$ del $\S 16$ del StGB, que en lo que aquí interesa dispone que "quien en la perpetración del hecho no conoce una circunstancia que pertenece al tipo legal, actúa sin dolo". La misma preocupación es tematizada por MAIER, Thomas, Die Objektivierung des Versuchsunrechts, Berlín: Duncker \& Humblot, 2005, pp. 43 ss., aun cuando para alcanzar la conclusión de que, tratándose de una tentativa, de todas formas tendría sentido hablar de un "componente cognitivo del dolo", el cual tendría que ser identificado con "la representación de circunstancias fácticas que, de concurrir efectivamente, realizarían el tipo objetivo del respectivo delito consumado". Más allá de que la exigencia de que la circunstancia en cuestión pertenezca al tipo deba ser aquí interpretativamente reformulada como la exigencia de que la circunstancia sea una de cuya efectividad depende la realización del tipo, pues en caso contrario se estarían confundiendo las nociones de elemento del tipo y de circunstancias que realizan algún elemento del tipo -así acertadamente KINDHÄUSER, "Zur Unterscheidung”, cit. nota $\mathrm{n}^{\circ}$ 45, pp. 407 ss.-, es crucial advertir que de la regla que conecta la falta de conocimiento de semejante circunstancia con la consecuencia (negativa) de una exclusión del dolo correspondiente no se sigue sin más que la existencia de dolo dependa (positivamente) del conocimiento de tal circunstancia, y no meramente de su representación. Pues aun definiendo "dolo" como la representación de las circunstancias que realizan el tipo, un desconocimiento de cualquiera de esas circunstancias - entendiendo por "desconocer" una circunstancia el hecho de no tener representación de la circunstancia en cuestión, siendo ésta (objetivamente) existente- es condición suficiente para una exclusión del dolo así entendido.

${ }^{78}$ La precisión en cuanto a que el cliente tendría que haber dado inicio a la ingesta de la ensalada se explica por la defensa, que no será objeto de fundamentación aquí, de la así llamada "solución global" para la determinación del inicio de la tentativa imputable en autoría mediata; véase al respecto MAÑALICH, Nötigung, cit. nota $\mathrm{n}^{\circ} 41$, pp. 150 ss., con múltiples referencias ulteriores.
} 


\section{Polít. crim. Vol. 14, No 27 (Julio 2019), Art. 10, pp. 296-375. [http://politcrim.com/wp-content/uploads/2019/05/Vol14N27A10.pdf]}

particularidad de una imputación del quebrantamiento de una norma de comportamiento jurídico-penalmente reforzada a título de tentativa se encuentra en la falta-de-verdad de la creencia predictiva fundante-de-dolo, que como tal es constitutiva de la discrepancia definitoria de la estructura de toda tentativa de delito. ${ }^{79}$

\section{4. ¿Fundamentación de la punibilidad de la tentativa a través del "argumento de la inversión"?}

\subsection{El método de la inversión y la fundamentación subjetivista de la punibilidad de la tentativa}

El dolo de toda tentativa queda constituido por una representación errónea de las circunstancias de cuya efectividad dependería que el comportamiento del agente hubiera objetivamente ejemplificado las respectivas propiedades fundantes-de-antinormatividad. En tal medida, el dolo de cuya adscripción depende la imputabilidad de un comportamiento a título de tentativa se deja identificar con un error cuya estructura se obtiene "invirtiendo" la estructura de un error excluyente del dolo del respectivo delito. Y ello equivale a afirmar que el dolo de la tentativa de un delito Dx quedaría constituido por un error inverso a un error excluyente del dolo de Dx. Así, un error inverso a un error excluyente del dolo puede ser caracterizado, trivialmente, como un error fundante-de-dolo. ${ }^{80}$

Precisando una observación de Puppe, el procedimiento a través del cual es posible dar lugar a la inversión de un error constituido por la representación de un estado de cosas inexistente, o bien por la falta de representación de un estado de cosas existente, consiste en intercambiar los valores de verdad de la constatación de la representación o la falta de representación atribuida al agente, por un lado, y de la constatación de la existencia o la inexistencia del respectivo estado de cosas, por otro. ${ }^{81}$ Así, si el error en cuestión consiste en la falta de representación de un estado de cosas existente, entonces el resultado de su inversión consistirá en la representación errónea de ese estado de cosas siendo éste inexistente, y viceversa. ${ }^{82}$

Que ambas variantes necesitan ser consideradas aquí, se sigue del hecho de que un error excluyente del dolo puede consistir ya sea en la falta de representación de un estado de cosas efectivamente existente, como ocurre tratándose de estados de cosas de cuya existencia depende la satisfacción de los elementos del tipo-de-delito, ya sea en la representación de un estado de cosas efectivamente inexistente, como ocurre tratándose de estados de cosas de cuya existencia depende la satisfacción de los elementos de una causa de justificación. ${ }^{83}$ Que en esta última constelación sea correcto reconocer una exclusión de una imputación a título de dolo, no depende de que la relación entre las categorías de la tipicidad y la antijuridicidad sea entendida en el sentido de la teoría de los elementos negativos del tipo. Pues la misma conclusión es compatible con la consideración de que las

\footnotetext{
${ }^{79}$ Véase ya MAÑALICH, "La tentativa”, cit. nota $n^{\circ}$ 5, pp. 483 ss.

${ }^{80}$ Stricto sensu, se trata en tal caso de un error co-fundante del dolo; véase infra, nota 96.

${ }^{81}$ PUPPE, Analyse, cit. nota no 45, pp. 313 s.; más recientemente PUPPE, Ingeborg, "Der Umkehrschluss", Zeitschrift für die gesamte Strafrechtswissenschaft 128, 2016, pp. 301-315, p. 303.

${ }^{82}$ PUPPE, "Der Umkehrschluss", cit. nota $n^{\text {o }} 81$, p. 303.

${ }^{83}$ PUPPE, Analyse, cit. nota $\mathrm{n}^{\circ} 45$, p. 313.
} 
normas de permisión y de liberación que se hacen operativas como causas de justificación son normas cuya aplicación da lugar a la inaplicabilidad de una o más normas de prohibición o de requerimiento bajo las cuales el respectivo comportamiento resultaría, en caso contrario, antinormativo. ${ }^{84}$

Ahora bien, que la "inversión" de un error excluyente del dolo resulte en la postulación de un error fundante-de-dolo, en el sentido ya precisado, es tan trivial como poco interesante. Esto es determinante para advertir la ineficacia del recurso al así llamado "argumento de la inversión" para la fundamentación de la punibilidad de la tentativa. ${ }^{85}$ Semejante estrategia suele ser vinculada con la asunción, por parte del Tribunal Supremo Imperial alemán o Reichsgericht (en adelante: "el RG"), de la "teoría subjetiva" de la tentativa, tal como ésta fuera fundamentalmente articulada por Von Buri. ${ }^{86}$ Pero está lejos de ser pacífica la determinación de la naturaleza precisa de esa conexión. Si bien es usual que se sostenga que el RG, en algunos de sus fallos emblemáticos a este respecto, habría basado su defensa de la teoría subjetiva en el recurso a la "inferencia por inversión" (Umkehrschlu $\beta),{ }^{87}$ cabe afirmar, más bien, que el recurso a este argumento tendió a constituirse como un complemento de la defensa de la solución favorecida por la "teoría subjetiva" por parte del $\mathrm{RG}$, precisamente en pos de la demarcación del ámbito de punibilidad asociado a la categoría de la tentativa respecto del ámbito de no-punibilidad asociado a la categoría de delito putativo. ${ }^{88}$ Esta distinción entre el plano de la fundamentación de la punibilidad de la tentativa, a través de la adopción de una concepción subjetivista, por un lado, y el plano de la operatividad aplicativa de esa fundamentación, a través del recurso al argumento de la inversión, por otro, no ha sido mantenida con la misma claridad por parte del Tribunal Supremo Federal alemán (en adelante: “el BGH”), ${ }^{89}$ que tempranamente hiciera suya la orientación estrictamente subjetivista de la jurisprudencia del RG. ${ }^{90}$

Materialmente, semejante fundamentación subjetivista de la punibilidad de la tentativa queda definida por la tesis de que la significación jurídico-penal de la tentativa se reduciría a la manifestación de una voluntad criminal reconocible en el respectivo comportamiento del agente. Estructuralmente, esa misma concepción se distingue por validar el axioma de la plena fungibilidad o "sustituibilidad" de la satisfacción de cualquier presupuesto objetivo

\footnotetext{
${ }^{84}$ Véase en detalle MAÑALICH, Juan Pablo, "Normas permisivas y deberes de tolerancia", Revista Chilena de Derecho 41, n 2, 2014, pp. 473-522, pp. 474 ss., 489 ss., con múltiples referencias ulteriores.

${ }^{85} \mathrm{Al}$ respecto ENGISCH, "Der ,umgekehrte Irrtum'", cit. nota n ${ }^{\circ} 10$, pp. 187 ss.

${ }^{86}$ Véase VON BURI, Maximilian, Abhandlungen aus dem Strafrecht, Gießen: Ferber'sche UniversitätsBuchhandlung, 1862, pp. 53 ss.; VON BURI, Maximilian, "Zur Lehre vom Versuche”, Der Gerichtssaal 19, 1867, pp. 60-80, pp. 60 ss.; VON BURI, Maximilian, "Der Versuch des Verbrechens mit untauglichen Mitteln oder an einem untrüglichen Object", Der Gerichtssaal 20, 1868, pp. 325-335, pp. 325 ss.; VON BURI, Maximilian, "Versuch und Kausalität", Der Gerichtssaal 32, 1880, pp. 321-389, pp. 321 ss.; VON BURI, "Untaugliche Versuchshandlungen ", cit. nota $\mathrm{n}^{\mathrm{o}} 6$, pp. 185 ss. Al respecto, véase detalladamente MAIER, Die Objektivierung, cit. nota $\mathrm{n}^{\circ} 77$, pp. 111 ss.; en lengua castellana, SOLA RECHE, Esteban, La llamada «tentativa inidónea» de delito. Aspectos básicos, Granada: Comares, 1996, pp. 26 ss.

87 Así SPENDEL, Günter, "Der sogenannte Umkehrschluß aus § 59 StGB nach der subjektiven Versuchstheorie", Zeitschrift für die gesamte Strafrechtswissenschaft 69, 1957, pp. 441-459, pp. 444 ss.; SPENDEL, Günter, "Kritik der subjektiven Versuchstheorie", Neue Juristische Wochenschrift, 1965, pp. 1881-1888, pp. 1885 s. Véase ya BINDING, Die Normen, cit. nota nº 6, pp. $554 \mathrm{~s}$.

${ }^{88}$ Véase MAIER, Die Objektivierung, cit. nota $\mathrm{n}^{\circ} 77$, pp. 119 ss.

${ }^{89} \mathrm{Al}$ respecto PUPPE, "Der Umkehrschluß", cit. nota $n^{\circ}$ 81, pp. $305 \mathrm{~s}$.

${ }^{90} \mathrm{Al}$ respecto MAIER, Die Objektivierung, cit. nota $\mathrm{n}^{\circ} 77$, p. 123.
} 


\section{Polít. crim. Vol. 14, No 27 (Julio 2019), Art. 10, pp. 296-375. [http://politcrim.com/wp-content/uploads/2019/05/Vol14N27A10.pdf]}

del carácter delictivo del comportamiento del potencial autor por la representación de la satisfacción de ese mismo presupuesto, desde el punto de vista de la constitución de la correspondiente tentativa. ${ }^{91}$ Este último aspecto de la concepción subjetivista se vuelve predominante si se pone el foco en la función de fundamentación de una punibilidad a título de tentativa que a veces pretende ser atribuida al "argumento de la inversión".

Según ya se anticipara, el argumento de la inversión es invocado para hacer operativa la distinción entre los conceptos de tentativa y delito putativo, en el entendido de que el primero se corresponde con una categoría de comportamiento punible, mientras el segundo con una categoría de comportamiento no punible. ${ }^{92} \mathrm{Y}$ esa distinción es entonces definida como equivalente a la distinción entre un error resultante de la inversión de un error excluyente del dolo, por un lado, y un error resultante de la inversión de un error no excluyente del dolo, por otro. En la medida en que la noción misma de dolo, en lo que aquí interesa, puede ser definida como la representación, acompañada de un determinado grado de probabilidad, de la efectividad de las circunstancias que realizan injustificadamente el correspondiente tipo-de-delito, ${ }^{93}$ es conveniente simplificar el análisis por la vía de formular los enunciados que componen la respectiva inferencia por "inversión" haciendo uso de un concepto puro de representación, esto es, prescindiendo de la cualificación de la representación en cuestión como acertada (verdadera) o desacertada (falsa). Pues sólo así es posible determinar las consecuencias lógicas de la sustitución de un determinado componente de algún estado de cosas por el componente (contradictoriamente) opuesto. ${ }^{94}$ Precisado lo anterior, la pregunta que plantea la invocación del argumento de la inversión es si éste puede contribuir a sustentar una fundamentación subjetivista de la punibilidad de la tentativa.

\subsection{La reconstrucción lógica del argumento de la inversión}

Bajo la reconstrucción aquí propuesta, la formulación genérica del argumento de la inversión asume la verdad del siguiente enunciado condicional:

\begin{tabular}{|c|c|}
\hline antecedente & consecuente \\
\hline $\begin{array}{l}\text { Siempre que } X \text { no se ha representado las } \\
\text { circunstancias que realizan el tipo, }\end{array}$ & $\begin{array}{l}\text { entonces (necesariamente) } \mathrm{X} \text { no es punible a } \\
\text { título de delito doloso. }\end{array}$ \\
\hline
\end{tabular}

\footnotetext{
${ }^{91}$ Véase al respecto MAIER, Die Objektivierung, cit. nota $n^{\circ} 77$, pp. 20 s., 83 s., 169, dando cuenta de cómo ese mismo axioma de la fungibilidad es asumido por la dominante "teoría de la impresión".

${ }^{92}$ Esto descansa en que el hecho de que una persona crea erróneamente estar comportándose de manera jurídicamente incorrecta no logra convertir ese comportamiento en objeto de referencia de un juicio de culpabilidad. Para una discusión acerca de la posibilidad de que, en el dominio de la moral (crítica), alguien pudiera resultar reprochable por la mera creencia de estar haciendo algo (moralmente) incorrecto, véase ZIMMERMAN, Michael, Living with Uncertainty. The Moral Significance of Ignorance, Cambridge: Cambridge University Press, 2008, pp. 193 ss., quien introduce el neologismo "accuse", como sustantivo obtenido por analogía invertida a partir del sustantivo "excuse", para designar el fundamento de reprochabilidad consistente en semejante creencia errónea.

${ }^{93}$ Véase supra, 3.1. y 3.2.

${ }^{94}$ Véase SPENDEL, "Umkerhschluß”, cit. nota no 87, pp. 447, 458 s.; PUPPE, Analyse, cit. nota n 45, pp. $314 \mathrm{~s}$.
} 

distinción entre tentativa y delito putativo".

Esta esquematización del enunciado condicional persigue hacer transparente su forma lógica, que determina que la proposición expresada en el antecedente se identifique con una condición suficiente, mas no necesaria, de la proposición expresada en el consecuente. ${ }^{95} \mathrm{Se}$ trata, como es obvio, de nada más que una enunciación formalizada del contenido de la regla que especifica la consecuencia jurídica de la inexistencia de una representación fundante-de-dolo; ${ }^{96}$ en tal medida, la existencia de la regla en cuestión funge como condición de verdad del enunciado que reproduce el contenido de aquélla. ${ }^{97}$ Llamemos en lo que sigue a este enunciado, a través del cual queda formulada la correspondiente regla de exclusión de la imputación, " $\mathrm{R}_{1}$ ". Sobre esta base, entonces, quienes recurren al argumento de la inversión, en el intento de fundamentar una punibilidad a título de tentativa, sostienen que de $\mathrm{R}_{1}$ sería derivable, por vía de "inversión", el siguiente e enunciado condicional, que llamaremos " $\mathrm{R}_{2}$ ":

\begin{tabular}{|c|c|}
\hline antecedente & consecuente \\
\hline $\begin{array}{l}\text { Siempre que } X \text { se ha representado las } \\
\text { circunstancias que realizan el tipo, }\end{array}$ & $\begin{array}{l}\text { entonces (necesariamente) } \mathrm{X} \text { es punible a } \\
\text { título de delito doloso. }\end{array}$ \\
\hline
\end{tabular}

$\mathrm{R}_{2}$ se presenta como un enunciado condicional cuyos términos se corresponden con la negación de las proposiciones respectivamente expresadas por el antecedente y el consecuente de $\mathrm{R}_{1}$ a sendas operaciones de negación. Puesto que esas dos proposiciones tienen - en el contexto de la enunciación de $\mathrm{R}_{1}$ - carácter negativo, y puesto que la negación de una proposición negativa resulta en la correspondiente proposición positiva (duplex negatio affirmat), ${ }^{98}$ ello determina que el antecedente $\mathrm{y}$ el consecuente de $\mathrm{R}_{2}$ expresen proposiciones respectivamente contradictorias de esas proposiciones negativas, que como es obvio tienen, a su vez, carácter positivo. Pero la pregunta que esto plantea es si la relación lógica que se da entre el antecedente y el consecuente de $R_{1}$ es preservada si su lugar es ocupado por el antecedente y el consecuente de $\mathrm{R}_{2}$. Pues sólo de ser afirmativa la respuesta cabría concluir que, en virtud de que la inexistencia de una representación fundante-de-dolo es condición suficiente para una exclusión de punibilidad a título de delito doloso, la existencia de una representación fundante-de-dolo sería condición suficiente para una punibilidad a título de delito doloso.

Pero la respuesta a la pregunta es negativa. Ello resulta del hecho de que el argumento de la “inversión”, así constituido, sólo sería válido si entre $\mathrm{R}_{1}$ y $\mathrm{R}_{2}$ existiera una relación de equivalencia lógica, consistente en que las condiciones de verdad de ambos enunciados sean exactamente las mismas, en cuyo caso el contenido de $\mathrm{R}_{2}$ sería analíticamente derivable de $\mathrm{R}_{1}$. Para demostrar que tal relación de equivalencia lógica no se satisface, cabe

\footnotetext{
${ }^{95}$ Se trata, con ello, de una relación de "implicación extensiva"; véase sólo SPENDEL, "Umkerhschluß", cit. nota $\mathrm{n}^{\mathrm{o}} 87$, p. 452.

${ }^{96}$ Se trata, en rigor, de una representación sólo co-fundante - $-\mathrm{y}$ no fundante sin más — del dolo, desde ya en consideración de que para la existencia de dolo es asimismo necesario que el agente no se represente circunstancias que hacen o haría objetivamente aplicable una causa de justificación.

${ }^{97}$ Ello se explica por el hecho de que una misma oración pueda ser usada para formular una regla y para enunciar una proposición que reproduce el contenido de esa misma regla; véase al respecto MAÑALICH, "Normas permisivas", cit. nota $n^{\circ} 84$, con referencias ulteriores.

${ }^{98}$ El locus classicus al respecto es el célebre artículo de Frege, titulado "La negación”; véase FREGE, Gottlob, Logische Untersuchungen, Gotinga: Vandenhoeck \& Ruprecht, 1966, pp. 63 ss., 69 ss.
} 


\section{Polít. crim. Vol. 14, No 27 (Julio 2019), Art. 10, pp. 296-375. [http://politcrim.com/wp-content/uploads/2019/05/Vol14N27A10.pdf]}

considerar cuáles son las vías de obtención de enunciados lógicamente equivalentes a un enunciado (asertórico) cualquiera, tradicionalmente reconocidas por la lógica proposicional, ${ }^{99}$ en referencia a $\mathrm{R}_{1}{ }^{100}$

Una primera vía para la formulación de un enunciado lógicamente equivalente a $R_{1}$ sería someterlo a una operación de obversión. ${ }^{101}$ Esta operación consiste en reemplazar el antecedente de $\mathrm{R}_{1}$ por la proposición obtenida a través de su correspondiente negación, lo cual tiene lugar en la forma precedentemente indicada. ${ }^{102} \mathrm{Si}$ el antecedente de $\mathrm{R}_{1}$ es reemplazado por la proposición contradictoria que resulta de su negación, el enunciado condicional que se obtiene, por obversión, y que podemos denominar " $\mathrm{R}_{3}$ ", es el siguiente:

\begin{tabular}{|c|c|}
\hline antecedente & consecuente \\
\hline $\begin{array}{l}\text { Siempre que } X \text { se ha representado las } \\
\text { circunstancias que realizan el tipo, }\end{array}$ & $\begin{array}{l}\text { entonces (sólo) posiblemente } \mathrm{X} \text { es punible a } \\
\text { título de delito doloso. }\end{array}$ \\
\hline
\end{tabular}

Es claro que $R_{3}$ no es equivalente a $R_{2}$, puesto que la formulación del consecuente de $R_{3}$ incorpora el operador modal de la posibilidad, que en tal medida debilita la relación de condicionamiento que se da entre el antecedente y el consecuente. En efecto, la relación en que se encuentran el antecedente y el consecuente de $\mathrm{R}_{3}$ es una que hace del primero condición necesaria, mas no suficiente, del segundo. Y ello no es más que una implicación de que el antecedente de $\mathrm{R}_{3}$ se obtenga a través de la negación del antecedente de $\mathrm{R}_{1}$. Si $p$ es condición suficiente de $q$, entonces $\neg p$ es condición necesaria de $\neg q$, y viceversa. ${ }^{103}$ En referencia al sistema de reglas de imputación al que pertenece la regla enunciada a través de $\mathrm{R}_{1}, \mathrm{R}_{3}$ también es un enunciado verdadero, en la medida en que la sola representación de las circunstancias que realizan el tipo es necesaria, pero no suficiente, para una punibilidad a título de delito doloso. Que no se trata de una condición suficiente resulta obvio si se repara, entre otras, en la posibilidad de que la responsabilidad fundante de esa eventual punibilidad resultara excluida, por ejemplo, en virtud de una causa de inculpabilidad o una causa de exculpación, que como tal dejase intacto el dolo atribuible al agente.

Tampoco es posible arribar a $\mathrm{R}_{2}$ a partir de $\mathrm{R}_{1}$ si este enunciado es sometido a una operación de conversión. ${ }^{104}$ Un enunciado condicional resulta convertido si su antecedente pasa a ocupar el lugar del consecuente y su consecuente el lugar del antecedente. El enunciado que se obtiene a través de la conversión de $R_{1}$, que llamaremos " $\mathrm{R}_{4}$ ", es el siguiente:

\footnotetext{
${ }^{99} \mathrm{Al}$ respecto véase la muy accesible exposición ofrecida en COHEN, Morris; NAGEL, Ernest, Introducción a la Lógica y al Método Científico, tomo I, Trad. MIGUEL, Nestor, Buenos Aires: Amorrortu editores, 1968, pp. 75 ss.

${ }^{100}$ Fundamental SPENDEL, “Umkerhschluß”, cit. nota no 87, pp. 453 ss.

${ }^{101}$ COHEN / NAGEL, Introducción, cit. nota $\mathrm{n}^{\circ}$ 99, pp. $76 \mathrm{~s}$.

102 Véase SPENDEL, "Umkerhschluß”, cit. nota n 87, pp. $453 \mathrm{~s}$.

${ }^{103}$ Viceversa, porque entre ambas proposiciones condicionales se da una relación de bicondicionalidad o doble implicación. Puesto en notación formalizada: ( $\rightarrow \mathrm{q}) \leftrightarrow(\neg \mathrm{p} \leftarrow \neg \mathrm{q})$, donde “ $\neg$ ” funge como el símbolo de la negación, “_ $\rightarrow$ _" expresa una relación entre dos proposiciones tal que la primera proposición es condición suficiente de la segunda, “_ $\leftarrow$ ” una relación tal que la primera proposición es condición necesaria de la segunda, $\mathrm{y}$ “_ $\leftrightarrow$ ” una relación de bicondicionalidad entre ambas proposiciones.

${ }^{104} \mathrm{Al}$ respecto $\mathrm{COHEN} / \mathrm{NAGEL}$, Introducción, cit. nota $\mathrm{n}^{\circ}$ 99, pp. $75 \mathrm{~s}$.
} 
MAÑALICH, Juan Pablo, "Tentativa, error y dolo. Una reformulación normológica de la distinción entre tentativa y delito putativo".

\begin{tabular}{|l|ll|}
\hline \multicolumn{2}{|c|}{ antecedente } & \multicolumn{2}{c|}{ consecuente } \\
\hline $\begin{array}{l}\text { Siempre que X no es punible a título de } \\
\text { delito doloso, }\end{array}$ & $\begin{array}{l}\text { entonces (sólo) posiblemente X no se ha } \\
\text { representado las circunstancias que realizan el tipo. }\end{array}$ \\
\hline
\end{tabular}

Puesto que entre el antecedente y el consecuente de $\mathrm{R}_{1}$ existe una relación que hace del primero condición suficiente (y no necesaria) del segundo, lo cual correlativamente determina que el segundo sea condición necesaria (y no suficiente) del primero, es claro que su intercambio de posiciones hace que entre el antecedente y el consecuente del enunciado así obtenido — que es $\mathrm{R}_{4}$ - exista una relación que hace del primero condición necesaria (y no suficiente) del segundo. ${ }^{105} \mathrm{Y}$ es claro que, en referencia al mismo sistema de reglas de imputación, si $\mathrm{R}_{1}$ es verdadero, entonces también lo es $\mathrm{R}_{4}$, en términos tales que el hecho de que el agente no sea punible a título de delito doloso es condición necesaria, mas no suficiente, de que el agente no se haya representado las circunstancias que realizan el tipo. Pues mientras no podría afirmarse que el agente no se ha representado las circunstancias que realizan o habrían realizado el tipo si aquél resulta punible a título de delito doloso, es posible que, a pesar de no resultar punible a título de delito doloso, el agente sí se haya representado las circunstancias que realizan el tipo, desde ya porque tal punibilidad podría encontrarse excluida por la configuración de un obstáculo de la imputación distinto de la inexistencia de dolo.

Finalmente, $\mathrm{R}_{1}$ podría ser sometido a una operación de contraposición, consistente en la combinación de una obversión y una conversión. ${ }^{106}$ El enunciado condicional así obtenido, que cabría denominar "R 5 ", se deja formular como sigue:

\begin{tabular}{|c|l|}
\hline antecedente & \multicolumn{1}{c|}{ consecuente } \\
\hline Siempre que X es punible a título de dolo, & $\begin{array}{l}\text { entonces necesariamente X se ha representado las } \\
\text { circunstancias que realizan el tipo. }\end{array}$ \\
\hline
\end{tabular}

No es difícil advertir que en un sistema de reglas de imputación en referencia al cual $\mathrm{R}_{1}$ sea verdadero, también lo será $R_{5}$. Pues que entre el antecedente y el consecuente de $R_{5}$ se dé una relación que hace del primero condición suficiente, mas no necesaria, del segundo, no es sino una implicación de que la falta de representación de las circunstancias que realizan el tipo sea suficiente para excluir una punibilidad a título de delito de doloso, que es precisamente lo que se enuncia a través de $\mathrm{R}_{1}{ }^{107}$

De lo anterior se sigue que ni por vía de obversión, ni por vía de conversión, ni por vía de contraposición es posible extraer un enunciado como $\mathrm{R}_{2}$ a partir de $\mathrm{R}_{1}$. Esto basta para concluir que de la existencia de una regla que excluye una punibilidad a título de delito doloso, en caso de que el agente no se represente las circunstancias que realizan el tipo, no es posible inferir la existencia de una regla que haga suficiente la representación de esas mismas circunstancias para una punibilidad a título de delito doloso. Pues $R_{2}$ no se corresponde con un enunciado lógicamente equivalente a $\mathrm{R}_{1}$, en alguno de los tres sentidos ya examinados, sino más bien con la formulación de una regla "inversa" a aquella cuyo

\footnotetext{
${ }^{105}$ Véase SPENDEL, “Umkerhschluß”, cit. nota no 87, p. 456.

${ }^{106}$ COHEN / NAGEL, Introducción, cit. nota $\mathrm{n}^{\circ}$ 99, pp. $77 \mathrm{~s}$.

${ }^{107}$ Véase SPENDEL, "Umkerhschluß”, cit. nota $\mathrm{n}^{\circ}$ 87, pp. $456 \mathrm{~s}$.
} 


\section{Polít. crim. Vol. 14, Nº 27 (Julio 2019), Art. 10, pp. 296-375. [http://politcrim.com/wp-content/uploads/2019/05/Vol14N27A10.pdf]}

contenido queda expresado por $\mathrm{R}_{1}$, para cuya postulación sería necesario contar con un punto de apoyo independiente, que es justamente lo que tendría que ofrecer la así llamada "teoría subjetiva de la tentativa". ${ }^{108} \mathrm{Y}$ si tal punto de apoyo no llega a ser ofrecido, entonces hay que concluir que del hecho de que la tentativa se corresponda con una forma de punibilidad que descansa en la adscripción de un dolo constituido por una representación errónea, no se sigue, empero, que el fundamento de semejante punibilidad pueda ser reducido a la adscripción de una creencia predictiva fundante-de-dolo. ${ }^{109} \mathrm{Y}$ esto no debería sorprender: del hecho de que la adscripción de dolo sea condición necesaria para la constitución de una tentativa de delito, ${ }^{110}$ no puede inferirse que también tuviera que ser condición suficiente.

La conclusión provisional así alcanzada hace posible organizar la indagación a la que se encuentra dirigido, en lo que sigue, el presente trabajo. Por un lado, que una adscripción de dolo es condición necesaria para una punibilidad a título de tentativa constituye la premisa a partir de la cual es posible demostrar que los casos de las así llamadas "tentativa irreal" y "tentativa supersticiosa" no son casos en que el comportamiento del agente resulte imputable a título de tentativa, porque se trata de casos en que no es posible adscribir dolo del respectivo delito a aquél. Por otro lado, que la adscripción de una creencia predictiva fundante-de-dolo no sea condición suficiente para una punibilidad a título de tentativa es una proposición que se ve corroborada por la solución a la que debe arribarse en los casos de la así llamada "tentativa subjetivamente inidónea", que de hecho no constituye tentativa alguna. ${ }^{111}$ Antes de entrar en ello, sin embargo, es fundamental volver sobre el hallazgo de que, estructuralmente, toda tentativa descansa en la existencia de una discrepancia entre las circunstancias efectivamente existentes y las circunstancias que el agente se representa como dadas. Pues el desarrollo consistente de la premisa así obtenida tiene una consecuencia drástica para uno de los lugares comunes de la dogmática de la tentativa, a saber: la impracticabilidad de la tradicional distinción entre los conceptos de tentativa idónea y tentativa inidónea.

\section{5. "Tentativa idónea" como contradictio in adjecto}

\subsection{El juicio de (in)idoneidad de la tentativa desde una perspectiva ex post}

La afirmación según la cual la estructura de toda tentativa de delito queda co-determinada por la existencia de error fundante-de-dolo, en los términos del análisis ya ofrecido,

\footnotetext{
${ }^{108}$ PUPPE, "Der Umkehrschluss", cit. nota $n^{\circ}$ 81, pp. 305 s. Al respecto. véase también MAIER, Die Objektivierung, cit. nota $\mathrm{n}^{\mathrm{o}} 77$, p. 122.

${ }^{109}$ Esto explica que sea en definitiva fútil el esfuerzo de SAX, Walter, "Zum logischen und sachlichen Gehalt des sogen. Umkehrschlusses aus $§ 59$ StGB”, Juristenzeitung, 1964, pp. 241-245, pp. 242 ss., por defender la validez lógica del "argumento de la inversión", por la vía de conceder que la invocación de éste jamás pretendía sustentar la punibilidad de la tentativa, sino sólo demostrar cómo la errónea representación de las circunstancias que realizarían el tipo sería condición suficiente para constatar la existencia de una "actitud criminal" (verbrecherische Gesinnung). Acertadamente impugnando la validez de esta última inferencia, SPENDEL, "Kritik", cit. nota no 87, pp. $1886 \mathrm{~s}$.

${ }^{110}$ Acerca de la relación de incompatibilidad en que se encuentran las estructuras de imputación de la tentativa y de la imprudencia, véase MAÑALICH, "La tentativa", cit. nota nº 5, pp. $488 \mathrm{~s}$.

${ }^{111}$ Véase infra, 7.3.
} 
constituye la premisa decisiva en la elaboración del argumento encaminado a disolver la muy generalizada distinción entre las categorías de tentativa idónea y tentativa inidónea.

La dificultad que enfrenta el esfuerzo por ofrecer una formulación unívoca de la distinción entre ambas categorías se encuentra suficientemente documentada en la literatura especializada. ${ }^{112}$ Desde este punto de vista, es llamativa la falta de precisión que exhibe la determinación del concepto de tentativa inidónea en el contexto de la discusión alemana. Considérese, verbigracia, la definición acuñada por Zaczyk, según quien el género de las así llamadas "tentativas inidóneas" comprendería aquellas "acciones sostenidas por una completa resolución al hecho, respecto de las cuales ya en el momento de su ejecución consta objetivamente que ellas no pueden realizar el tipo". ${ }^{113}$ La ambigüedad de esta definición resulta del hecho de que no es en absoluto claro qué quiere decirse cuando se habla de que la imposibilidad de la realización del tipo pudiera "constar objetivamente" ya en el momento de ser ejecutada (u omitida) la acción respectiva. La situación no mejora si, para alcanzar mayor precisión, se introduce la referencia a "un observador familiarizado con las circunstancias" para identificar el punto de vista desde el cual tendría que ser reconocible la inadecuación del comportamiento del potencial autor para realizar el tipo. ${ }^{114}$ Pues esto sólo reproduce el problema que aqueja a la así llamada "teoría de la imputación objetiva", en cuanto a cómo construir el campo de conocimiento atribuido al observador ficticio desde cuyo asimismo ficticio punto de vista tendría que determinarse el carácter riesgoso o no riesgoso del comportamiento del agente. ${ }^{115}$

En lo que sigue se intentará demostrar, antes bien, que la distinción entre tentativas idóneas y tentativas inidóneas es impracticable, ${ }^{116}$ en la medida en que se asuman los dos siguientes postulados, a saber: el postulado de la clausura causal del dominio físico, con arreglo al cual "si un evento físico tiene una causa en [en el punto de tiempo] $t$, entonces tiene una causa física en $t$ "; ${ }^{117}$ y el postulado de la equivalencia de todas las condiciones de las cuales

\footnotetext{
${ }^{112}$ Para una erudita revisión del problema, en perspectiva comparatista, véase el monumental estudio monográfico de SEMINARA, Sergio, Il delitto tentato, Milán: Giuffrè Editore, 2012, pp. 332 ss., 694 ss., 836 ss. En la discusión española, véase especialmente SOLA RECHE, Tentativa inidónea, cit. nota nº 86, pp. 8 ss.; ALCÁCER, Rafael, La tentativa inidónea, Granada: Editorial Comares, 2000, pp. 6 y ss. Al respecto también, y desde perspectivas diferentes, FARRÉ TREPAT, Elena, La tentativa de delito, $2^{\mathrm{a}}$ ed., Madrid, Montevideo y Buenos Aires: Edisofer y BdF, 2011, pp. 333 ss.; REYES, Yesid, El delito de tentativa, Montevideo y Buenos Aires: BdF, 2016, pp. 130 ss., con múltiples referencias ulteriores. En la literatura chilena, véase especialmente CURY, Enrique, Tentativa y delito frustrado, Santiago: Editorial Jurídica de Chile, 1977, pp. 147 ss.; GARRIDO, Mario, Etapas de ejecución del delito. Autoría y participación, Santiago: Editorial Jurídica de Chile, 1984, pp. 147 ss.; POLITOFF, Sergio, Los actos preparatorios del delito. Tentativa y frustración, Santiago: Editorial Jurídica de Chile, 1999, pp. 105 ss., 133 ss.

${ }^{113}$ ZACZYK, Rainer, "§ 22” y "§ 23”, en: KINDHÄUSER, Urs; NEUMANN, Ulfrid; PAEFFGEN, HansUllrich (coords.), Strafgesetzbuch. NomosKommentar, $5^{\mathrm{a}}$ ed., tomo I, 2017, § 22, n.m. 34.

${ }^{114}$ KINDHÄUSER, Urs, Strafgesetzbuch. Lehr- und Praxiskommentar, $4^{\mathrm{a}}$ ed, 2010, § 22, n.m. 4.

${ }^{115}$ Fundamental KINDHÄUSER, "Der subjektive Tatbestand”, cit. nota no 72, pp. 451 ss., 456 ss. Véase también HAAS, Volker, "Die strafrechtliche Lehre von der objektiven Zurechnung — eine Grundsatzkritik", en: KAUFMANN, Matthias; RENZIKOWSKI, Joachim. (coords.), Zurechnung als Operationalisierung von Verantwortung, Fráncfort del Meno: Peter Lang, 2004, pp. 193-224, pp. 209 ss.

${ }^{116}$ Véase ya JAKOBS, Strafrecht, cit. nota n ${ }^{\circ} 47,25 / 36$.

${ }^{117}$ Así KIM, Jaegwon, Physicalism, or Something Near Enough, Princeton y Oxford: Princeton University Press, 2005, p. 15; véase también KIM, Jaegwon, Mind in a Physical World, Cambridge (Mass.): The MIT Press, 1998, pp. 37 s., 40 s.; KIM, Jaegwon, Essays in the Metaphysics of Mind, Oxford: Oxford University
} 


\section{Polít. crim. Vol. 14, No 27 (Julio 2019), Art. 10, pp. 296-375. [http://politcrim.com/wp-content/uploads/2019/05/Vol14N27A10.pdf]}

depende el acaecimiento de la transformación de algún estado del mundo. ${ }^{118}$ Sobre este trasfondo, la usual caracterización de una tentativa como idónea o inidónea descansa en una metodología arbitraria de selección de las circunstancias que son tenidas por suprimibles o no suprimibles a la hora de responder la pregunta de si la consumación del delito en cuestión era, en atención a las circunstancias dadas, posible o imposible.

Aun cuando ello no siempre es hecho explícito, la jerga doctrinal más generalizada identifica las constelaciones de tentativas supuestamente inidóneas adoptando una perspectiva ex post. ${ }^{119}$ Pues sólo a partir de la adopción de una perspectiva ex post puede asumirse que los casos en que alguien dispara un arma de fuego contra el cadáver de un ser humano, confundiéndolo con un ser humano vivo, o en que alguien dispara un arma no cargada con bala alguna contra un ser humano, confundiéndola con una pistola cargada, serían casos paradigmáticos de tentativa inidónea (de homicidio). ${ }^{120}$ Lo distintivo de tales casos es que la falta de idoneidad de la tentativa es compatible con que cualquier persona situada en la posición en la que se encontraba el agente al momento de disponerse a ejecutar $\mathrm{u}$ omitir la acción en cuestión hubiese desconocido la circunstancia que determinaba esa misma falta de idoneidad. El problema está en que, desde esa misma perspectiva, toda tentativa resulta ser, necesariamente, inidónea. ${ }^{121}$

Para sustentar esta última afirmación, cabe restringir el análisis a grupos de casos en los cuales, en referencia a la constitución de la tentativa de un delito de resultado puro, como lo es el homicidio, el foco queda puesto ya en el aspecto de la idoneidad o inidoneidad del objeto en el cual habría de tener lugar la transformación constitutiva del respectivo resultado, por un lado, ya en el aspecto de la idoneidad o inidoneidad del "medio" —o más adecuadamente: del método - de cuya utilización dependería el acaecimiento de esa misma transformación en el objeto respectivo, por otro. ${ }^{122}$ Esta formulación tiene la ventaja de superar la ambigüedad que a veces se atribuye a la distinción entre objeto y medio desde el punto de vista de su posible inidoneidad, en razón de que la conjunción de uno y otro componente constituiría una "unidad de sentido". 123

Press, 2010, pp. 290 s. Al respecto también SCHRÖDER, Jürgen, Einführung in die Philosophie des Geistes, Fráncfort del Meno: Suhrkamp, 2004, pp. 270, 282 ss.

${ }^{118}$ Este postulado de la equivalencia de las condiciones no debe ser confundido con la fórmula de la condicio sine qua non, en la medida en que aquél resulta igualmente compatible, por ejemplo, con una definición del concepto de causa a través de la fórmula de la condición mínima suficiente; véase al respecto MAÑALICH, Norma, cit. nota $\mathrm{n}^{\circ} 23$, pp. 39 ss., $42 \mathrm{~s}$.

${ }^{119}$ En referencia a la literatura española, véase especialmente ALCÁCER, Rafael, La tentativa inidónea, Granada: Editorial Comares, 2000, pp. 6 ss., 13 s.

${ }^{120}$ Véase por ejemplo KÜHL, Kristian, Strafrecht Allgemeiner Teil, $4^{\mathrm{a}}$ ed., Múnich: Verlag Vahlen, 2002, § $15 / 88$ ss.

${ }^{121}$ Detalladamente SOLA RECHE, Tentativa inidónea, cit. nota $\mathrm{n}^{\circ}$ 86, pp. $164 \mathrm{ss}$.

${ }^{122}$ Acertadamente observaba STRUENSEE, Eberhard, "Verursachungsvorsatz und Wahnkausalität", Zeitschrift für die gesamte Strafrechtswissenschaft 102, 1990, pp. 21-50, pp. 46 s., que, usada para dar cuenta de la estructura típica de delitos de resultado (causalmente condicionado) — sobre esta última noción, véase MAÑALICH, Norma, cit. nota n $\mathrm{n}^{\mathrm{0}} 23$, pp. 32 ss.-, la expresión "medio" resulta equivalente, y sustituible por, la de "factor causal".

${ }^{123}$ WACHTER, Matthias, Das Unrecht der versuchten Tat, Friburgo: Mohr Siebeck, 2015, pp. 40 s. 
En estos términos, se piensa, en un caso en el cual A dispara haciendo uso de un revólver contra B, estando B cubierto por una armadura impenetrable para una bala, resultaría arbitrario cifrar la explicación de la imposibilidad de consumación del correspondiente homicidio privilegiando uno de los dos factores aisladamente, con prescindencia del otro. Pues es claro que el arma usada por A habría sido idónea para dar muerte a B si éste no hubiese llevado puesta la armadura, y es asimismo claro que B podría haber resultado muerto si, en vez de la pistola, A hubiese disparado un proyectil de bazuca. Con arreglo a la formulación de la distinción ofrecida más arriba, empero, lo correcto sería reconocer que, en semejante caso, el problema es uno de inidoneidad del medio, y no del objeto. Pues en sentido técnico, por "objeto" de un posible delito de homicidio viene en consideración todo individuo que satisfaga la descripción "ser humano (nacido) vivo", precisamente porque un individuo semejante es susceptible de padecer la transformación en la que consiste el resultado típicamente relevante.

Lo anterior no obsta, con todo, a que sea enteramente correcto poner en duda la relevancia de la distinción categorial entre objeto y medio, aun al interior del muy acotado ámbito de los delitos de resultado puros. Pues desde el punto de vista de la realización del tipo de semejante delito, tanto la idoneidad del objeto como la del medio fungen como presupuestos de cuya efectividad depende, homogéneamente, la posibilidad de que el agente condicione - aquí: causalmente- el resultado típico. ${ }^{124}$ En tal medida, ambos factores resultan ser co-determinantes de la existencia de una situación en la cual el potencial autor cuente con la correspondiente "oportunidad-para-la-acción", esto es, con la oportunidad de dar lugar, ejecutando u omitiendo una determinada acción, a la transformación en la que consiste el resultado típicamente relevante. ${ }^{125} \mathrm{Y}$ es justamente la inexistencia, reconocible ex post, de semejante situación lo que acompaña la configuración de toda tentativa. ${ }^{126}$

\section{2. ¿Idoneidad de la tentativa por idoneidad del objeto?}

Puede ser conveniente partir considerando dos casos que parecerían ser suficientemente contrastables desde el punto de vista de la idoneidad o falta de idoneidad del objeto de un eventual homicidio. Así, el siguiente caso parece ser paradigmático de la constelación de una tentativa inidónea por falta de idoneidad del objeto:

(5) A dispara su arma de fuego apuntando contra lo que cree sería su enemigo B durmiendo cubierto por la frazada de su cama, en circunstancias de que B ha muerto, a consecuencia de un infarto, media hora antes de que A efectuara su disparo.

\footnotetext{
${ }^{124}$ En este sentido ya HÄLSCHNER, Strafrecht, cit. nota $\mathrm{n}^{\circ}$ 4, pp. $348 \mathrm{~s}$.

${ }^{125}$ Acerca de esta noción, véase VON WRIGHT, Georg Henrik, Norm and Action, Londres: Routledge \& Kegan Paul, 1963, pp. 37, 42 ss., 45 ss.; VON WRIGHT, Georg Henrik, Explanation and Understanding, Londres: Routledge \& Kegan Paul, 1971, pp. 125 ss.; VON WRIGHT, Georg Henrik, Practical Reason. Philosophical Papers I, Oxford: Basil Blackwell, 1983, pp. 170 ss. Al respecto, véase también MAÑALICH, Norma, cit. nota $\mathrm{n}^{\circ} 23$, pp. 71 ss.

${ }^{126}$ Claramente en este sentido ya VON BURI, "Versuch", cit. nota $n^{\circ} 86$, pp. 362 s.; también VON BURI, "Untaugliche Versuchshandlungen", cit. nota n 6, p. 191.
} 


\section{Polít. crim. Vol. 14, No 27 (Julio 2019), Art. 10, pp. 296-375. [http://politcrim.com/wp-content/uploads/2019/05/Vol14N27A10.pdf]}

Por su parte, el siguiente caso se presenta como igualmente paradigmático de la constelación de una tentativa idónea en atención a la idoneidad de su objeto:

(6) A dispara su arma de fuego apuntando contra su enemigo B, que se encuentra durmiendo cubierto por la frazada de su cama, quien no obstante sufrir un impacto de bala logra ser salvado por el equipo médico alertado por la policía después del aviso de la audición de un disparo por parte de un vecino.

La diferencia entre (5) y (6) resulta ser, a primera vista, insoslayable. Pues mientras en (6) A parece haber contado con la oportunidad de dar muerte a $\mathrm{B}$, haciendo exactamente lo que A hizo, en (5) A no contaba, ab initio, con tal oportunidad, siendo esto último, empero, sólo constatable ex post (para cualquier "observador" que no hubiese estado al tanto del previo fallecimiento de B). Tal caracterización de la situación en la que se encontraba A en (5) no es impugnable en modo alguno. El problema está, más bien, en la caracterización de (6). Para comprobarlo, considérese ahora un ulterior caso:

(7) A dispara su arma de fuego apuntando contra su enemigo B, que se encuentra durmiendo cubierto por la frazada de su cama, quien súbitamente muere, a consecuencia de un infarto, un instante antes de que la bala impacte su cuerpo.

Aquí es crucial reparar en que el hecho de que B se encuentre todavía vivo en el momento en que A efectúa el disparo no es razón suficiente para concluir que, por esa sola circunstancia, la eventual tentativa de homicidio tendría que ser caracterizada como idónea. Pues ello supondría desconocer que A ha efectuado el disparo en contra de una persona que se encontraba en una situación que determinaba que esa persona fuese a morir un instante antes de recibir el impacto de bala. Y el disparo de un arma de fuego dirigido hacia una persona que habrá de morir antes de recibir el eventual impacto de bala carece de idoneidad para producir la muerte de esa misma persona.

Lo anterior se traduce en que, desde el punto de vista de la posibilidad de consumación del homicidio en cuestión, no hay diferencia relevante alguna entre los casos (5) y (7). Pues mientras en (5) B no es susceptible de ser matado, por tratarse de un ser humano que ya se encuentra muerto al momento en que tiene lugar el disparo, en (7) B tampoco es susceptible de ser matado a través del disparo efectuado por A, por tratarse de un ser humano que habrá de morir antes de que la bala pudiera impactarlo letalmente. En uno y otro caso, entonces, al efectuar el disparo A no cuenta con la oportunidad para condicionar causalmente la muerte de B, a consecuencia de la situación en la que éste respectivamente se encuentra. La explicación para la equivalencia estructural de los dos casos radica en que la situación en la que A ejecuta su acción se encuentra, en ambos casos, configurada por circunstancias antecedentes que determinan que la muerte de B no pueda resultar de la ejecución de esa acción. Esto es lo que, en lo que aquí interesa, se sigue de la adopción del postulado de la clausura causal del dominio físico. ${ }^{127}$

Pero una vez que se repara en ello, cabe preguntarse si, frente a los casos (5) y (7), (6) presenta alguna divergencia estructuralmente relevante, en lo tocante a la posibilidad de

\footnotetext{
${ }^{127}$ Véase supra, 5.1.
} 
consumación del homicidio respectivo bajo el postulado de la clausura causal del dominio físico. La respuesta es negativa. Pues que en (6) sea el desarrollo de un curso causal salvador, desplegado por el equipo médico a su vez alertado por la policía, deja intacto el hecho de que la situación en la cual A efectuó el disparo era una que integraba circunstancias que determinaron que la vida de B fuese salvada, privando así a la acción ejecutada por A de la propiedad de ser letal para B. Entre esas circunstancias figura la disposición de los agentes policiales involucrados a alertar a los integrantes del equipo médico del peligro de muerte al que se enfrentaba B, acompañada de las circunstancias que llevaron a la activación de esa disposición latente, manifestada en la alerta efectivamente comunicada a los integrantes del equipo médico, así como la disposición de los propios integrantes del respectivo equipo médico a desplegar el salvamento, activada a través de la alerta recibida de parte de la policía, y que en definitiva llevara a la preservación de la vida de B. Nótese, adicionalmente, que la consideración del comportamiento de los funcionarios policiales y de los integrantes del equipo médico como subordinado al postulado de la clausura causal del dominio físico, y en tal medida como determinado, resulta enteramente compatible con su posible consideración como un comportamiento autónomamente motivado, en la medida en que se asuma, como aquí se hace, la viabilidad de una estrategia — valga la redundancia_ "compatibilista" para disolver la pretendida antinomia entre libertad y determinismo. ${ }^{128}$

La conclusión así alcanzada descansa en el hecho de que las circunstancias que configuran la situación en la cual un delito cualquiera no llega a consumarse son conjuntamente suficientes para que el delito en efecto no se haya consumado. Eso quiere decir que en cualquier mundo posible en el cual el comportamiento del potencial autor hubiese tenido lugar en una situación idéntica a la situación configurada por esas precisas circunstancias, el delito en cuestión no se habría consumado. Y esto vale, irrestrictamente, también cuando la circunstancia que diferencialmente explica la falta de consumación del delito está constituida por una disposición del potencial autor en orden a impedir la eventual consumación del delito, acompañada de circunstancias que condicionan la activación de esa misma disposición. Considérese, al efecto, el siguiente nuevo caso:

(8) A dispara su arma de fuego apuntando contra su enemigo B, que se encuentra durmiendo bajo la frazada de su cama, quien no obstante ser impactado por la bala logra ser salvado por el servicio de urgencia al que A mismo alertara por vía telefónica, tras entrar en pánico.

Que en (8) A haya impedido la consumación del homicidio en la forma de un desistimiento (activo) de la correspondiente tentativa (acabada), cuyo carácter "voluntario" o "involuntario" no necesita ser examinado aquí, sólo resulta explicable a partir de la hipótesis de que A poseía una disposición susceptible de ser activada en pos del impedimento de la muerte de B. Que esa disposición conductual fuera conocida o desconocida para A en el momento en que éste efectuó el disparo apuntando contra B, es enteramente irrelevante para lo que aquí interesa. Pues una situación en la cual alguien

\footnotetext{
${ }^{128}$ Véase por ejemplo PARDO, Michael; PATERSON, Dennis, Minds, Brains, and Law, Oxford y Nueva York: Oxford University Press, 2013, pp. 191 ss. Al respecto, MAÑALICH, Juan Pablo, "Determinismo, autonomía y responsabilidad penal", en: KINDHÄUSER, Urs; MAÑALICH, Juan Pablo, Pena y culpabilidad en el Estado democrático de derecho, $2^{\mathrm{a}}$ ed., Montevideo y Buenos Aires: BdF, 2011, pp. 181-210, passim.
} 


\section{Polít. crim. Vol. 14, No 27 (Julio 2019), Art. 10, pp. 296-375. [http://politcrim.com/wp-content/uploads/2019/05/Vol14N27A10.pdf]}

efectuase el disparo que A efectivamente efectuó contra B, poseyendo el autor del disparo la disposición que en efecto A mostró tener, al realizar el llamado telefónico que en definitiva llevó al impedimento de la muerte de B, y dándose las demás circunstancias configuradoras de esa misma situación (incluida la disposición y la capacidad de los integrantes del equipo médico para responder con eficacia al llamado recibido), es una situación en la cual el preciso disparo efectuado por A no resultaba idóneo para producir la muerte de B.

Una corroboración de este último aserto se obtiene, palmariamente, a través del siguiente experimento mental: si complementásemos el caso (8) con la suposición de que A hubiese estado cabalmente al tanto de todas las circunstancias constitutivas de la situación, incluidas su disposición a dar lugar, eficazmente, al salvamento de la vida de B y la disposición y la capacidad del equipo médico para practicar ese mismo salvamento, en términos tales que, en el momento de efectuar el disparo, a A pudiese atribuirse una seguridad rayana en la certeza de que B en definitiva no habría de resultar muerto a consecuencia de ese mismo disparo, entonces lo consistente sería negar que A haya tenido la creencia predictiva de que su comportamiento, consistente en el disparo efectuado contra $\mathrm{B}$, podría resultar letal para B. Esto equivale a decir, entonces, que en esa situación lo correcto sería descartar la imputación de una tentativa de homicidio a A, en razón de la inexistencia de dolo de homicidio. ${ }^{129}$ Pero justamente la inverosimilitud de la suposición de que alguien pudiese llegar a tener semejante certeza explica que difícilmente vaya a ser admisible, al revés, excluir una adscripción de dolo por el hecho de que el potencial autor haya meramente confiado en poder hacer uso, con posterioridad, de una oportunidad para impedir la consumación del respectivo delito, en cuanto esa consumación hubiera de corresponderse con la realización de un riesgo cuya generación el agente efectivamente se ha representado.

Del análisis de los cuatro casos recién contrastados es posible extraer la conclusión de que la tradicional distinción entre tentativas idóneas y tentativas inidóneas se apoya en una infundada focalización en uno, y sólo uno, de los factores que condicionan la posibilidad de consumación del delito. Esto desconoce que —en el sentido del postulado lógico de la "equivalencia de las condiciones"- la sola satisfacción aislada de alguno de los elementos que componen la descripción que especifica la correspondiente forma de comportamiento antinormativo, como lo es el elemento que especifica en qué ha de consistir el objeto de la transformación prohibida o requerida por la norma respectiva, nada dice acerca de la adecuación del respectivo comportamiento para realizar esa misma descripción.

\section{3. ¿Idoneidad de la tentativa por idoneidad del medio?}

Puede ser conveniente reforzar el argumento hasta aquí desarrollado, dando cuenta de la manera en que éste resulta igualmente pertinente tratándose de casos cuyo análisis tiende a focalizarse en la idoneidad o falta de idoneidad del medio (o método) del que se vale el potencial autor. Considérese el siguiente caso:

\footnotetext{
${ }^{129}$ Sobre la exclusión del dolo en casos de asunción (errónea) de la propia "capacidad preventiva" del agente, véase sólo KINDHÄUSER, Urs, "Der Vorsatz als Zurechnungskriterium", Zeitschrift für die gesamte Strafrechtswissenschaft 96, 1984, pp. 1-35, pp. 25 ss., 28 ss.
} 


\section{MAÑALICH, Juan Pablo, “Tentativa, error y dolo. Una reformulación normológica de la distinción entre tentativa y delito putativo".}

(9) A tira del gatillo de su arma apuntando contra su enemigo B, ubicado a unos pocos metros de distancia, desconociendo que lo que tiene en su mano es, empero, una pistola de fantasía.

Éste sería un caso paradigmático de una así llamada "tentativa inidónea" por falta de idoneidad del medio. Es fundamental advertir, ahora bien, que la falta de idoneidad del medio en cuestión no necesita siempre consistir, como sucede en (9), en alguna propiedad intrínseca de aquello de un objeto del cual pudiera valerse el agente. Antes bien, es posible que la falta de idoneidad pueda estar condicionada por un estado (transitorio) de un artefacto genéricamente apto para ser usado de manera típicamente relevante. Considérese, en efecto, el siguiente caso:

(10) A tira del gatillo de su arma apuntando contra su enemigo B, ubicado a unos pocos metros de distancia, desconociendo que la pistola no se encuentra cargada.

En referencia a este último caso, es fácil imaginar una situación suficientemente parecida a aquella en la que se encuentra A, en la cual la maniobra de tirar del gatillo pudiera, ceteris paribus, resultar letal para B. Eso sucedería si (10) fuese leve, pero decisivamente modificado, en el sentido de que el arma en cuestión sí se encontrase cargada. Pero hay que advertir, de inmediato, que ello no bastaría volver idónea la eventual tentativa de homicidio. Pues considérese ahora el siguiente caso:

(11) A tira del gatillo de su arma apuntando contra su enemigo B, ubicado a unos pocos metros de distancia, desconociendo que la pistola se encuentra con el seguro puesto.

Estructuralmente, (11) en nada se diferencia de (10). Que para A pudiera haber sido "más fácil" revertir la falta de idoneidad del arma en (11) que en (10) deja intacto el hecho de que, en uno y otro caso, se da una circunstancia, desconocida por A, que determina la ejecución de la acción consistente en tirar del gatillo del arma en cuestión no pueda resultar en la muerte de B. Como ya observara Von Buri: "Entre la utilización inidónea de un medio idóneo y la utilización de un medio inidóneo no puede haber diferencia alguna". ${ }^{130}$ Pero es crucial ahora insistir en que es enteramente irrelevante que la circunstancia que determina la imposibilidad de que el correspondiente homicidio se consume concierna al artefacto cuya utilización el agente (erróneamente) tiene por apta para dar lugar a la transformación típicamente relevante, o bien concierna a cualquier otro aspecto de la situación, según cuál hubiera de ser el campo causal sobre el trasfondo del cual pudiera tener lugar esa misma transformación. ${ }^{131}$ Pues considérese todavía un ulterior caso:

(12) A tira del gatillo de su arma apuntando contra su enemigo B, ubicado a unos pocos metros de distancia, desviándose la bala a consecuencia de una súbita ráfaga de viento.

\footnotetext{
${ }^{130}$ VON BURI, “Untaugliche Versuchshandlungen ”, cit. nota n ${ }^{\circ}$ 6, p. 187.

${ }^{131}$ Para esta noción de "campo causal", véase MACKIE, J.L., The Cement of the Universe, Oxford: Clarendon Press, 1980, pp. 34 ss.
} 


\section{Polít. crim. Vol. 14, No 27 (Julio 2019), Art. 10, pp. 296-375. [http://politcrim.com/wp-content/uploads/2019/05/Vol14N27A10.pdf]}

El hecho de que, a diferencia de los casos anteriores, en (12) el arma detentada por A sea "en sí misma" idónea para, ceteris paribus, la ejecución de un disparo de bala eventualmente letal para otro ser humano nada dice acerca de la aptitud de la maniobra consistente en tirar del gatillo de esa misma arma para, dadas las demás circunstancias constitutivas de la situación en la que se encuentra A, impactar letalmente a B. Pues entre esas ulteriores circunstancias también se encuentra el estado climático resultante en el despliegue de la "súbita" - lo cual significa aquí: imprevista - ráfaga de viento que a su vez determinara el desvío de la bala. Sostener que en (12) la acción ejecutada por A habría sido, no obstante ello, idónea para producir la muerte de B, por el solo hecho de que la circunstancia impeditiva de la consumación del respectivo homicidio no habría concernido a la fisonomía ni el estado del arma, supondría desconocer que la posibilidad de que la descripción "matar a otro ser humano" resulte verdadera de una acción cualquiera no depende de la aptitud abstracta del artefacto del cual pudiera valerse el agente, sino de la totalidad de las circunstancias que han de proveer la correspondiente oportunidad para dar lugar a la transformación típicamente relevante. ${ }^{132}$ Una situación co-definida por la existencia de una condición climática que habría de llevar a la presencia de la ráfaga de viento condicionante del desvío de la bala disparada por A es una situación en la cual, todo lo demás siendo igual, A no contaba con la oportunidad de producir la muerte de B.

Lo anterior confirma la sospecha de que la tradicional focalización aislada en la idoneidad o falta de idoneidad del objeto, o bien en la idoneidad o falta de idoneidad del medio, resulta teóricamente infundada. El hallazgo de que toda tentativa queda definida, más bien, por el hecho de la situación en la cual se encontraba el autor se muestra, ex post, como una situación en la cual aquél no contaba con la correspondiente oportunidad para la acción, ha de conducir, más bien, a dar razón a Von Buri, cuando observaba que "toda tentativa es, en la realidad, inidónea tanto respecto del medio como respecto del objeto". ${ }^{133}$

\subsection{La tentativa de delito como delito circunstancialmente imposible en el mundo actual}

El análisis precedente ha estado encaminado a demostrar que, desde un punto de vista de vista ex post, toda tentativa se muestra como inidónea, en la medida en que es siempre alguna circunstancia constitutiva de la situación en la que tiene lugar el comportamiento del potencial autor lo que determina que ese comportamiento no llegue a exhibir el conjunto de las propiedades respectivamente fundantes de antinormatividad. Ese mismo análisis encuentra su precedente más preclaro en la muy perspicaz crítica que Herbert Hart dirigiera al giro jurisprudencial que el año 1973 la Cámara de los Lores impuso al régimen de punibilidad de la tentativa (attempt) aplicable en el Reino Unido. ${ }^{134}$ El pronunciamiento de la Cámara de los Lores, recaído en el caso Haughton versus Smith, ${ }^{135}$ declaró que quien comerciaba bienes en la creencia errónea de que habrían sido hurtados o robados no podía ser condenado como autor de una tentativa de receptación.

\footnotetext{
${ }^{132}$ En este sentido ya VON BURI, "Untaugliche Versuchshandlungen”, cit. nota no 6, pp. 186 ss., 190 s.

${ }^{133}$ VON BURI, "Versuch", cit. nota no 86, p. 345.

${ }^{134}$ HART, H.L.A, "The House of Lords on Attempting the Impossible", Oxford Journal of Legal Studies 1, 1981, pp. 149-166, pp. 149 ss.

${ }^{135}$ [1975] AC 476. Al respecto, véase DUFF, Antony, Criminal Attempts, Oxford: Clarendon Press, 1996, pp. 88 s., 103 ss.
} 
En lo fundamental, Hart sostuvo que al pronunciamiento de la Cámara de los Lores subyacían dos dogmas diferenciables, aun cuando relacionados entre sí, a saber: el dogma constituido por el así llamado "modelo de la interrupción”, por un lado, y el dogma del así llamado "requerimiento de un objeto extensional", por otro. ${ }^{136}$ Es sumamente interesante constatar que cada uno de estos dogmas, denunciados por Hart, muestra una conexión precisa con el problema de la idoneidad o falta de idoneidad del medio y del objeto, respectivamente, en los términos ya examinados.

El modelo de la interrupción asume que lo definitorio de una tentativa sería el hecho de que el delito en cuestión no llegue a consumarse debido a "la interrupción de una secuencia de eventos que, de no verse interrumpida, constituiría el actus reus del delito intentado". ${ }^{137}$ Tal modelo, observaba Hart, resulta del todo inapropiado para dar cuenta de casos en los cuales inequívocamente se reconoce la existencia de una tentativa de delito, en los cuales la falta de consumación no se sigue de alguna interrupción en el desarrollo del correspondiente curso de acontecimientos, sino del hecho de que el medio del cual se vale el agente se encuentra mal dirigido o resulta insuficiente. ${ }^{138}$ Esto sucede, por ejemplo, tratándose de un caso en el cual el potencial autor simplemente apunta mal al disparar su arma de fuego, de manera tal que la bala en definitiva no alcanza a impactar a la potencial víctima. Nótese que, estructuralmente, este es un caso que no diverge del caso (12), ya considerado. Pues sea que la falta de impacto del proyectil disparado por el autor se explique por haber éste apuntado mal, sea que se explique por haber sido desviada la bala por la presencia de una ráfaga de viento, que la potencial víctima no haya sido letalmente impactada resulta determinado, en uno y otro caso, por una circunstancia desconocida para el autor del disparo al momento de efectuar éste.

Por su parte, el dogma consistente en el requerimiento de un objeto extensional se obtendría en la forma de un argumento que partiría de la (correcta) premisa de que el significado de muchos de aquellos verbos-de-acción de carácter transitivo que - como "matar", "lesionar", "hurtar", etc.- generalizadamente conforman las descripciones que especifican en qué ha de consistir la acción cuya ejecución u omisión es delictiva impondría, como condición de verdad de una oración que afirmarse que alguien ha ejecutado u omitido la correspondiente acción, la existencia de un objeto particular en el cual tendría que tener lugar la transformación especificada por el verbo en cuestión. El mito consiste, según Hart, en extraer de esa premisa la conclusión de que ese mismo requerimiento de un objeto extensional valdría una vez que la respectiva forma verbal es modificada a través de la fórmula que define las condiciones de punibilidad de la tentativa de semejante delito. ${ }^{139} \mathrm{La}$ invalidez de semejante inferencia resulta del hecho de que, aun cuando el uso del respectivo verbo-de-acción genere un contexto extensional, ello no obsta a que la puesta en relación de ese mismo verbo con la expresión que especifica la forma de punibilidad (dependiente)

\footnotetext{
${ }^{136}$ HART, "The House of Lords", cit. nota no 134, pp. 158 s.

${ }^{137}$ HART, "The House of Lords", cit. nota $n^{\circ} 134$, p. 152. La asunción irrestricta de semejante modelo es definitoria de la concepción de la tentativa qua "delito parcial", defendida por Binding; véase BINDING, Die Normen, cit. nota $\mathrm{n}^{\circ}$ 6, pp. 427 ss., 441 ss. En la doctrina chilena, véase especialmente NOVOA, Eduardo, "Algunas consideraciones acerca de la tentativa", Revista de Ciencias Penales XX, n⿳ 1, 3 época, 1961, pp. 3-32, pp. 10 ss., 13 s.

${ }^{138}$ HART, "The House of Lords", cit. nota no 134, pp. 152 s.

${ }^{139}$ HART, "The House of Lords", cit. nota no 134, pp. $156 \mathrm{~s}$.
} 


\section{Polít. crim. Vol. 14, № 27 (Julio 2019), Art. 10, pp. 296-375. [http://politcrim.com/wp-content/uploads/2019/05/Vol14N27A10.pdf]}

asociada a la noción de tentativa genere, por el contrario, un contexto intensional. ${ }^{140} \mathrm{Y}$ esto se explica por el hecho de que la noción de tentativa, en cuanto modificadora del título de punibilidad en el que consiste el respectivo delito consumado, hace posible que el lugar (lógico) que habría de ser ocupado por el correspondiente objeto extensional, tratándose de un delito consumado, sea ocupado por un objeto puramente "intencional", en el sentido filosóficamente técnico de esta última expresión. ${ }^{141}$

Así por ejemplo, si bien la verdad de la oración "X mató a $\mathrm{Y}$ " depende, entre otras condiciones, de que haya existido $\mathrm{Y}$, de ello no se sigue que la verdad de una oración como "X intentó matar a Y", "X se dispuso inmediatamente a dar muerte a Y" o "X ejecutó una acción en la creencia de que ello resultaría en la muerte de Y", dependa, asimismo, de la existencia de Y. En cualquiera de las tres últimas oraciones, "Y" puede hacer referencia a un objeto puramente intencional. ${ }^{142}$ Con esto último no se pretende sugerir que esas últimas tres oraciones sean equivalentes desde el punto de vista de la reproducción de los presupuestos de constitución de una tentativa; es claro, más bien, que la concepción aquí favorecida debería privilegiar la tercera fórmula, especialmente en contra de la primera, en la medida en que la concepción aquí defendida vuelve irrelevante la intención que acompaña el comportamiento del agente. ${ }^{143}$ Mas en este marco sólo interesa advertir que, más allá de cuál sea el particular concepto de tentativa que se defienda, cualquier concepto de tentativa tenderá a incluir el uso de alguna expresión verbal que, combinada con la forma verbal que integra la especificación del correspondiente delito consumado, privará a ésta de sus implicaciones semánticamente extensionales. ${ }^{144}$

No puede pasarse por alto que, en su impugnación de la ya caracterizada conjunción de los dos dogmas, Hart llegó a presentar una poderosa objeción contra la tendencia a identificar algunas constelaciones de casos de tentativa con la noción de imposibilidad, tal como ello se expresa en la más bien ya superada equiparación de las expresiones "tentativa inidónea" y "delito imposible", ${ }^{145}$ y en particular contra la tendencia a diferenciar entre casos de "imposibilidad relativa" e "imposibilidad absoluta". ${ }^{146}$ Así, quien recurre a esta última

${ }^{140}$ En detalle acerca del carácter dependiente de la forma de punibilidad propia de la tentativa, véase MAÑALICH, "La tentativa", cit. nota ${ }^{\circ}$ 5, pp. 467 ss., con referencias ulteriores.

${ }^{141}$ Supra, 3.1.

${ }^{142}$ Latamente al respecto ya FIEDLER, Herbert, Vorhaben und Versuch im Strafrecht, Baden-Baden: Nomos, 1967, pp. 57 ss., 68 ss., en el contexto de su presentación de un "modelo de la acción fallida" (Modell der Fehlhandlung) para la reconstrucción de la dogmática de la tentativa.

${ }_{143}$ MAÑALICH, "La tentativa", cit. nota n ${ }^{\circ} 5$, pp. 471 ss., 483 ss.

${ }^{144}$ Acerca de la relación que cabe reconocer entre el uso de verbos expresivos de estados intencionales y la generación de contextos intensionales, véase SEARLE, Intentionality, cit. nota $\mathrm{n}^{\circ} 38$, pp. 22 ss. La explicación se encuentra en que toda oración usada para hacer un enunciado acerca de algún estado intencional puede ser entendida como "la representación [lingüística] de una representación", de manera tal que "las condiciones de verdad del enunciado dependerán de las características de la representación siendo representada, $[\ldots]$ y no de las características de los objetos o los estados de cosas representados [por el estado intencional en cuestión]".

${ }^{145}$ Véase al respecto, y a favor de semejante equiparación, JIMÉNEZ DE ASÚA, Tratado, cit. nota no 19 , pp. 629 ss. Acertadamente en contra, SOLA RECHE, Tentativa inidónea, cit. nota n $86, \mathrm{pp} .11 \mathrm{ss}$.

${ }^{146}$ HART, "The House of Lords", cit. nota no 134, p. 159. Acerca de la inviabilidad de semejante distinción, en virtud de su irreductible arbitrariedad según qué circunstancias del caso respectivo sean tenidas por modificables o inmodificables, véase ya VON BURI, "Zur Lehre", cit. nota $\mathrm{n}^{\circ}$ 86, pp. 71 ss.; VON BURI, "Versuch", cit. nota no 86, pp. 347 s.; coincidentemente HÄLSCHNER, Strafrecht, cit. nota no 4, pp. 349 ss. 
distinción podría pretender decir que mientras la tentativa de hurto imputable a quien introduce su mano buscando monedas en el bolsillo del pantalón de otro, que sin embargo se encuentra vacío, sería "absolutamente" imposible, la tentativa de homicidio imputable a quien dispara contra otro ser humano que resulta ileso, al rebotar la bala en la cajetilla metálica de cigarrillos que éste porta en el bolsillo de su camisa, ${ }^{147}$ sólo lo sería "relativamente". Al respecto, observa Hart:

"Some such distinction is hinted at in the literature; but in fact it is quite arbitrary and explains nothing. For if the possibility of success in other than the actual circumstances may be invoked to show that success in the shooting case where the bullet was obstructed [...] was only 'relatively impossible' why should it not be invoked in the empty pocket case? There too 'in other circumstances' i.e. if there had been coins in the pocket, success would have been possible". ${ }^{148}$

El punto de Hart es el punto ya hecho a propósito de la consideración comparativa de los casos (5) a (12): la única vía disponible para mantener una distinción entre casos de tentativa idónea y casos de tentativa inidónea, vinculándola a la adopción de una perspectiva ex post, consiste en discriminar arbitrariamente entre algunas circunstancias que se toman como insustituibles y otras que se toman como sustituibles para determinar si, en un mundo distinto del actual, el comportamiento del potencial autor habría podido llegar a realizar injustificadamente el respectivo tipo-de-delito. ${ }^{149}$ Por esa vía, y como observa Duff, la "posibilidad" o "imposibilidad" de la consumación del delito en cuestión deviene enteramente relativa a la descripción de las circunstancias bajo la cual se tematiza el comportamiento del agente. ${ }^{150}$ La inadecuación de semejante proceder se muestra en que la posibilidad de consumación de un delito que en el mundo actual no llegó a consumarse sólo es imaginable en referencia a un mundo distinto del actual. Esto fue temprana y perspicazmente observado por Von Buri:

"Ahora bien, a la acción pertenecen con necesidad las circunstancias externas, bajo las cuales se ha actuado. Pues una acción sin circunstancias externas bajo las cuales ella tenga lugar es impensable. De esto sigue entonces la pregunta que ha de ser planteada, en cuanto a si bajo las circunstancias externas en las cuales fue ejecutada la acción el resultado habría sido posible, pregunta, con todo, que en la tentativa siempre encuentra su negación". ${ }^{151}$

En el mundo actual, cuyas exactas circunstancias determinaban la situación en la cual el potencial autor ejecutó u omitió la acción en cuestión, que el delito no haya alcanzado la consumación, constituyéndose en cambio como una tentativa, es indicador suficiente de la imposibilidad de su consumación. Nuevamente, sería difícil encontrar una formulación más precisa de esta constatación que la ofrecida por Von Buri:

"Pues si la acción se ha quedado ya sin resultado, entonces la realidad contiene la prueba de que una abstracción desviada de ella habría sido incorrecta. La afirmación de

\footnotetext{
147 Tal es el ejemplo propuesto por HART, "The House of Lords", cit. nota $\mathrm{n}^{\mathrm{o}} 134, \mathrm{p} .159$.

${ }^{148}$ HART, "The House of Lords", cit. nota n ${ }^{\circ} 134$, p. 159.

${ }^{149}$ Véase WACHTER, Das Unrecht, cit. nota no 123, pp. 39 s.

${ }^{150}$ DUFF, Attempts, cit. nota ${ }^{\circ} 135$, pp. 78 ss.

${ }^{151}$ VON BURI, "Untaugliche Versuchshandlungen”, cit. nota ${ }^{\circ}$ 6, p. 200.
} 


\section{Polít. crim. Vol. 14, No 27 (Julio 2019), Art. 10, pp. 296-375. [http://politcrim.com/wp-content/uploads/2019/05/Vol14N27A10.pdf]}

que si el impedimento no hubiese tenido lugar, entonces la acción habría llevado al resultado, no se sostiene en el suelo del presente, sino que presenta una inferencia a partir del pasado hacia el futuro, esto es, pone una acción sólo pensada en el lugar de la acción realmente existente. Pero si uno estuviera autorizado para semejante mutación de la realidad en la abstracción, entonces uno debería aun poder castigar, en el autor, la tentativa que realmente ha quedado sin resultado ya como consumación. Pues cada acción abstracta puesta en el lugar de la realidad puede, ya con necesidad abstracta, conducir al resultado pensado en abstracto. Mas puesto que la tentativa recién llega a ser objeto de cognición judicial si la acción se ha mostrado como no-apta, entonces se encuentra aquí la prueba de que cada tentativa contiene una acción no-apta, de que el concepto de tentativa sería suprimido a través de esta exigencia de aptitud". ${ }^{152}$

En este preciso sentido, la imposibilidad de consumación en el mundo actual es una propiedad exhibida por todo comportamiento que llega a ser constitutivo de una tentativa de delito.

\section{La tentativa como delito circunstancialmente imposible en un mundo nomológica y jurídicamente posible}

\section{1. ¿Solipsismo en la fundamentación del dolo?}

Hasta aquí se ha asumido, en congruencia con el punto de vista más extendido en el debate doctrinal tradicional, que la pregunta por la idoneidad o falta de idoneidad de la tentativa habría de ser asociada a la adopción de una perspectiva ex post. ${ }^{153}$ Ello llevó a la presentación de un argumento encaminado a poner en cuestión la viabilidad teórica de la distinción en cuestión, en razón de que, desde esa misma perspectiva, toda tentativa resulta ser inidónea. Pero ahora es necesario notar que aquélla no es la única perspectiva desde la cual cabría intentar hacer practicable esa misma distinción. En efecto, un sector relevante de la doctrina especializada defiende la adopción de una perspectiva ex ante para articular la distinción entre tentativas idóneas y tentativas inidóneas. En estos términos, la idoneidad de una tentativa se identificaría con su peligrosidad ex ante, en tanto que su inidoneidad, con su falta de peligrosidad ex ante. ${ }^{154}$

Nótese que esta última propuesta de distinción es conceptualmente independiente de cuál sea la tesis acerca del fundamento de punibilidad de la tentativa que se defienda. En efecto, es perfectamente concebible que la definición del concepto de inidoneidad en el sentido de una falta de peligrosidad ex ante sea combinada con la defensa de una exigencia de peligrosidad ex ante como condición de punibilidad de toda tentativa. La consecuencia de la combinación de esas dos premisas, una conceptual y otra sustantiva, sería la negación fundada en la segunda premisa - de la punibilidad de aquellas tentativas definidas — con arreglo a la primera premisa - como inidóneas. Con todo, resulta imposible desconocer que semejante criterio de definición conceptual suele ser adoptado por autores que, en los

\footnotetext{
${ }^{152}$ VON BURI, "Versuch", cit. nota n 86, pp. 343 s. Véase ya VON BURI, "Zur Lehre”, cit. nota n 86, pp. 66 s.; también VON BURI, "Untaugliche Versuchshandlungen ”, cit. nota nº 6, pp. 194 s., 199 ss.

${ }^{153}$ Véase supra, 5.1.

${ }^{154}$ Véase al respecto SOLA RECHE, Tentativa inidónea, cit. nota ${ }^{\circ} 86$, pp. 171 ss.
} 
términos de esa misma definición, defienden la punibilidad de tentativas caracterizadas como inidóneas, esto es, como ex ante no peligrosas.

El marco conceptual así configurado es difícil de disociar, en los hechos, de la regulación de la tentativa plasmada en el StGB a partir de la entrada en vigor, en el año 1975, de las modificaciones dispuestas por la así llamada "Segunda Ley de Reforma Jurídico-Penal". 155 En efecto, una de las particularidades de esta regulación se encuentra en la regla establecida en el apartado 3 del $\S 23$ del StGB, que explícitamente prevé la punibilidad de la así llamada "tentativa crasamente insensata". ${ }^{156}$ Esta se ve definida por la circunstancia de que el agente haya desconocido, "por crasa insensatez" (aus grobem Unverstand) de su parte, que, en razón de la especie del objeto sobre el cual o del medio a través del cual el hecho habría de haberse perpetrado, éste no podía en absoluto alcanzar la consumación. ${ }^{157}$ En tal caso, el tribunal queda habilitado o bien para prescindir íntegramente de la pena correspondiente, o bien para atenuarla según su discreción, pudiendo en este último caso o bien llevar la pena prevista a su límite inferior, o bien, tratándose de una pena privativa de libertad, sustituirla por una pena de multa. ${ }^{158}$

Esta caracterización general del problema tiene importancia para lo que aquí interesa. Pues la interpretación más generalizada del apartado $3^{\circ}$ del $\S 23$ del StGB asume sin más como practicable la disociación del juicio objetivo, susceptible de ser formulado ex ante, acerca de la "absoluta falta de idoneidad" del comportamiento del agente (en función del objeto sobre el cual aquél habría de incidir o del medio a través del cual éste habría de hacer uso), por un lado, y el juicio subjetivo del propio agente acerca de la aptitud-para-laconsumación que ex ante exhibiría su comportamiento, por otro. Esto es importante, en cuanto hace posible detectar que, por esa vía, la exégesis más estandarizada del aparatado 3 del $\S 23$ del StGB hace suya, aun cuando no siempre de manera consciente, una concepción tendencialmente "solipsista" de la adscripción del dolo, resultante en que sea el propio agente quien en definitiva resulte competente para determinar si puede adscribírsele el dolo correspondiente. ${ }^{159}$

Desentrañar y refutar tal concepción es imprescindible para reivindicar, como contrapartida, la irreductible objetividad de la adscripción del dolo. Esta reivindicación constituye el punto de partida indisponible para sustentar la tesis de que los casos en que se habla de una "tentativa irreal" o "tentativa supersticiosa" no son casos en los cuales sea

\footnotetext{
${ }^{155}$ Ley cuya aprobación data del 4 de julio de 1969.

${ }^{156}$ Al respecto STRUENSEE, "Verursachungsvorsatz", cit. nota no 122, pp. 21 ss., 44 ss.; BLOY, René, "Unrechtsgehalt und Strafbarkeit des grob unverständigen Versuchs", Zeitschrift für die gesamte Strafrechtswissenschaft 113, 2001, pp. 76-111, passim; MITSCH, Wolfgang, "§ 23 Abs. 3 StGB: grob unverständiges Strafrecht”, Zeitschrift für internationale Strafrechtsdogmatik 6, 2016, pp. 352-365, passim.

${ }^{157}$ Véase sólo MAIER, Die Objektivierung, cit. nota $\mathrm{n}^{\circ} 77$, pp. 75 ss.

${ }^{158}$ En contraste con la regulación alemana, el apartado $2^{\circ}$ del art. 22 Código Penal suizo (schStGB) prevé la plena e irrestricta exclusión de la punibilidad para esos mismos casos.

159 En general, por "solipsismo" cabe entender un conjunto de posiciones filosóficas cuyo común denominador se encuentra en una validación de la primacía epistémica de la perspectiva de la primera persona que alcanza el escepticismo acerca de la existencia del "mundo exterior", incluida la existencia misma de “otras mentes". Al respecto, véase por ejemplo NOZICK, Robert, Philosophical Explanations, Cambridge (Mass.): The Belknap Press, 1981, pp. 217 ss., 280 ss.
} 


\section{Polít. crim. Vol. 14, No 27 (Julio 2019), Art. 10, pp. 296-375. [http://politcrim.com/wp-content/uploads/2019/05/Vol14N27A10.pdf]}

imputable tentativa alguna, precisamente a consecuencia de que aquéllos son casos en los cuales no es posible adscribir el dolo del respectivo delito al agente.

La preocupación por evitar la validación de alguna variante de solipsismo en la fundamentación del dolo aparece claramente documentada en la propuesta, defendida por Struensee, de articular "el principio de demarcación entre la tentativa y el delito putativo", lo cual exigiría "medir el estado de cosas representado bajo los conceptos que integran el tipo, y no ampliar éstos, al revés, según las asunciones del agente". ${ }^{160}$ La pertinencia de la prevención de Struensee resulta evidente una vez que se repara en que la fundamentación de una imputación a título de dolo no es sino el resultado de una adscripción del dolo del delito respectivo, la cual constituye una operación consistente en la aplicación de una regla (de imputación) que en tal medida fija el alcance del concepto de dolo. ${ }^{161}$ Precisamente en este sometimiento de la correspondiente imputación a reglas que fijan parámetros de corrección para las respectivas operaciones adscriptivas consiste, en lo que aquí interesa, la ya anticipada objetividad de la fundamentación del dolo. Esto se traduce en que el concepto mismo de dolo no se encuentre a disposición del agente que puede fungir como sujeto pasivo de una imputación a título de dolo. En lo que sigue se intentará delinear con precisión las implicaciones de esta tesis.

Para ello, cabe partir reformulando la observación de Struensee a partir de las precisiones ya efectuadas a propósito de la caracterización del dolo como un título de imputación fundado en la adscripción de una creencia predictiva. ${ }^{162}$ En estos términos, el punto de Struensee consiste en que el estado de cosas que constituye el objeto de referencia ("intencional") de la creencia predictiva cuya adscripción es fundante-de-dolo queda irrestrictamente determinado por el contenido semántico de los elementos conceptuales del respectivo tipo-de-delito. ${ }^{163} \mathrm{Y}$ que el concepto de dolo no se encuentre a disposición del agente a quien pudiera adscribirse la correspondiente creencia predictiva, significa, por de pronto, que es enteramente irrelevante que el agente llegue a enjuiciar su comportamiento como doloso. Más precisamente, ello significa que una correcta aplicación del concepto de dolo por parte del agente no condiciona en absoluto la imputabilidad del quebrantamiento de la norma respectiva a ese título.

De acuerdo con el método de adscripción de la correspondiente creencia predictiva sobre la base del recurso a un determinado catálogo de indicadores-de-dolo, aquí favorecido, ${ }^{164}$ una imputación a título de dolo queda condicionada por la exigencia de que el potencial autor se

${ }^{160}$ STRUENSEE, "Verursachungsvorsatz", cit. nota no 122, p. 42. Coincidentemente SANCINETTI, Marcelo, Fundamentación subjetiva del ilícito y desistimiento de la tentativa, Bogotá: Temis, 1995, pp. 194 ss., con referencias ulteriores.

${ }^{161}$ Véase KINDHÄUSER, "Der subjektive Tatbestand", cit. nota $\mathrm{n}^{\circ}$ 72, p. 447; también PUPPE, Ingeborg, "Die Zurechnung des Erfolgs zum Vorsatz", Zeitschrift für die gesamte Strafrechtswissenschaft 129, 2017, pp. 1-19, pp. 9 s. En general acerca del carácter reglado de las operaciones de imputación jurídico-penal — de lo cual depende que tenga sentido la tematización de su eventual corrección o incorrección-, fundamental HRUSCHKA, Joachim, Strukturen der Zurechnung, Berlín y Nueva York: Walter de Guyter, 1976, pp. 14 ss., 30 ss.; véase también MAÑALICH, Juan Pablo, "El concepto de acción y el lenguaje de la imputación", DOXA 35, 2012, pp. 663-690, pp. 676 ss.

${ }^{162}$ Supra, 3.1.

${ }^{163}$ Supra, 3.2.

${ }^{164} \mathrm{Al}$ respecto MAÑALICH, "La tentativa”, cit. nota $\mathrm{n}^{\circ}$ 5, pp. 473 s., con referencias ulteriores. 
haya representado - en el sentido de tenido-por-existentes - circunstancias constitutivas de un correspondiente síndrome de riesgo, esto es, un síndrome de la chance (peyorativamente valorada) de que el comportamiento en cuestión llegue a exhibir las propiedades específicamente fundantes-de-antinormatividad. En tal medida, que tal representación de las circunstancias constitutivas del síndrome de riesgo fundamente la adscripción de la creencia predictiva referida a ese mismo riesgo de ejemplificación del respectivo tipo de delito, es algo que no depende de datos internos al agente, sino del sometimiento de la correspondiente operación de imputación a la regla (dogmáticamente reconstruida o articulada) que especifica el respectivo concepto de dolo. En otras palabras: el contenido proposicional de la creencia predictiva fundante-de-dolo queda determinado por el significado que la respectiva regla de imputación atribuye a la creencia de cuya adscripción se trata. ${ }^{165}$

La magnitud del impacto teórico de la adopción de este método para la adscripción del dolo puede demostrarse en referencia a dos ámbitos de problemas de los cuales tradicionalmente ha tenido que ocuparse la dogmática de la tentativa. Se trata del estatus de la así llamada "causalidad putativa", por una parte, y del así llamado "error invertido" acerca de la satisfacción de un elemento normativo del tipo, por otra.

\subsection{La "tentativa irreal" 0 "tentativa supersticiosa" como delito putativo}

\subsubsection{El problema de la "causalidad putativa"}

La primera constelación con relevancia para ilustrar el impacto de la concepción objetivista de la fundamentación del dolo, ya reseñada, se corresponde con casos que en la literatura han llegado a ser identificados con la etiqueta de la así llamada "causalidad putativa", noción esta última que fuera decisivamente clarificada a través del fundamental trabajo de Struensee. ${ }^{166}$ Una muestra especialmente elocuente del problema aquí involucrado la encontramos en el célebre fallo del RG, que condenara como autora de una tentativa de aborto a una joven mujer que, creyéndose embarazada tras besar a (y haber sido besada por) un hombre, consumió una ingente cantidad de cubos de azúcar, en la expectativa de estar condicionado así la muerte de la pretendida criatura. ${ }^{167}$

La validación, en el marco de la temprana jurisprudencia del RG, de esta conclusión enteramente favorecida por su adhesión — asegurada por el destacado influjo de Von Buri- a una concepción estrictamente subjetivista del fundamento de punibilidad de la tentativa, ciertamente contribuye a explicar la (muy) posterior decisión legislativa plasmada en la introducción del ya mencionado apartado $3^{\circ}$ del $\S 23$ del StGB. Pues si la ingesta de azúcar por parte de una mujer, acompañada de la creencia de que lo ingerido por ella es azúcar y de la creencia de que ella estaría embarazada a consecuencia de haber sido besada por un hombre, pudo ser judicialmente tenida por constitutiva de una tentativa de aborto, parece comprensible que legislativamente se haya procurado establecer una base de

\footnotetext{
165 Para una posición próxima a la aquí defendida, aun cuando sin problematizar la tematización del "contenido intelectual" del dolo a través del recurso a la noción de conocimiento, fundamental RAGUÉS, Ramón, El dolo y su prueba en el proceso penal, Barcelona: Bosch, 1999, pp. 374 ss.

${ }^{166}$ STRUENSEE, "Verursachungsvorsatz", cit. nota no 122, pp. 29 ss., 33 ss.

${ }^{167}$ RGSt 34, 217. Véase al respecto STRUENSEE, "Verursachungsvorsatz", cit. nota no 122, p. 21.
} 


\section{Polít. crim. Vol. 14, No 27 (Julio 2019), Art. 10, pp. 296-375. [http://politcrim.com/wp-content/uploads/2019/05/Vol14N27A10.pdf]}

exoneración, o en todo caso de morigeración punitiva, para casos suficientemente similares a aquél. ${ }^{168} \mathrm{Al}$ mismo tiempo, ello vuelve explicable la dificultad que la doctrina alemana enfrenta a la hora de intentar demarcar la "tentativa crasamente insensata", ahí regulada, de las así llamadas "tentativa irreal" y "tentativa supersticiosa", que generalizadamente son tenidas por no punibles sin más. ${ }^{169}$ Es difícil encontrar una caracterización más radical del aparente dilema así suscitado que la ofrecida por Bloy, quien en referencia a la situación jurídica existente en Alemania escribiera:

"El derecho vigente presupone que puede ser trazada una línea divisoria entre la tentativa irreal y la tentativa crasamente insensata, pero esta diferenciación no está meramente cargada de dificultades, como es generalizadamente enfatizado, sino que ella no es siquiera practicable, puesto que se trata aquí de sinónimos". ${ }^{170}$

Y la incertidumbre demarcatoria sólo se ve agudizada una vez que se advierte que el caso sobre el cual recayó aquel pronunciamiento condenatorio del RG es paradigmático de la constelación de la "tentativa irreal", en circunstancias de que el propio RG tomó partido, asimismo tempranamente, por la falta de punibilidad de la "tentativa supersticiosa". ${ }^{171}$ Como se intentará mostrar en lo que sigue, la solución del problema pasa por reconocer la estricta identidad estructural que se da entre los casos que integran estas últimas dos constelaciones, que descansa, pace Bloy, en la falta de satisfacción de los presupuestos de una adscripción del dolo respectivo. De ahí que no sea posible renunciar a las comillas cuando se hace uso (parasitario) de ambas denominaciones, puesto que ninguna de ellas designa casos en las cuales se configure una tentativa. Y ello debería llevar a favorecer, como corolario y también pace Bloy, una propuesta de interpretación restrictiva de las condiciones de aplicación de la regla del apartado $3^{\circ}$ del $\S 23$ del StGB, que asegure que los casos en los cuales pueda constatarse la existencia de una tentativa "crasamente insensata" sean casos en los cuales cabe hablar de una tentativa, lo cual mínimamente significa: casos en los cuales pueda adscribirse el dolo respectivo al agente.

Aquello que Struensee denomina "causalidad putativa" consiste, stricto sensu, en una conexión causal imaginaria entre un comportamiento y el pretendido acaecimiento de un evento, que descansa en una postulación (explícita o implícita), por parte del agente, de una o más leyes causales igualmente imaginarias, lo cual quiere decir: de presuntas leyes causales cuya postulación no encuentra apoyo en el conocimiento científicamente avanzado. Se trata, en tal medida, de una creencia errónea susceptible de ser caracterizada como un error nomológico. ${ }^{172}$ En un error semejante se encontraba, indudablemente, la joven mujer cuya condena como autora de tentativa de aborto fuese validada por el $\mathrm{RG}$, en el caso ya referido, y — sin que esto haya sido debidamente advertido en la discusión especializada - ya por partida doble. Pues tanto su creencia de encontrarse embarazada a

\footnotetext{
${ }^{168}$ Véase ZACZYK, “§ 22”, cit. nota $n^{\circ} 113, \S 23$, n.m. 15 , quien caracteriza el apartado $3^{\circ}$ del $\S 23$ del StGB como el resultado del esfuerzo legislativo (no exitoso) por contener las consecuencias que se siguen de la validación de la "teoría subjetiva". Al respecto, también STRUENSEE, "Verursachungsvorsatz", cit. nota no 122 , pp. $44 \mathrm{~s}$.

${ }^{169}$ Véase por todos ZACZYK, "§ 22", cit. nota no $113, \S 22$, n.m. 38.

${ }^{170}$ BLOY, "Unrechtsgehalt", cit. nota $\mathrm{n}^{\circ}$ 156, p. 109.

${ }^{171}$ RGSt 33, 321.

${ }^{172}$ STRUENSEE, "Verursachungsvorsatz", cit. nota no 122, pp. $30 \mathrm{~s}$.
} 
consecuencia de haberse besado con un varón, por un lado, como su creencia de poder producir la muerte del feto pretendidamente anidado en su útero mediante la ingesta de azúcar, por otro, descansan en la suposición de que aquello que Mackie denominara "el cemento del universo" — esto es, la estructuración causal de la realidad física ${ }^{173}$ integraría, entre otras, correlaciones "legaliformes" de tipos de eventos consistentes en besos y fecundaciones, por una parte, y en ingestas de azúcar y muertes de fetos, por otra. Y como Struensee acertadamente lo sugiriese, ${ }^{174}$ la inviabilidad de identificar ese error con una tentativa de delito se funda en la inexistencia de dolo en tal caso, que a su vez descansa en la manera en que el correspondiente tipo-de-delito fija el contenido representacional del dolo de cuya posible adscripción se trata.

Esto exige clarificar el sentido en que, tratándose delitos de resultado causalmente condicionado, la noción de causalidad se corresponde con un elemento del tipo en cuestión. A este respecto, Struensee traía a colación la polémica tesis de Armin Kaufmann en cuanto a que el elemento del tipo, aquí relevante, susceptible de ser designado como "causación" (Verursachung), resultaría "llenado" por un determinado cúmulo de leyes causales, las cuales en tal medida integrarían las condiciones de aplicación de la norma jurídica que contiene semejante elemento. ${ }^{175}$ Según Struensee, la única alternativa plausible a esta última tesis, según la cual serían las leyes causales singulares las que, llenando la exigencia de "causación", integrarían conceptualmente el respectivo tipo-de-delito, sería la que, a través de un ascenso en un nivel de abstracción, identificaría el correspondiente elemento del tipo con la así llamada "legalidad causal" (Kausalgesetzlichkeit), entendida como la conjunción de las propiedades comunes a toda ley causal. ${ }^{176}$ Como observa Struensse, esto último supondría identificar el elemento de la "causación" con el concepto mismo de ley causal. $^{177}$

Acertadamente, Struensee sugiere que la opción por una de ambas posibilidades teóricas no tiene impacto en la pregunta decisiva, a saber, y en la terminología aquí favorecida: la pregunta de si el vínculo de causalidad que tendría que darse entre el comportamiento del agente y el acaecimiento del correspondiente resultado típico ha de quedar abarcado, en alguna medida, por la creencia predictiva fundante del dolo correspondiente. ${ }^{178} \mathrm{La}$ demostración más elocuente de que la respuesta a esta última pregunta es afirmativa se obtiene con la constatación de la incompatibilidad de la tesis opuesta con la inteligibilidad misma de la tematización de una así llamada "desviación del curso causal" en cuestión. ${ }^{179}$ Con todo, es necesario ofrecer un argumento que respalde la tesis de la "referencia-a-lacausalidad" de la creencia predictiva fundante-de-dolo que no deje teóricamente abierta la pregunta acerca de la correcta caracterización de la estructura típica de los delitos de resultado causalmente condicionado.

\footnotetext{
${ }^{173}$ Véase MACKIE, The Cement, cit. nota $\mathrm{n}^{\circ} 131$, pp. $1 \mathrm{~s}$.

${ }^{174}$ STRUENSEE, "Verursachungsvorsatz", cit. nota no 122, pp. 23 ss., 29 ss.

175 STRUENSEE, "Verursachungsvorsatz", cit. nota $\mathrm{n}^{\circ} 122$, p. 25.

${ }^{176}$ STRUENSEE, "Verursachungsvorsatz", cit. nota no 122, pp. 24 ss.

177 STRUENSEE, "Verursachungsvorsatz", cit. nota no 122, pp. 25 s.

${ }^{178}$ STRUENSEE, "Verursachungsvorsatz", cit. nota $\mathrm{n}^{\circ} 122$, pp. 26 ss.

${ }^{179}$ STRUENSEE, "Verursachungsvorsatz", cit. nota no 122, pp. 27 s.
} 


\section{Polít. crim. Vol. 14, No 27 (Julio 2019), Art. 10, pp. 296-375. [http://politcrim.com/wp-content/uploads/2019/05/Vol14N27A10.pdf]}

\subsubsection{Análisis causal y adscripción de dolo}

En la elaboración de tal argumento, cabe partir impugnando la premisa que Struensee hace suya como punto de partida. Pues es posible reconstruir la estructura típica de los delitos de resultado causalmente condicionado sin hacer de la causalidad ni de la "legalidad causal" un elemento del tipo respectivo. Estas últimas categorías son ciertamente imprescindibles para hacer operativo el análisis causal, pero ellas no se corresponden con elemento alguno del tipo respectivo; ellas sirven, más bien, a clarificar las condiciones de cuya satisfacción depende la consumación del delito en cuestión. ${ }^{180} \mathrm{El}$ análisis causal se presenta, operativamente, como una herramienta de subsunción. Esto quiere decir que opera como una herramienta que hace posible comprobar si un comportamiento cualquiera satisface semánticamente la descripción que especifica alguna forma de comportamiento consistente en la ejecución u omisión de una acción resultativa.

Como tipos de acción resultativa vienen en consideración tipos-de-acción cuya característica común es que ellos se ven ejemplificados por acciones cuya correspondiente marca de éxito consiste en la transformación de un determinado estado, como sucede tratándose de acciones productivas y acciones destructivas, o bien en la no-transformación de un determinado estado, como sucede tratándose de acciones preservativas y acciones impeditivas. ${ }^{181}$ Por esta vía, si la noción de resultado es identificada con una transformación cuyo acaecimiento es objeto de una valoración generalizadoramente peyorativa, cabe sostener que un subconjunto suficientemente representativo de las normas de comportamiento jurídico-penalmente reforzadas consiste en prohibiciones de acciones productivas del resultado en cuestión, o bien en requerimientos de acciones impeditivas del resultado en cuestión.

La pertinencia del análisis causal como herramienta de subsunción depende, ahora bien, de si el correspondiente "verbo-de-acción", que identifica el tipo de acción respectivo, determina que la conexión que ha de darse entre la ejecución o la omisión de una acción de ese tipo y el acaecimiento o el no-acaecimiento del resultado sea una de carácter causal, o bien una de carácter constitutivo (o convencional). Pues sólo en el primer caso cabrá decir que el delito constituido por el quebrantamiento o bien de la prohibición de la producción de un resultado de cierta índole, o bien del requerimiento del impedimento de un resultado de cierta índole, tiene el estatus de un delito de resultado causalmente condicionado, o de resultado extrínseco. En cambio, si el tipo-de-acción en cuestión determina que la conexión tiene carácter constitutivo, el delito correspondiente debe ser caracterizado como uno de resultado constitutivamente condicionado, o de resultado intrínseco. ${ }^{182}$

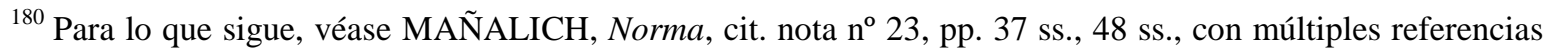
ulteriores.

${ }^{181}$ La terminología está tomada de VON WRIGHT, Norm, cit. nota no 125, pp. 17 ss., 27 ss., donde la noción de transformación es usada con mayor laxitud, de manera tal de resultar abarcadora tanto de la modificación como de la no-modificación del estado respectivo; véase al respecto MAÑALICH, Norma, cit. nota n 23 , pp. 32 ss.

${ }^{182}$ Para la correspondiente distinción entre descripciones "causalmente complejas" y "constitutivamente


distinción, en pos de la caracterización del hurto como un delito de resultado intrínseco, véase OLAVE, Alejandra, "El delito de hurto como tipo de delito de resultado", Política Criminal 13, n 25, 2018, pp. 175-
} 
Luego, sólo en la medida en que el tipo-de-delito del cual se trate se corresponda con una descripción (abstracta) que especifica una forma de comportamiento consistente en la ejecución o la omisión de una acción causalmente resultativa es necesario echar mano al análisis causal para comprobar si un comportamiento cualquiera es subsumible bajo ese mismo tipo-de-delito. En tal medida, las categorías involucradas en el análisis causal, como lo son, entre otras, las categorías de causa y ley causal, se comportan como meta-conceptos que contribuyen a esclarecer las condiciones de realización - en cuanto satisfacción semántica- de determinados tipos-de-delito. Y si, tratándose de tipos-de-delito de esta clase, las categorías en las que se apoya el análisis causal tienen relevancia para el correspondiente juicio de subsunción, entonces por definición, como observa Struensee, ellas también han de tener alguna relevancia para determinar el objeto de referencia del dolo correspondiente.

En qué consista, precisamente, esa relevancia, está lejos de ser una perogrullada. El punto admite ser formulado, con todo, en los términos de la metodología de adscripción del dolo aquí favorecida. Esta se apoya en la invocación de algún catálogo cerrado de indicadores del dolo respectivo, los cuales a su vez se corresponden con codificaciones de determinados síndromes de riesgo referidos — tratándose de tipos-de-delito de resultado causalmente condicionado - al acaecimiento del resultado cuyo condicionamiento causal tiene relevancia típica. ${ }^{183}$ La clave se encuentra, entonces, en el hecho de que el concepto de riesgo es secundario en relación con el concepto de causa: un factor de riesgo respecto del acaecimiento de $\mathrm{X}$ no es sino una causa potencial para el acaecimiento de $X .{ }^{184}$ De ahí que en la codificación (doctrinal y jurisprudencial) de las circunstancias que han de fungir como síndromes estereotipados del riesgo correspondiente no pueda prescindirse de las generalizaciones causales que proveen las "recetas", ${ }^{185}$ o los "métodos", ${ }^{186}$ cuya aplicación sería mínimamente suficiente para hacer racional y razonablemente esperable, aun cuando sea con un grado relativamente bajo de probabilidad, el condicionamiento de un resultado típicamente relevante.

Pero aquí deviene fundamental no confundir las nociones de generalización causal y ley causal. Esta distinción resulta imprescindible, por de pronto, para esclarecer la manera en que usualmente se elaboran explicaciones causales referidas al acaecimiento de eventos de cierta clase. Pues fuera de contextos de investigación científica avanzada en ciertos campos, es usual que los enunciados causales singulares, que conectan eventos particulares de cierto tipo como causa y efecto, queden apoyados no en leyes causales stricto sensu, sino más

207, pp. 195 ss. Notablemente, una distinción enteramente coincidente con la aquí presentada aparece en la reformulación de la distinción entre los así llamados "delitos materiales" y "delitos formales", tempranamente propuesta por VON BURI, "Versuch", cit. nota n' 86, pp. 325 ss.

${ }_{183}$ Fundamental al respecto RAGUÉS, El dolo, cit. nota n ${ }^{\circ} 165$, pp. 455 ss., quien identifica los aquí denominados "indicadores de dolo" con "reglas de atribución de conocimiento".

${ }^{184}$ En detalle al respecto KINDHÄUSER, Urs, "Risikoerhöhung und Risikoverringerung", Zeitschrift für die gesamte Strafrechtswissenschaft 120, 2008, pp. 481-503, pp. 487 ss. Al respecto véase también MAÑALICH, Norma, cit. nota $\mathrm{n}^{\mathrm{0}} 23$, pp. $106 \mathrm{~s}$.

185 Véase GASKING, Douglas, "Causation and Recipes”, Mind 64, 1955, pp. 479-487, passim.; KINDHÄUSER, Urs, Intentionale Handlung, Berlín: Duncker \& Humblot, 1980, pp. 84 ss.

${ }^{186}$ PUPPE, "Die Zurechnung", cit. nota no 161, pp. 10 s. 


\section{Polít. crim. Vol. 14, No 27 (Julio 2019), Art. 10, pp. 296-375. [http://politcrim.com/wp-content/uploads/2019/05/Vol14N27A10.pdf]}

bien en generalizaciones causales, esto es, en enunciados causales generales que se distinguen por incorporar cláusulas "ceteris paribus", que expresan una remisión a algún conjunto de "circunstancias apropiadas" no ulteriormente especificadas. ${ }^{187} \mathrm{Y}$ para usar la terminología favorecida por Von Wright, son semejantes generalizaciones causales los enunciados (generales) que expresan las "proposiciones anankásticas" de cuya verdad depende que el método especificado a través de la correspondiente regla técnica —esto es, la regla de experiencia en cuestión - sea un método eficaz para el condicionamiento del acaecimiento del evento en el cual consiste el resultado relevante. ${ }^{188}$

Para ilustrar el punto, considérese el siguiente caso, construido a partir de una sugerencia de Renzikowski: ${ }^{189}$

(13) Para dar muerte a su enemigo B, A le suministra una dosis de 20 milígramos de un veneno de cierta clase, en circunstancias de que recién una dosis de 22 milígramos habría sido suficiente para matar a B.

Renzikowski sostiene que en este caso a A no sería imputable una tentativa de homicidio, en la medida en que A se haya representado, correctamente, haber estado suministrando a B una dosis de $20 \mathrm{mg}$. del veneno en cuestión. ${ }^{190}$ Pues entonces habría que decir que A se representó estar haciendo algo que, de acuerdo con leyes causales, no podía producir la muerte de B, lo cual dejaría sin sustento alguno una adscripción de dolo-de-homicidio. Pero esto desconoce que para la construcción del respectivo conjunto de indicadores de dolo-dehomicidio la pregunta relevante no puede estar referida a la dosis de veneno in concreto suficiente para dar muerte a B. Pues la determinación precisa de tal dosis con toda seguridad dependerá de la especificación de circunstancias que normalmente sólo podrán ser conocidas ex post, ${ }^{191}$ entre ellas, por ejemplo, la circunstancia de que B haya tenido tal o cual volumen de masa corporal, haya tenido tal o cual estado de salud, etcétera. Antes bien, la generalización involucrada en la propia formulación del tipo-de-delito, que a su vez reproduce la generalización intrínseca a la norma abstracta de comportamiento cuyo quebrantamiento tiene relevancia típica, determina que los indicadores del dolo respectivo también hayan de exhibir una correspondiente medida de generalización, que en tal medida

\footnotetext{
${ }^{187}$ Véase al respecto HEMPEL, Carl, Philosophy of Natural Science, Upper Saddle River (N.J.): PrenticeHall, 1966, pp. 52 ss.; HEMPEL, Carl, The Philosophy of Carl. G. Hempel, Oxford: Oxford University Press, 2001, pp. 91 ss.; también WRIGHT, Richard, "Causation, Responsibility, Risk, Probability, Naked Statistics, and Proof: Pruning the Bramble Bush by Clarifying the Concepts", Iowa Law Review 73, 1988, pp. 10011077, pp. 1031 ss.

${ }^{188}$ VON WRIGHT, Norm, cit. nota $\mathrm{n}^{\circ} 125$, pp. 9 ss., con la importante observación de que la verdad de un enunciado que expresa una proposición anankástica se corresponde con la existencia de una "primitiva 'ley de la naturaleza"; véase también VON WRIGHT, Georg Henrik, The Varieties of Goodness, Londres: Routledge \& Kegan Paul, 1963, pp. 157 ss., 160 s. Latamente al respecto, GONZÁLEZ LAGIER, Daniel, Acción y norma en G.H. von Wright, Madrid: Centro de Estudios Constitucionales, 1995, pp. 264 ss.

${ }^{189}$ RENZIKOWSKI, "Wahnkausalität", cit. nota no 55 , p. 317.

${ }^{190}$ RENZIKOWSKI, "Wahnkausalität", cit. nota $\mathrm{n}^{\mathrm{0}} 55$, pp. $317 \mathrm{~s}$.

${ }^{191}$ Acerca de la necesidad de no confundir la elaboración de la explicación causal del acaecimiento del respectivo resultado, que tiene lugar ex post, con la formulación de la "regla de experiencia" que ex ante habría de especificar un método apto para el eventual condicionamiento de semejante resultado, véase ya JOERDEN, "Wesentliche", cit. nota n ${ }^{\circ}$ 55, pp. 307 s.
} 
sea compatible con la incertidumbre acerca de múltiples circunstancias con posible relevancia causal que acompañará la representación del agente. ${ }^{192}$

De ahí que, en referencia al caso (13), la pregunta crítica sea si la dosis de veneno que A se representó estar suministrando a otro ser humano es una dosis cuyo suministro, con arreglo a generalizaciones causales que el tribunal no pueda desconocer, debiera hacer esperable, con un grado de probabilidad mínimamente suficiente para una persona de la cual se espera el reconocimiento de la prohibición de matar a otro como una premisa vinculante, la muerte de un ser humano cuya constitución física se ajuste a la descripción que A haya podido tener por verdadera de la persona a la que se representaba estar suministrando esa misma dosis de veneno. Que ex post se compruebe que esa dosis se quedó corta en $2 \mathrm{mg}$. para haber resultado efectivamente letal para B, no logra desvirtuar la posibilidad de que a A se adscriba la representación de circunstancias constitutivas de síndrome de riesgo en referencia a la realización, a través de su comportamiento, del tipo del homicidio. Pues de lo contrario habría que decir que en un caso en el cual $\mathrm{X}$ haya disparado un arma de fuego contra Y, a una distancia tal que Y resulte lesionado, mas no muerto, a consecuencia del disparo, comprobándose que el disparo sólo habría sido letal si $\mathrm{X}$ se hubiese encontrado medio metro más cerca de Y, habría que negar la adscripción de dolo de homicidio a $\mathrm{A}$, en la medida en que éste haya estado al tanto, con exactitud, de la distancia en cuestión. Y ello sería absurdo.

\subsubsection{La "tentativa irreal" como delito putativo}

Lo anterior es suficiente para advertir que, en un caso como aquel al cual se encontraba referido el ya mencionado fallo del RG, lo correcto sería negar la correspondiente adscripción de dolo (de aborto) y así, por implicación, negar la existencia de una tentativa (de aborto). Y esto, nuevamente, por partida doble. Pues alguien que (acertadamente) se ha representado estar ingiriendo una cantidad considerable de azúcar en cubos no es alguien que, ceteris paribus, ${ }^{193}$ se haya representado estar haciendo algo que, con arreglo a generalizaciones causales fundamentadas en las ciencias biológicas, sirva como método apto para producir la muerte de un feto anidado en el útero de quien hubiera ingerido el azúcar. Pero la inviabilidad de adscribir dolo de aborto a la mujer que hubo ingerido el azúcar con el propósito de interrumpir un presunto embarazo también debe afirmarse, y ya con independencia de la consideración precedente, por el hecho de que quien (acertadamente) se ha representado haber sido meramente besada por un varón no es alguien que se haya representado haber hecho algo que, con arreglo a generalizaciones

\footnotetext{
${ }^{192}$ En tal medida, el problema consiste en hacer aprovechables los criterios objetivos usualmente esgrimidos para determinar la existencia de una "conexión de riesgo" entre el comportamiento del agente y el resultado de cuyo condicionamiento causal se trata, pero redefinidos como criterios de imputación subjetiva; así ya KINDHÄUSER, Urs, "Objektive und subjektive Zurechnung beim Vorsatzdelikt”, en: BYRD, Sharon; JOERDEN, Jan (coords.), Philosophia Practica Universalis. Festschrift für Joachim Hruschka, Berlín: Duncker \& Humblot, 2005, pp. 527-542, pp. 539 ss.

${ }^{193}$ La introducción de esta última cláusula es necesaria para dejar a salvo la posibilidad de que la presencia de alguna condición fisiológica más o menos singular — que en todo caso tendría que haber sido objeto de representación por parte del agente - pudiera hacer de la ingesta de una determinada cantidad de azúcar un método apto para, por ejemplo, condicionar una complicación del embarazo, y por esa vía eventualmente, el acaecimiento de la muerte del feto.
} 


\section{Polít. crim. Vol. 14, No 27 (Julio 2019), Art. 10, pp. 296-375. [http://politcrim.com/wp-content/uploads/2019/05/Vol14N27A10.pdf]}

causales fundamentadas en las ciencias biológicas, pudiera resultar en un proceso de gestación.

Lo anterior se puede reformular como sigue: en el caso en cuestión, las circunstancias que determinaban que tanto el objeto (por su inexistencia en cuanto objeto extensional) como el medio (por su ineptitud causal) hicieran inidóneo el comportamiento de la presunta hechora para realizar el tipo del delito de aborto no eran circunstancias desconocidas por ella. En tal medida, la mujer no se encontraba en un error acerca de las circunstancias que acompañaban la ejecución de la acción respectiva que pudiera constituirse como un error fundante-de-dolo. Y esta sola consideración basta para concluir que, en cuanto ella hubiese erróneamente asumido que su comportamiento resulta delictivo a título de aborto, ese error habría dado lugar a nada más que un delito imaginario, esto es, un delito putativo.

La objetividad que exhibe semejante estrategia de fundamentación o negación del dolo del delito respectivo queda de manifiesto en su incompatibilidad con las consecuencias a las que, de acuerdo con Von Buri, habría de conducir la adopción de una concepción subjetivista del fundamento de punibilidad de la tentativa. Para ilustrar el punto cabe comparar dos simples casos, inspirados en sendos casos que fueran propuestos por Von Buri en el contexto de una de sus múltiples defensas de la "teoría subjetiva". ${ }^{194}$ El primer caso es el siguiente:

(14) Apuntando contra B, A tira del gatillo de su rifle, que previamente él mismo ha cargado con lo que él cree es pólvora, pero que en realidad es arena.

Acertadamente, Von Buri sugería que en un caso como éste a A resultaría imputable, sin más, una tentativa (de homicidio). Con arreglo a la concepción aquí defendida, ello se sustenta en que, al disparar el rifle bajo la creencia (errónea) de que estaría cargado con pólvora, A se representaba estar disparando bajo circunstancias que de ser existentes objetivamente - lo cual quiere decir: con independencia de la evaluación que de ello pudiera tener, o no tener, A mismo - determinarían la existencia de un síndrome de riesgo de muerte para B. En contra de lo sostenido por Von Buri, lo mismo no puede afirmarse en referencia al segundo de los dos casos:

(15) Apuntando contra B, A tira del gatillo de su rifle, que previamente él mismo ha cargado con lo que él acertadamente se representa como arena, creyendo que la fricción que el rifle habría de ejercer sobre ésta haría posible la obtención de un disparo.

Correctamente, Von Buri sostenía que la diferencia entre ambos casos "sólo podría ser subjetiva", aun cuando "no en cuanto al propósito criminal, pues también éste es en ambos casos el mismo, sino en cuanto al medio utilizado", justamente en razón de que se constata, entonces, una divergencia en lo tocante al error padecido por el agente. ${ }^{195}$ Al mismo tiempo, empero, Von Buri declaraba que esa divergencia en cuanto a la naturaleza del error involucrado carecería de toda relevancia, "por cuanto subjetivamente al tipo de un crimen

\footnotetext{
${ }^{194}$ VON BURI, "Der Versuch", cit. nota no 86, pp. 327 s.

${ }^{195}$ VON BURI, "Der Versuch”, cit. nota no 86, p. 328.
} 
nada más pertenece que el propósito del agente de perpetrarlo". ${ }^{196}$ Más allá de que esta identificación del dolo con relevancia para la constitución de la tentativa con el así llamado "dolo directo de primer grado" deba ser rechazada sin más, ${ }^{197}$ aquí interesa detenerse en la caracterización que Von Buri ofrecía del error padecido por el agente en uno y otro caso:

"Es ciertamente correcto [decir] que en ambos casos aparece una divergencia en cuanto al error. En uno de los casos [a saber: el segundo] no se daba la propiedad, erróneamente presupuesta, del medio, en el otro caso [a saber: el primero] no estaba presente el medio mismo que habría de ser utilizado". ${ }^{198}$

En efecto, en el caso (14) A creía haber cargado el rifle con pólvora, y no con arena, y es en esta confusión acerca de la sustancia de lo cargado en el rifle que consiste su error. Y éste resulta ser un error fundante del dolo de homicidio, en razón de que la creencia de estar disparando un rifle cargado con pólvora es una creencia acerca de la existencia de circunstancias cuya existencia objetivamente fundamenta un síndrome de riesgo con relevancia bajo el tipo del homicidio. Precisamente ello no se deja predicar del error que A padece en (15). Pues en este último caso A no ha incurrido en error alguno en lo tocante a la sustancia con la que hubo cargado el rifle; antes bien, su error consiste en la creencia de que la arena, como tal, sería una sustancia que, siendo cargada en un rifle, sería susceptible de ser activada, mediante fricción, en pos de la generación de un disparo potencialmente letal para un ser humano.

Así presentada, la divergencia entre uno y otro error se corresponde exactamente con la distinción, célebremente reconstruida por Struensee, entre un error ontológico y un error nomológico, distinción bajo la cual la creencia en la existencia de una ley causal inexistente - esto es, la creencia involucrada en una situación de "causalidad putativa" - se identifica con un error de la segunda clase. ${ }^{199}$ No es infrecuente que se sostenga que esta última distinción sería irremediablemente arbitraria. ${ }^{200}$ Así, por ejemplo, razona Maier:

"Todo error nomológico descansa, en su génesis, en un error ontológico: son desconocidas conexiones causales, porque son desconocidas circunstancias de hecho el contenido de sustancias tóxicas, el alcance de disparo de un arma. Toda la diferenciación como tal es simplemente irrelevante, puesto que todas estas representaciones erróneas descansan en el desconocimiento de circunstancias de hecho". ${ }^{201}$

\footnotetext{
${ }^{196}$ VON BURI, "Der Versuch", cit. nota no 86, p. 328.

${ }^{197}$ Véase al respecto ya MAÑALICH, "La tentativa", cit. nota $n^{\circ}$ 5, pp. 471 ss., 483 ss., con referencias ulteriores; críticamente a propósito del estado de la cuestión en la jurisprudencia chilena, véase asimismo MAÑLICH, "Incompatibilidad", cit. nota $n^{\circ} 11$, pp. 175 ss.

${ }^{198}$ VON BURI, "Der Versuch", cit. nota no 86, p. 328.

199 STRUENSEE, "Verursachungsvorsatz", cit. nota no 122, pp. 33 ss. Al respecto, véase MAIER, Die Objektivierung, cit. nota n n $^{\circ}$, pp. 86 ss.; WACHTER, Das Unrecht, cit. nota no 123, pp. 201 ss.

${ }^{200}$ Véase por ejemplo JAKOBS, Strafrecht, cit. nota $\mathrm{n}^{\circ} 47,25 / 36$, nota 56a; SANCINETTI, Fundamentación, cit. nota $\mathrm{n}^{\mathrm{o}}$ 160, pp. 185 ss.; BLOY, "Unrechtsgehalt", cit. nota $\mathrm{n}^{\mathrm{o}} 156$, pp. 86 ss., 103 ss.; MAIER, Die Objektivierung, cit. nota $\mathrm{n}^{\circ} 77$, pp. 88 s.

${ }^{201}$ MAIER, Die Objektivierung, cit. nota $\mathrm{n}^{\mathrm{o}} 77$, p. 89.
} 


\section{Polít. crim. Vol. 14, № 27 (Julio 2019), Art. 10, pp. 296-375. [http://politcrim.com/wp-content/uploads/2019/05/Vol14N27A10.pdf]}

Para defender la pertinencia de la distinción entre errores ontológicos y errores nomológicos, es necesario partir observando que, trivialmente, aquello sobre lo cual se yerra, en el sentido aquí relevante de "error", es siempre algún hecho. ${ }^{202}$ Sobre esta base, la distinción necesita ser precisada en atención a la naturaleza del hecho cuyo desconocimiento puede ser constitutivo de un error de una u otra clase. Desde este punto de vista, es clara la diferencia que cabe constatar entre los errores involucrados en los casos (14) y (15).

En (14), el error de A consiste en la suposición de que aquello con lo que ha sido cargado su rifle sería pólvora, y así en el desconocimiento del hecho particular $-\mathrm{o}$ en la terminología de Burkhardt: "singular" ${ }^{203}$ — de que el rifle que tiene en sus manos fue cargado con arena. ${ }^{204}$ En (15), en cambio, el error de A consiste en la suposición de que la arena es algo cuya fricción tendría aptitud causal para servir como medio de detonación, y así en el desconocimiento del hecho general de que la arena es una sustancia cuya fricción no tiene aptitud causal para servir como medio de detonación. ${ }^{205} \mathrm{Y}$ este último error admite ser redefinido, sin más, como consistente en la suposición de la existencia de una o más leyes causales inexistentes. ${ }^{206}$ La importancia de esta precisión no puede ser sobreestimada. Pues sólo en un mundo nomológicamente distinto del mundo actual —esto es, del mundo al cual pertenece el hecho de que A tirase del gatillo del rifle cargado con arena-, podría la

${ }^{202}$ Véase ya BINDING, Die Normen, cit. nota $\mathrm{n}^{\circ}$ 6, pp. 112 ss., 114: "Sólo es posible errar acerca de aquello que puede ser sabido. Y para el círculo infinitamente vasto de aquello que puede ser sabido, la lengua alemana no tiene otra denominación que la de hecho. Los hechos se conocen, sobre los hechos se yerra".

${ }^{203}$ Véase supra, 2.3.

${ }^{204}$ Que se trata aquí de un hecho particular se sigue de que el hecho en cuestión consiste en la existencia del estado de cosas a su vez consistente en que aquello con lo que ha sido cargado el rifle de A es arena. Semejante estado de cosas, consistente en que algún ítem particular, o algún conglomerado de ítems particulares, sea la instancia de alguna propiedad o algún conjunto de propiedades (como el conjunto de propiedades de cuya instanciación depende que algo sea arena), se corresponde con lo que Armstrong denomina un "estado de cosas atómico". Véase al respecto ARMSTRONG, David, A World of States of Affairs, Cambridge: Cambridge University Press, 1997, pp. 19 ss., 65 ss.

${ }^{205}$ El carácter general de semejante error queda de manifiesto, asimismo, si se repara en que el sustantivo "arena" designa aquello que en la filosofía del lenguaje se conoce como un "género natural" (natural kind), entendido como una clase cuyos miembros comparten una determinada naturaleza, de manera tal que — según lo sostienen los partidarios de la así llamada "teoría de la referencia directa" - la extensión de un término tal queda determinada con plena independencia de los criterios reconocibles en el comportamiento lingüístico de quienes hacen uso de ese mismo término. Fundamental PUTNAM, Hilary, Mind, Language and Reality, Cambridge: Cambridge University Press, 1975, pp. 215 ss., 223 ss. Al respecto MOORE, Michael, "The Semantics of Judging", Southern California Law Review 54, 1981, pp. 151-294, pp. 204 ss.; también MOORE, Michael, "A Natural Law Theory of Interpretation", Southern California Law Review 58, 1985, pp. 277-398, pp. 291 ss., 322 ss.; con especial referencia a sus implicaciones para la interpretación de la ley penal, véase MONTIEL, Juan Pablo; RAMÍREZ, Lorena, "De camareros estudiantes de biología a jueces biólogos. A propósito de la sentencia del BGH sobre los hongos alucinógenos y la deferencia a los expertos en el ámbito penal", InDret 1, 2010, en: [http://www.indret.com/pdf/691.pdf], pp. 13 ss. De esto se sigue que en el caso (15) A se encuentra afectado por un error que, no impidiéndole hacer referencia a algo que es constitutivo de arena (si llegara a hacer uso, para ello, de la expresión "arena"), sí le hace creer que "arena" designa algo que tendría propiedades (causales) que de hecho no tiene, lo cual equivale a decir que A tiene una creencia errónea acerca de qué es la arena.

${ }^{206}$ En la terminología de ARMSTRONG, $A$ World, cit. nota ${ }^{\circ}$ 204, pp. 223 ss., la creencia en la existencia de una ley causal inexistente no es sino la creencia en la existencia de un estado de cosas inexistente, que a su vez consistiría en la existencia de una determinada relación — que como tal tiene el estatus de un universalentre universales. 
ejecución de una acción consistente en tirar del gatillo de un rifle cargado con arena llegar a producir la muerte de otro ser humano. En la medida en que los indicadores de dolo con cargo a los cuales se adscriba dolo de homicidio queden co-definidos por generalizaciones causales que pretenden ser congruentes con la estructuración de la realidad física, un error como el padecido por A en el caso (15) no legitima una adscripción de dolo de homicidio. En la acertada formulación de Renzikowski: "Pero no tiene justificación tomar la representación del hechor como indicio determinante para el peligro, si las razones que el hechor tiene para su expectativa objetivamente no ameritan ser consideradas". ${ }^{207}$

Que semejante error nomológico dé lugar a nada más que un delito putativo es consistente, a su vez, con que se trate de un error que, bajo la distinción entre las nociones de error-dereferencia y error-de-sentido, se corresponde con una sub-variante de esta última clase. Esto es algo que se sigue de la caracterización, ya ofrecida, de las categorías que integran el análisis causal como herramienta de subsunción. Si las nociones de causa y ley causal funcionan como meta-conceptos que contribuyen a esclarecer las condiciones de satisfacción semántica de todo tipo de un delito de resultado causalmente condicionado, entonces la suposición de que existirían una o más leyes causales inexistentes es un error que impide a quien lo padece juzgar adecuadamente si su propio comportamiento habrá de ser o no subsumible bajo el tipo en cuestión, ${ }^{208}$ en cuanto le impide aplicar correctamente el concepto expresado por el correspondiente "verbo causativo", en cuanto determinante del respectivo elemento del tipo.

\subsubsection{La "tentativa supersticiosa" como "tentativa irreal"}

No obstante la disparidad de estipulaciones terminológicas que se registra en la discusión especializada, ${ }^{209}$ el caso en el cual — de acuerdo con el argumento precedente- el RG erróneamente estimó la existencia de una tentativa de aborto, y en el cual sólo se configuraba, en cambio, un delito putativo, pertenece a la constelación usualmente asociada a la etiqueta de "tentativa irreal". Habiéndose ya demostrado que, así entendida, esta última etiqueta resulta del todo equívoca, en razón de que la constelación así designada queda compuesta por casos que precisamente se distinguen por la inexistencia de una tentativa de delito, cabe ahora volver sobre la pregunta acerca de la relación en que estos casos se encuentran respecto de aquellos que son agrupados bajo la etiqueta de "tentativa

\footnotetext{
${ }^{207}$ RENZIKOWSKI, “Wahnkausalität”, cit. nota no 55, p. 314.

${ }^{208}$ Véase RENZIKOWSKI, "Wahnkausalität”, cit. nota ${ }^{\circ} 55$, pp. 316 s., quien acertadamente sugiere que si en un caso de "causalidad putativa" el agente tuviera su comportamiento por subsumible bajo el respectivo tipo de delito él estaría dando aplicación a una "regla de experiencia" que como tal no podría ser reconocida por el juez como una regla que pudiera contribuir a determinar si las circunstancias que aquél se representó son circunstancias que objetivamente fundamenten un riesgo de acaecimiento del resultado correspondiente. El planteamiento de Renzikowski ha encontrado resonancia, aun cuando con algunas matizaciones, en WACHTER, Das Unrecht, cit. nota n ${ }^{\circ} 123$, pp. 204 ss.

${ }^{209}$ Véase al respecto ALWART, Heiner, Strafwürdiges Versuchen, Berlín: Duncker \& Humblot, 1982, pp. 201 ss., favoreciendo la comprensión de la categoría de la "tentativa supersticiosa" como una sub-variante de la de "tentativa irreal"; coincidentemente MORENO-TORRES, M ${ }^{\mathrm{a}}$ Rosa, Tentativa de delito y delito irreal, Valencia: Tirant lo Blanch, 1999, pp. 343 ss. La existencia de una relación de heterogeneidad (o mutua exclusión) de ambas categorías es afirmada por SANCINETTI, Fundamentación, cit. nota n ${ }^{\circ} 160$, pp. 181 ss., quien propone asociar la primera a "la aplicación de una regla de experiencia totalmente distorsionada" por parte del agente, en tanto que la segunda al reconocimiento del "carácter mágico de su comportamiento".
} 
supersticiosa". Considérese como un caso suficientemente prototípico de esta última constelación el siguiente:

(16) En la expectativa de poder así dar muerte a su enemigo B, A procede a insertar alfileres en un muñeco de trapo, bajo la creencia de que ello habría de condicionar una hemorragia interna en $\mathrm{B}$, que en definitiva habría de llevar a su muerte.

La denominación "tentativa supersticiosa" es usada para hacer referencia a casos que, como éste, involucran alguna creencia en la eficacia causal de determinados cursos de acción que el agente asocia con la invocación o activación de fuerzas pretendidamente sobrenaturales o mágicas. Que esta caracterización logre diferenciar los casos así etiquetados de aquellos en los cuales se habla de una "tentativa irreal", puede ser puesto en duda. Según Sancinetti, habría que admitir una diferencia en la medida en que la expresión "tentativa supersticiosa" sea reservada para designar "aquella clase de proyectos en los que el autor reconoce el carácter mágico de su comportamiento", frente a lo cual la expresión "tentativa irreal" tendría que designar "los casos (distintos) en que el autor supone obrar sobre la base de leyes 'terrenales' (empíricas), pero en virtud de una regla de experiencia totalmente distorsionada". 210

Bajo una concepción objetivista de la adscripción del dolo, empero, no cabe reconocer diferencia alguna entre ambos grupos de casos. Pues también tratándose de una "tentativa supersticiosa" el agente atribuye eficacia causal a acontecimientos que no se encuentran correlacionados por alguna generalización causal que, de acuerdo con el conocimiento científico disponible, reclame ser objetivamente reconocida. Que en tal caso el propio agente tematice esa pretendida eficacia causal como fundada en fuerzas mágicas o sobrenaturales, en nada altera lo aquí determinante: las circunstancias que el agente (acertadamente) reconoce como definitorias de aquello en que consiste su comportamiento y de la situación que lo circunda son circunstancias cuya representación no es fundante-dedolo, porque no se trata de circunstancias que objetivamente constituyan un síndrome de riesgo respecto del acaecimiento del resultado típicamente relevante. ${ }^{211}$

La irrelevancia de que el propio agente caracterice su "proyecto de acción" como supersticioso se ve decisivamente corroborada por el hecho de que, per se, semejante caracterización no fundamente la inexistencia de dolo. Pues considérese ahora el siguiente caso, propuesto por Renzikowski: ${ }^{212}$

(17) El paranoide A cree estar siendo seguido y torturado a través de una irradiación de rayos por parte de su vecino B. Creyendo A que B sería capaz, asimismo, de volverse físicamente invulnerable, A asume que existiría una sola vía para darle muerte, a saber: disparándole con una pistola bañada en oro que haya sido purificada con agua bendita a medianoche. Encontrándose ya en posesión de un arma (cargada) que satisface las condiciones precedentes, A dispara contra B.

\footnotetext{
${ }^{210}$ SANCINETTI, Fundamentación, cit. nota $\mathrm{n}^{\mathrm{o}} 160$, pp. $182 \mathrm{~s}$.

${ }^{211}$ Fundamental al respecto MITSCH, “\$ 23”, cit. nota $n^{\circ} 156$, pp. 358 ss., 363 ss.

${ }^{212}$ RENZIKOWSKI, “Wahnkausalität”, cit. nota $n^{\circ}$ 55, p. 317.
} 
En este último caso cabe adscribir dolo de homicidio a $\mathrm{A}$ en el momento en que éste dispara el arma apuntando contra B, con total independencia de que A haya creído que la específica letalidad de su disparo, en relación con $\mathrm{B}$, dependía de factores (que él mismo hubiese caracterizado como) sobrenaturales, adicionales al hecho de haber estado disparando un arma de fuego, cargada, en contra de otro ser humano vivo. Pues que A se haya representado estas últimas circunstancias es contextualmente suficiente para una adscripción de dolo de homicidio, en cuanto ellas se corresponden con un síndrome de riesgo en relación con el condicionamiento de la muerte de otro ser humano, sin que esa misma adscripción pudiera verse afectada por su creencia extravagante acerca de la presunta relevancia causal de aquel otro complejo de circunstancias. ${ }^{213}$ Una corroboración inequívoca de esta última proposición debería obtenerse de la consideración según la cual, en caso de que $\mathrm{B}$ hubiese en definitiva resultado muerto a consecuencia del disparo, nada obstaría a afirmar la responsabilidad de A como autor del correspondiente homicidio (doloso) consumado. ${ }^{214}$

\subsection{5. ¿La tentativa "crasamente insensata" como pseudo-tentativa?}

Cabe cerrar el análisis del problema de la así llamada "causalidad putativa" volviendo al problema que plantea la regla del apartado $3^{\circ}$ del $\S 23$ del StGB. En la medida en que la noción de una tentativa crasamente insensata no altere el significado técnico de la expresión "tentativa", sólo cabe favorecer la interpretación que de esa misma disposición ofreciera Struensee. De acuerdo con éste, y bajo la hipótesis de que sería ciertamente infundado atribuir al apartado $3^{\circ}$ del $\S 23$ del StGB el sentido de una regla constitutivamente amplificadora del ámbito de punibilidad de la tentativa (originariamente fijado por la definición del $\S 22$ del StGB), ${ }^{215}$ es necesario concluir que errores nomológicos concernientes a qué puede ser "objeto" o "medio" tratándose del respectivo hecho punible no logran constituir una tentativa crasamente insensata. ${ }^{216}$ Antes bien, sólo un "error ontológico", esto es, un error-de-referencia acerca de las circunstancias que definen la situación del agente en lo tocante a la falta de aptitud del objeto o del medio, que a su vez pueda entenderse fundado en una crasa insensatez del agente, esto es, en un déficit de racionalidad práctica manifestado en la extravagancia del proceso de formación de la

\footnotetext{
${ }^{213}$ Coincidentemente RENZIKOWSKI, "Wahnkausalität", cit. nota $\mathrm{n}^{\circ} 55$, p. 317 , quien siguiendo a Joerden sostiene que la particularidad de los casos que exhiben tal estructura se reduce a que en ellos la "regla de experiencia" de la que parte el propio agente se encuentra en una relación lógica de subordinación (o inclusión) respecto de la regla de experiencia que el tribunal tendría que asumir como válida para el establecimiento de la eventual conexión causal. Al respecto, véase JOERDEN, "Wesentliche", cit. nota n ${ }^{\circ} 55$, pp. $311 \mathrm{ss}$.

${ }^{214}$ Acerca de la inviabilidad de sustentar, por el contrario, la constitución de un delito doloso consumado en un caso en el cual acaeciera el evento consistente en el resultado típicamente relevante en aparente conexión con el comportamiento de un agente en virtud de un vínculo de "causalidad putativa", acertadamente MITSCH, “\$ 23”, cit. nota n n $^{\circ} 156$, pp. 368 s., 362 s.

${ }^{215}$ Esta es, como contrapartida, la interpretación en definitiva favorecida por quienes, de cara al tenor del apartado $3^{\circ}$ del $\S 23$ del StGB, concluyen que no es posible detectar una diferencia conceptual relevante entre la noción de "tentativa irreal" y la de "tentativa crasamente insensata"; así BLOY, "Unrechtsgehalt", cit. nota $\mathrm{n}^{\circ} 156$, pp. 109 ss. Véase al respecto MITSCH, "§ 23", cit. nota $\mathrm{n}^{\circ}$ 156, pp. 363 ss., 365, quien sobre esa base demanda enérgicamente la supresión del precepto, en cuanto representativo de un "derecho penal crasamente insensato". Ya RENZIKOWSKI, "Wahnkausalität", cit. nota n 55, hablaba, a tal respecto, de un "error de la ley".

${ }^{216}$ STRUENSEE, “Verursachungsvorsatz”, cit. nota n ${ }^{\circ} 122$, pp. 44 ss.
} 


\section{Polít. crim. Vol. 14, No 27 (Julio 2019), Art. 10, pp. 296-375. [http://politcrim.com/wp-content/uploads/2019/05/Vol14N27A10.pdf]}

correspondiente creencia, ${ }^{217}$ debería dar lugar al privilegio punitivo así previsto. Pues sólo un error semejante, consistente en una errónea representación de circunstancias cuya existencia objetivamente constituiría el correspondiente síndrome de riesgo, es compatible con la objetividad de la adscripción del dolo. Lo contrario, como ha observado Mitsch, supondría reconocer competencia al propio agente para determinar qué circunstancias realizan el concepto legal plasmado en la expresión "matar a otro". ${ }^{218} \mathrm{Y}$ ello significaría, precisamente, validar una metodología solipsista para la fundamentación del dolo.

Lo anterior significa que, en el caso de la presunta tentativa de embarazo que fuera fallado por el RG, no cabría hablar de una tentativa crasamente insensata, porque en un caso tal no se configura, de entrada, tentativa alguna. Desde este punto de vista, toda tentativa de delito tiene el estatus de un delito circunstancialmente imposible en un mundo nomológicamente posible.

\subsection{El error-de-sentido invertido acerca de un elemento normativo del tipo como delito putativo}

La segunda constelación con relevancia para ilustrar el impacto de la concepción objetivista de la fundamentación del dolo, ya reseñada, está conformada por casos que involucran alguna instancia de error referido a algún elemento normativo del tipo de cuya realización o falta de realización se trate. Para ilustrar el problema, considérese la siguiente variación del caso (1) presentado más arriba, ${ }^{219}$ que también representa una adaptación de un caso propuesto por Kindhäuser: ${ }^{220}$

(18) Entre las cosas comprendidas por la masa hereditaria adquirida en propiedad por $\mathrm{H}$ como único heredero figuran tres jarrones de porcelana, de los cuales uno cualquiera debe ser traspasado por $\mathrm{H}$ al legatario (de género) $\mathrm{L}$, en virtud del legado a tal efecto instituido por el causante $\mathrm{C}$ al momento de otorgar el testamento. Motivado por el odio que siente por $\mathrm{L}, \mathrm{H}$ destruye los tres jarrones, en la creencia errónea de que uno cualquiera de ellos habría ya pertenecido en propiedad a L en razón de su condición de legatario.

\footnotetext{
${ }^{217}$ Véase al respecto BLOY, “Unrechtsgehalt", cit. nota $\mathrm{n}^{\circ}$ 156, pp. 98 ss., quien identifica la noción de crasa insensatez con una "falta de realidad social —o equivalentemente, de relevancia comunicativa - del pensar y el actuar", aun cuando ciertamente sin validar la interpretación restrictiva favorecida por Struensee. El criterio del déficit de competencia práctica como base de la formación de la correspondiente creencia predictiva, aquí sugerido, es divergente del uso que de esa misma noción hace Yaffe para redefinir la particularidad de los casos que, en los ordenamientos jurídicos de la tradición del common law, se agrupan bajo la etiqueta de "imposibilidad inherente"; véase al respecto YAFFE, Gideon, Attempts in the Philosophy of Action and in the Criminal Law, Oxford: Oxford University Press, 2010, pp. 237 ss., 244 ss., quien recurre a la noción de incompetencia práctica como criterio de falta de evidencia suficiente de la disposición del agente a perpetrar el delito de cuya pretendida tentativa se trata. Para una reseña crítica de la concepción de la tentativa defendida por Yaffe, en cuanto construida sobre la noción de intentar, véase MAÑALICH, "La tentativa", cit. nota $\mathrm{n}^{\circ} 5$, pp. $485 \mathrm{~s}$., con referencias ulteriores.

${ }^{218}$ MITSCH, “§ 23”, cit. nota ${ }^{\circ} 156$, pp. $363 \mathrm{~s}$.

${ }^{219}$ Supra, 3.2.

${ }^{220}$ KINDHÄUSER, "Versuch", cit. nota no 7, p. 325.
} 
El caso (18) pertenece inequívocamente a la constelación que en el género literario de la criminalidad de manual se discute, entre otras, ${ }^{221}$ bajo la etiqueta de "error invertido sobre un elemento normativo del tipo", suscitándose a su respecto una controversia que ve enfrentadas a la "solución de la tentativa", por un lado, y la "solución del delito putativo", por otro, según si el error así caracterizado resulta fundante o no de una adscripción del dolo del delito respectivo.

Pero la expresión "error invertido sobre un elemento normativo del tipo" es insuficientemente refinada, en cuanto no logra hacer explícita una distinción analíticamente imprescindible, a saber, la distinción concerniente al objeto preciso del error en cuestión. Como ya se sostuviera, el método más promisorio para identificar diferenciadamente las formas de error que pueden tener eficacia excluyente de la imputación pasa por diferenciar, más básicamente, los dos niveles de representación —en el sentido del contenido representacional de las respectivas actitudes doxásticas- con relevancia para la fundamentación de una posible imputación jurídico-penal. ${ }^{222}$ En esos mismos términos, un error-de-referencia se distingue por tener como objeto las circunstancias que objetivamente satisfarían el conjunto de los elementos conceptuales que fijan las condiciones de aplicación de la norma respectiva. En cambio, un error-de-sentido se distingue por tener como objeto, más bien, el sentido o alcance mismo de los elementos conceptuales que fijan esas mismas condiciones de aplicación.

Tratándose de elementos conceptuales de la formulación de la norma que se corresponden con elementos normativos del tipo-de-delito respectivo, como lo es el elemento consistente en la ajenidad de la cosa que puede fungir como objeto de una apropiación o una destrucción delictivas, cabe recordar que ellos se distinguen por expresar propiedades convencionales, y no naturales, cuya realización o ejemplificación se corresponde con la existencia de hechos institucionales. ${ }^{223}$ Para que semejante propiedad convencional o institucional resulte efectivamente ejemplificada en el mundo, es necesaria que se vean satisfechas las condiciones fijadas por el respectivo conjunto de reglas constitutivas. ${ }^{224}$ Así por ejemplo, que una cosa corporal cualquiera exhiba la propiedad (relacional) de ser ajena, para quien pudiera llegar a apropiársela o a destruirla, depende de que esa cosa satisfaga las condiciones fijadas por las reglas constitutivas de la institución jurídica de la propiedad.

Nótese que no hay incompatibilidad alguna entre sostener que un elemento normativo del tipo en cuestión, como el consistente en la ajenidad de la cosa, funciona, en la forma de un

\footnotetext{
${ }^{221}$ La terminología vuelve a ser sumamente dispar aquí. La constelación aquí analizada comprende, desde luego, los casos que a veces son discutidos bajo la etiqueta de "error-de-delimitación" (Grenzirrtum), consistente éste en la atribución al correspondiente elemento del tipo de un alcance mayor que el que en efecto tiene, así como los casos que suelen discutirse bajo la etiqueta de "error acerca del campo previo del tipo" (Vorfeldirrtum), esto es, casos que involucrarían errores concernientes al alcance de normas externas al tipo, pero que co-determinan su alcance. Sobre ambas categorías, véase por ejemplo MAIER, Die Objektivierung, cit. nota $\mathrm{n}^{\mathrm{o}} 77$, pp. 84 ss., 90 ss.

222 Supra, 3.1.

${ }^{223}$ Véase supra, 3.2.

${ }^{224}$ Fundamental SEARLE, John, The Construction of Social Reality, Nueva York: The Free Press, 1995, pp. 27 ss., 43 ss.; SEARLE, Making, cit. nota no 39, pp. 9 ss., 93 ss. Véase al respecto KINDHÄUSER, Urs, "Rohe Tatsachen und normative Tatbestandsmerkmale", Jura, 1984, pp. 465-478, passim; KINDHÄUSER, "Zur Unterscheidung”, cit. nota n 45, pp. 417 ss.; NEUMANN, "Regel”, cit. nota n” 28, pp. 181 ss.
} 


\section{Polít. crim. Vol. 14, No 27 (Julio 2019), Art. 10, pp. 296-375. [http://politcrim.com/wp-content/uploads/2019/05/Vol14N27A10.pdf]}

"elemento en blanco", como una remisión al complejo de reglas constitutivas que definen las condiciones bajo las cuales una cosa corporal cualquiera cuenta como ajena para alguien, por un lado, ${ }^{225}$ y sostener que tal elemento normativo del tipo expresa una propiedad convencional cuya realización se corresponde con la existencia de un hecho institucional, por otro. ${ }^{226}$ Pues como acertadamente ha observado Toepel, semejante elemento normativo del tipo expresa, en efecto, una propiedad institucional cuyas condiciones de realización se encuentran constitutivamente fijadas por el correspondiente complejo de reglas, resultando enteramente impertinente, a este respecto, la diferenciación de un error acerca de la realización de la propiedad en cuestión, por un lado, y un error acerca de la satisfacción de las condiciones fijadas por las reglas que la constituyen, por otro. $^{227}$

Para que, tratándose de la potencial satisfacción de un elemento normativo del tipo en cuestión, el agente se encuentre en un error-de-referencia (invertido) que resulte fundante del dolo del delito respectivo, de manera tal que pudiera resultarle imputable la correspondiente tentativa de delito, es necesario que aquel se represente como existentes circunstancias que, de ser existentes, conllevarían — sobre la base de las correspondientes reglas constitutivas - la ejemplificación de la propiedad convencional expresada por el elemento en cuestión. Si, en cambio, el agente se representa como existentes circunstancias que, de existir, no conllevarían la ejemplificación de la respectiva propiedad convencional, y no obstante esto se representa como ejemplificada la propiedad en cuestión, entonces aquel habrá incurrido, más bien, en un error-de-sentido. ${ }^{228}$ Pues su representación de la ejemplificación de la respectiva propiedad convencional sólo podrá explicarse, entonces, como el resultado de su errónea suposición de la existencia de reglas constitutivas distintas de aquellas que subyacen a la atribución jurídica de la propiedad en cuestión, esto es: como el resultado de una representación de reglas constitutivas imaginarias. ${ }^{229}$

No es difícil advertir, volviendo al caso (18), que el error en el cual incurre $\mathrm{H}$, consistente en su creencia de que alguno cualquiera de los tres jarrones por él destruidos habría pertenecido, en propiedad, a L, debe ser categorizado como uno que tiene por objeto las reglas constitutivas que definen bajo qué condiciones una cosa corporal jurídicamente cuenta, para alguien, como ajena. En tal medida, su error es uno que concierne a los elementos conceptuales que fijan las condiciones de aplicación de la respectiva prohibición. Pues de acuerdo con las reglas del derecho civil chileno, un legatario de género, como lo es L, no se hace dueño de cosa alguna por la sola apertura de la sucesión, correspondiendo la propiedad sobre cada uno de los bienes que conforman la masa hereditaria al conjunto de

\footnotetext{
225 Así BURKHARDT, Björn, "Nachschlag", cit. nota $\mathrm{n}^{\circ}$ 27, pp. 350 ss.; véase ya BURKHARDT, "Rechtsirrtum", cit. nota no 27, pp. 686 ss.

${ }^{226}$ Así KINDHÄUSER, "Versuch“, cit. nota no 7, pp. 332 ss., argumentando contra Burkhardt.

227 TOEPEL, Friedrich, "Zur Abgrenzung von untauglichem Versuch und Wahndelikt", Zeitschrift für internationale Strafrechtsdogmatik 10, 2017, pp. 606-611, pp. 608 s.

${ }^{228}$ Acertadamente BURKHARDT, Björn, "Nachschlag", cit. nota n ${ }^{\circ}$ 27, pp. 353 ss. Esto es desconocido por NEUMANN, "Regel", cit. nota $\mathrm{n}^{\circ} 28$, pp. 182 ss., cuya defensa de la "solución de la tentativa" descansa en la mera consideración de que, por tratarse de la suposición errónea de la existencia de un hecho institucional, la suposición errónea de la ajenidad de la cosa constituiría un "error de hecho".

${ }^{229}$ Fundamental KINDH ̈̈USER, "Versuch", cit. nota no 7, pp. 337 ss.; coincidentemente TOEPEL, "Zur Abgrenzung”, cit. nota n 227, pp. 609 s.
} 
los herederos del causante, conjunto que en el caso en cuestión tiene como único elemento a H.

El error de este último tiene el estatus, por ello, de un error-de-sentido (invertido), que determina que $\mathrm{H}$ se haya representado estar destruyendo una cosa ajena que en ningún mundo en el cual rija el mismo ordenamiento jurídico que rige en el mundo al cual pertenecen los hechos que configuran el caso sería, en efecto, una cosa ajena para $\mathrm{H}$. Ello quiere decir que la consciencia de la ilicitud que $\mathrm{H}$ pudiera llegar a tener, en referencia a su propio comportamiento consistente en la destrucción de los tres jarrones, es una consciencia de la ilicitud que no tendría sustento objetivo alguno en una prohibición efectivamente perteneciente al ordenamiento jurídico que vale en el mundo actual. Esa eventual consciencia puramente ilusoria de la ilicitud de su propio comportamiento confiere a éste el carácter de un delito putativo.

La premisa decisiva que lleva a la conclusión precedente se deja reformular como sigue: en ningún mundo posible en el cual rigiese el mismo ordenamiento jurídico al que pertenece la prohibición del daño de cosa ajena, cuya aplicabilidad o falta de aplicabilidad se plantea en el caso, podría esa misma prohibición resultar quebrantada a través de un comportamiento que exhiba las propiedades básicas que $\mathrm{H}$ tuvo (acertadamente) por realizadas. Esto último significa que la creencia de $\mathrm{H}$ en cuanto a que, al destruir los tres jarrones, habría estado destruyendo una cosa ajena es una creencia que tiene por objeto un estado de cosas jurídicamente imposible. ${ }^{230} \mathrm{Y}$ en la medida en que la configuración del ordenamiento jurídico bajo el cual puede verse constituido el quebrantamiento de la norma eventualmente imputable al agente no se encuentre, solipsistamente, a disposición de éste, ningún error del agente acerca de la configuración de ese mismo ordenamiento jurídico puede llevar a que se vea quebrantada alguna de las normas que lo integran, tampoco imperfectamente, en una situación en la cual las circunstancias que el propio agente tiene por existentes objetivamente conllevan la falta de aplicabilidad de la norma en cuestión.

Esto quiere decir que si bien toda tentativa de delito tiene el estatus de un delito imposible en el mundo actual, ${ }^{231}$ la imposibilidad involucrada en la constitución de una tentativa necesita estar basada en una o más circunstancias que podrían contingentemente darse o no darse en mundos alternativos al mundo actual, siempre que en éstos rigiese el mismo ordenamiento jurídico que rige en el mundo actual. Pues como observa Kindhäuser: "El orden normativo del derecho es, así, un parámetro unitario para la valoración de todos los mundos que son alternativas fácticamente posibles al mundo real", en términos tales que si "el comportamiento del autor no puede llevar a la consumación en virtud de una razón de naturaleza normativa, la falta de realización del tipo no se explica por un acaso afortunado, sino que es consecuencia de una imposibilidad jurídica". ${ }^{232}$ En tal medida, y desde este punto de vista, una tentativa de delito puede ser entendida como un delito circunstancialmente imposible en un mundo (ontológica y) jurídicamente posible.

\footnotetext{
${ }^{230}$ Así ya KINDHÄUSER, “Versuch”, cit. nota no 7, pp. 337, 340 ss.; TOEPEL, “Zur Abgrenzung”, cit. nota $\mathrm{n}^{\circ} 227$, p. 610.

${ }^{231}$ Véase supra, 5.4.

${ }^{232}$ KINDHÄUSER, "Versuch", cit. nota nº 7, p. 341.
} 


\title{
Polít. crim. Vol. 14, No 27 (Julio 2019), Art. 10, pp. 296-375. [http://politcrim.com/wp-content/uploads/2019/05/Vol14N27A10.pdf]
}

\subsection{La objetividad de la adscripción del dolo como superación del solipsismo}

En las secciones precedentes se ha intentado demostrar el rendimiento que una concepción objetivista de la adscripción del dolo tiene para el aseguramiento de la objetividad de la fundamentación de la punibilidad de un comportamiento a título de tentativa de delito, de un modo que al mismo tiempo asegura el abandono de la tradicional distinción entre tentativas idóneas e inidóneas. Cabe cerrar la presentación del argumento así desarrollado volviendo al punto concerniente a cómo semejante objetivismo en lo tocante a la adscripción del dolo puede ser entendido como una superación del solipsismo que ha tendido a amenazar la dogmática de la tentativa bajo el influjo de una concepción subjetivista de su fundamento de punibilidad.

Esta preocupación fue muy claramente planteada por Hruschka. ${ }^{233}$ El punto de partida para ello se encuentra en su redefinición general del concepto de acción en el sentido de una instancia de aplicación de una regla por parte de un agente, siendo el caso que un evento o proceso cualquiera sólo adquiriría ese estatus por vía de interpretación, o más precisamente, de imputación. ${ }^{234}$ Entre esas reglas pueden figurar, desde luego, "reglas de experiencia", ${ }^{235}$ esto es, reglas técnicas que instruyen acerca de los medios adecuados para la realización de algún fin determinado. ${ }^{236}$ Sobre esta base, Hruschka formulaba una objeción contra la así llamada "teoría subjetiva de la tentativa", que él asociaba a la tesis de que "también la utilización de un 'medio' inidóneo con el fin de la perpetración de un hecho punible representa una tentativa de este hecho punible". ${ }^{237}$ La objeción reza como sigue: en la medida en que "la tentativa de un hecho punible sea entendida como el inicio del hecho punible" en cuestión,

\begin{abstract}
"entonces la tentativa de una determinada acción es el inicio de la aplicación de aquella regla que yo, el imputador, tengo por aplicada, cuando la acción es ejecutada hasta el final, esto es, la tentativa de un homicidio es el inicio de la aplicación de la regla del matar reconocida por mí. Frente a esto, la problemática tesis de la teoría subjetiva de la tentativa dice que un actuar podría ser ya imputado como inicio de un actuar constitutivo de homicidio si el agente considera su actuar como un actuar constitutivo de homicidio". 238
\end{abstract}

Nótese que la objeción de Hruschka no consiste en que, de acuerdo con la "teoría subjetiva", habría que reconocer como una tentativa de homicidio un comportamiento que en definitiva no llevó a la muerte de la potencial víctima, por haber el agente hecho uso de un medio inidóneo. ${ }^{239}$ Pues Hruschka no está tematizando la circunstancia de que el agente haya hecho uso de un medio inidóneo, sino el hecho de que el agente haya tenido por idóneo un medio que, con arreglo a la "regla de experiencia" validada por el juzgador,

\footnotetext{
${ }^{233}$ HRUSCHKA, Strukturen, cit. nota no 161 , pp. 58 ss.

${ }^{234}$ HRUSCHKA, Strukturen, cit. nota $\mathrm{n}^{\circ} 161$, pp. 11 ss. Al respecto, y de manera tendencialmente crítica, véase KINDHÄUSER, Handlung, cit. nota $\mathrm{n}^{\circ} 185$, pp. 197 ss.

${ }^{235}$ HRUSCHKA, Strukturen, cit. nota $\mathrm{n}^{\circ} 161$, pp. $11 \mathrm{~s}$.

${ }^{236} \mathrm{Al}$ respecto, véase supra, nota 188.

${ }^{237}$ HRUSCHKA, Strukturen, cit. nota n ${ }^{\text {1 }} 161$, p. 58.

${ }^{238}$ HRUSCHKA, Strukturen, cit. nota $\mathrm{n}^{\circ} 161$, pp. $58 \mathrm{~s}$.

${ }^{239}$ Así empero KINDHÄUSER, Handlung, cit. nota ${ }^{\circ}{ }^{185, \text { p. }} 201$.
} 
carece de tal idoneidad. ${ }^{240}$ En tal medida, Hruschka está correctamente advirtiendo que la punibilidad a título de tentativa de homicidio que un partidario de la "teoría subjetiva" afirmaría - como de hecho lo hiciera Von Buri- en referencia al caso (15), ${ }^{241}$ quedaría fundamentada por la validación, por parte del juzgador, de una regla que el agente valida, pero que el juzgador no puede tener por válida.

Esto quiere decir que la concepción subjetivista lleva a que el juzgador, en cuanto tribunal sometido al derecho efectivamente vigente, debiese proceder como si validase una regla determinada que de hecho no amerita ser objetivamente reconocida, ${ }^{242}$ sea que se trate de una pretendida "regla de experiencia" que descansa en una o más leyes causales de hecho inexistentes, sea que se trate de una pretendida regla constitutiva que fija condiciones de realización de una propiedad institucional que de hecho no coinciden con las condiciones fijadas por las reglas constitutivas jurídicamente validadas. La inconsistencia a la que se vería forzado, de esa manera, el juzgador, es la inconsistencia que resulta de asumir un punto de partida favorable al solipsismo en la fundamentación de la imputación subjetiva. Frente a ello, el mejor antídoto disponible consiste, precisamente, en la reivindicación de la objetividad de la imputación subjetiva.

\section{La tentativa como quebrantamiento imperfecto de una norma públicamente vinculante}

\subsection{El modelo de la vinculación a reglas públicas}

En sus consecuencias, el argumento desarrollado en las secciones precedentes lleva a la refutación de aquella tesis acerca del fundamento de punibilidad de la tentativa que tradicionalmente se asocia a la así llamada "antigua teoría de la peligrosidad", cuyo precursor más señero es identificado con Feuerbach. ${ }^{243}$ Esta tesis hace depender la punibilidad de la tentativa de la comprobación de su peligrosidad, entendida como aptitud causal "en abstracto", desde un punto de vista ex post. ${ }^{244}$ Esa refutación es consistente con el resultado al que arriba la así llamada "moderna teoría de la peligrosidad", que hace depender la punibilidad de la tentativa de la peligrosidad ex ante exhibida por el comportamiento del agente, con independencia de que las circunstancias in concreto definitorias de la situación hicieran reconocible, ex post, la imposibilidad de la

\footnotetext{
${ }^{240}$ Hay que notar que la interpretación del pasaje pudiera volverse menos unívoca si se trae a colación la manera en que HRUSCHKA, Strukturen, cit. nota $\mathrm{n}^{\circ} 161$, p. 60, ilustra su objeción planteando un ejemplo desprovisto de relevancia jurídico-penal: “¿Estaría yo de acuerdo o en desacuerdo con un pianista que [mientras toca un piano] afirmase que él estaría intentando tocar órgano? Yo no le daría razón, tampoco si su error estuviera fácticamente fundado (por ejemplo, porque el piano se encuentra en una iglesia en el lugar donde usualmente se ubica el órgano, etc.)". La dificultad quedaría salvada si se asume, de manera compatible con el tenor de esta última cita, que el sustento fáctico del error en el cual se encontraría el pianista no afecta su representación de que lo que está tocando se ajusta, perceptualmente, a las características de un objeto que queda comprendido en la extensión del sustantivo "piano", y no del sustantivo "órgano". Pues en tal caso, el error en cuestión tendrá el estatus de un error-de-sentido, y no de un error-de-verdad.

${ }^{241}$ Supra, 6.2.3.

${ }^{242}$ HRUSCHKA, Strukturen, cit. nota n ${ }^{\text {1 }} 161$, p. 59.

${ }^{243}$ Latamente al respecto SEMINARA, Il delitto, cit. Nota ${ }^{\circ} 112$, pp. 228 ss.

${ }^{244}$ Véase en detalle SOLA RECHE, Tentativa inidónea, cit. nota $\mathrm{n}^{\circ}$ 86, pp. 17 ss.
} 


\section{Polít. crim. Vol. 14, No 27 (Julio 2019), Art. 10, pp. 296-375. [http://politcrim.com/wp-content/uploads/2019/05/Vol14N27A10.pdf]}

consumación. ${ }^{245}$ Pero la coincidencia en el resultado no logra hacer desaparecer una muy sensible diferencia de fundamentación: mientras la moderna teoría de la peligrosidad introduce la exigencia "objetiva" de una peligrosidad ex ante como un filtro antepuesto a la eventual comprobación del dolo, la propuesta aquí presentada descansa en una defensa de la objetividad intrínseca a la fundamentación del dolo qua criterio de imputación subjetiva.

Con todo, la variante de objetivismo asociada a la obra de Feuerbach sigue resultando persuasiva para un sector relevante de la doctrina chilena, en cuanto comprometida con la tesis de la falta de punibilidad de la así llamada "tentativa absolutamente inidónea". ${ }^{246}$ Esto se explica, a mi juicio, por un aspecto distintivo de esa concepción, que de hecho no logra ser captado, transparentemente, en la jerga de la peligrosidad. Se trata, más bien, de la validación de la premisa según la cual un comportamiento con relevancia jurídico-penal sólo podría consistir en la vulneración de un derecho subjetivo ajeno. Esto puede explicar, específicamente, la resistencia de los auto-proclamados "objetivistas" a aceptar la punibilidad de una tentativa en un caso como (5), en el cual al momento en que el agente se dispone a ejecutar una acción pretendidamente letal no existe un ser humano vivo que, en cuanto objeto de la transformación típicamente relevante, hubiera de ser titular del derecho subjetivo pretendidamente vulnerado por el comportamiento del potencial autor.

El déficit insuperable que aqueja, en general, a semejante modelo de legitimación de la punibilidad se encuentra en su incompatibilidad con un modelo de fundamentación de deberes de abstención o de acción a partir de normas públicamente vinculantes. ${ }^{247}$ Esto quiere decir, más precisamente, que el deber de omitir o ejecutar la acción respectiva, cuya infracción resulta delictiva, no tiene como correlato el derecho subjetivo de la (eventual) víctima, sino que se fundamenta como la conclusión de un silogismo práctico cuya premisa mayor está constituida por la norma pública de comportamiento cuya falta de reconocimiento como razón vinculante representa el objeto del eventual reproche de culpabilidad. ${ }^{248}$ Este modelo resulta igualmente pertinente tratándose de la fundamentación de la punibilidad de un delito consumado y de su correspondiente tentativa. ${ }^{249}$

Una implicación fundamental de semejante modelo de vinculación a normas públicas fue advertida por Hart. La "técnica de control" así caracterizada consistiría en "designar, mediante reglas, ciertos tipos de comportamiento como estándares para la guía ya sea de los

\footnotetext{
${ }^{245}$ Véase SOLA RECHE, Tentativa inidónea, cit. nota ${ }^{\circ}$ 86, pp. 23 ss.

${ }^{246}$ Véase al respecto POLITOFF, Los actos, cit. nota $n^{\circ} 112$, pp. 107 ss., 133 ss., con referencias ulteriores, aun cuando al mismo tiempo defendiendo la adopción de una perspectiva objetiva ex ante para la adopción del correspondiente juicio de (in)idoneidad.

${ }^{247}$ En detalle MAÑALICH, "Normas permisivas", cit. nota n ${ }^{\circ} 84$, pp. 500 ss., con referencias ulteriores; véase más recientemente KINDHÄUSER, Urs, "Zur ,Drittwirkung' strafrechtlicher Verhaltensnormen”, en: SALIGER, Frank et al. (coords.), Rechtsstaatliches Strafrecht. Festschrift für Ulfrid Neumann zum 70. Geburtstag, Heidelberg: C.F. Müller, 2017, pp. 917-930, pp. 927 s.

${ }^{248}$ Acerca de la incompatibilidad entre un modelo de obligación para con terceros y un modelo de vinculación a reglas, véase NEUMANN, Ulfrid, "Normtheorie und strafrechtliche Zurechnung”, Goltdammer's Archiv für Strafrecht, 1985, pp. 389-401, pp. 398 ss.; NEUMANN, Ulfrid, "Normlogik, Argumentationstheorie und das Problem der negativen Tatbestandsmerkmale", en: KARDA, Piotr, et al. (coords.), Państwo prawa i prawo karne. Księga Jubileuszowa Profesora Andrzeja Zolla, tomo II, Varsovia: Wolters Kluwer, 2012, pp. 417432, pp. 422 ss.

${ }^{249}$ En detalle MAÑALICH, “La tentativa”, cit. nota n 5 , pp. 469 ss., 475 ss.
} 
miembros de la sociedad en su conjunto o [de miembros] de ciertas clases en su interior", esperándose de quienes han de guiar su comportamiento dando seguimiento a esos estándares que "entiendan las reglas y se ocupen de si las reglas les son aplicables y se sujeten a ellas". ${ }^{250}$ Y lo distintivo de esa técnica, añade Hart, es que los miembros de la sociedad son dejados a descubrir las reglas y sujetar su comportamiento a ellas", en términos tales que, "en este sentido, ellos 'aplican' por sí mismos las reglas a ellos mismos". ${ }^{251}$ Precisamente porque cada destinatario de la norma respectiva ha de ocuparse de reconocer las circunstancias que la hacen aplicable, en pos de adecuar a ella su comportamiento, es correcto que la fundamentación del concreto deber de abstención o de acción se haga depender de la representación de las circunstancias con la cual cuenta el destinatario de la norma. ${ }^{252} \mathrm{Si}$ ex post se muestra acertada la creencia predictiva, sustentada en esa representación, de que su propio comportamiento, consistente en la ejecución o la omisión de una determinada acción, habría de exhibir las propiedades respectivamente fundantes-de-antinormatividad, entonces el quebrantamiento de la norma, constituido por la falta de omisión o falta de ejecución de tal acción, le será imputable qua delito consumado; si esa misma creencia se muestra, ex post, como desacertada, ello implicará que su comportamiento le sea imputable qua tentativa de delito.

De ahí que, en contra de lo sostenido por Haas, el autor de una tentativa no responda, por vía de ficción, "de aquello que no ha conseguido"; 253 antes bien, al autor de una tentativa se lo hace responsable de un comportamiento que, en el mundo actual, no ha resultado ser antinormativo, sobre la base de la adscripción de una creencia predictiva que ha resultado ser falsa, pero que habría resultado antinormativo en un mundo nomológica y jurídicamente posible en el cual esa misma creencia hubiese resultado verdadera.

\subsection{Los delitos especiales como instancias de quebrantamiento de normas especiales}

\subsubsection{La estructura de las normas especiales}

Es fundamental reparar en que, en los términos del modelo recién esbozado, la vinculación individual del agente a la norma presupone que aquél efectivamente cuente como destinatario de la norma de cuyo quebrantamiento se trata. Como Hart mismo lo sugiriera, es posible sin más que la propia norma restrinja el universo de agentes para cuyo comportamiento ella tendría que fungir como razón vinculante. Ello es precisamente lo que define a las así llamadas "normas especiales", esto es, aquellas cuyo quebrantamiento es constitutivo de un delito especial (propio). ${ }^{254}$ Pues una norma de comportamiento es especial, a su vez, siempre que el lugar de destinatario de la misma sólo puede ser ocupado por alguien que exhibe un determinado estatus especial. Esto quiere decir, de paso, que en rigor no hay tal cosa como un "delito especial impropio", tal como lo sugiere esta misma denominación, en cuanto hace explícita la impropiedad de semejante caracterización. Pues

\footnotetext{
${ }^{250}$ HART, H.L.A., The Concept of Law, $3^{\mathrm{a}}$ ed., Oxford: Oxford University Press, p. 38.

${ }^{251}$ HART, The Concept, cit. nota $\mathrm{n}^{\circ} 250$, p. 39.

${ }^{252}$ Acertadamente RENZIKOWSKI, "Wahnkausalität", cit. nota no 55, p. 314.

${ }^{253}$ Así empero HAAS, Volker, "Zum Rechtsgrund von Versuch und Rücktritt", Zeitschrift für die gesamte Strafrechtswissenschaft 123, 2011, , pp. 226-259, pp. 245 ss.

${ }^{254}$ Véase al respecto MAÑALICH, Juan Pablo, "La malversación de caudales públicos y el fraude al fisco como delitos especiales", Política Criminal 7, n 14, 2012, pp. 357-377, pp. 358 s.
} 


\section{Polít. crim. Vol. 14, № 27 (Julio 2019), Art. 10, pp. 296-375. [http://politcrim.com/wp-content/uploads/2019/05/Vol14N27A10.pdf]}

lo que usualmente se tematiza como un "delito especial impropio" no es más que el quebrantamiento de una norma general, que en cuanto tal es constitutivo de un delito común, el cual se ve cualificado en el nivel de sus presupuestos de punibilidad en virtud de la concurrencia de un determinado estatus especial en la persona del autor.

Esta concepción normológica de los delitos especiales, que fuera apenas delineada por Binding, ${ }^{255}$ a la vez que programáticamente desarrollada por Nagler, ${ }^{256}$ se ha visto enfrentada a dos objeciones fundamentales, una de índole conceptual y otra de índole "legitimatoria". ${ }^{257}$ Esta última, destacadamente planteada por Langer, ${ }^{258}$ descansa en la consideración de que no serían reconocibles razones para postular una restricción del círculo de destinatarios de una norma de comportamiento, en cuanto norma legitimada en exclusiva referencia al principio de protección de bienes jurídicos. ${ }^{259}$ Mas esto desconoce que toda norma de comportamiento jurídico-penalmente reforzada representa una solución autoritativa de un determinado conflicto de libertad referido a una distribución (del disfrute o aprovechamiento) de bienes jurídicos. El hecho de que toda norma de comportamiento, ex definitione, circunscriba el espacio de juego (jurídicamente reconocido) para la acción de sus destinatarios puede contar sin más como una razón que vuelva justificable, en consideración del bien jurídico de cuya protección se trata, una demarcación del universo de sus destinatarios a través de la exigencia de una determinada cualificación personal. ${ }^{260}$

Esto último fue claramente advertido por Nagler, quien observara que la restricción del alcance de una norma de comportamiento a través de una cualificación personal de sus destinatarios podía, en general, responder a las dos siguientes razones, a saber: o bien que el bien jurídico de cuya protección se trata se encuentre configurado de tal manera "que sólo sea alcanzable para un grupo particular de los sometidos [a la autoridad de la ley]"; o bien que se asuma que "para la consecución de aquellas transformaciones del mundo exterior no tenga que ser puesta en movimiento la generalidad de los sujetos jurídicos", en cuyo caso tales transformaciones sólo serán requeridas "de una categoría determinada de personas". ${ }^{261}$ No es en absoluto implausible, entonces, que una restricción del universo de personas respecto de las cuales la norma en cuestión ha de fungir como razón inmediata para la

\footnotetext{
255 Véase BINDING, Die Normen, cit. nota $\mathrm{n}^{\circ}$ 11, pp. 126 s., quien identificaba el respectivo círculo cualificado de destinatarios de una norma especial como constituido por "los integrantes del estamento para el cual la norma vale”. Al respecto KAUFMANN, Normentheorie, cit. nota $\mathrm{n}^{\circ} 16$, pp. 132 ss.

${ }^{256}$ Véase NAGLER, Johannes, Die Teilnahme am Sonderverbrechen, Léipzig: Wilhelm Engelmann, 1903, pp. 4 ss., 18 ss. Como observa LANGER, Winrich, Die Sonderstraftat, $2^{a}$ ed., Berlín: Duncker \& Humblot, 2007, pp. 227 s., la contribución capital de Nagler consistió en proveer una definición del concepto de delito especial que superaba íntegramente el paradigma del "delito estamental".

${ }^{257}$ En general sobre el problema, véase GÓMEZ MARTIN, Víctor, Los delitos especiales, Madrid, Montevideo y Buenos Aires: Edisofer y BdF, 2006, pp. 67 ss.

${ }^{258}$ LANGER, Die Sonderstraftat, cit. nota $\mathrm{n}^{\circ} 256$, pp. 273 ss.

${ }^{259}$ LANGER, Die Sonderstraftat, cit. nota n ${ }^{\circ} 256$, pp. 276 s.

${ }^{260}$ Frente a la objeción, presentada por LANGER, Die Sonderstraftat, cit. nota no 256 , pp. 277 ss., de que ningún método de interpretación de la ley podría conducir a demostrar la existencia de semejantes normas especiales, cabría recordar las muy rigurosas disquisiciones metodológicas que Nagler aportara en pos de la identificación de los criterios de reconocimiento de semejantes normas especiales a partir de la formulación de algún conjunto de normas de sanción penal; véase al respecto NAGLER, Die Teilnahme, cit. nota $n^{\circ} 256$, pp. 26 ss.

${ }^{261}$ NAGLER, Die Teilnahme, cit. nota n 256, p. 9.
} 
acción quede expresada en la fijación del correspondiente ámbito de aplicabilidad interna de esa misma norma. ${ }^{262}$

Justamente una formulación como la precedente hace suficientemente explícito el punto crítico al cual se encuentra referida la ya anticipada objeción conceptual, que pone en cuestión la viabilidad de la pretensión de ver restringido el círculo de destinatarios de la norma al universo de individuos a los cuales ella podría "obligar inmediatamente". Pues esto dejaría enteramente inexplicado el hecho de que individuos extraños a ese mismo círculo puedan, con todo, resultar responsables del quebrantamiento de aquélla, a saber: aun cuando no como autores, sí como partícipes del delito especial en cuestión. ${ }^{263}$ La constatación de la pretendida inconsistencia en la que habría incurrido Binding, al sostener que "mediatamente todos los demás sometidos a la autoridad de la ley serían obligados por la norma especial", ${ }^{264}$ llevó a Kaufmann a proponer una redefinición del concepto mismo de norma especial. Según Kaufmann, lo definitorio de una norma especial no se encontraría en la pretendida restricción de su universo de destinatarios, sino en una "determinación más precisa del sujeto de la norma", esto es, una especificación de quien puede fungir como "el autor del acto normado". 265

Una primera objeción que Kaufmann esgrimiera en contra de la existencia de normas dirigidas a un círculo restringido de destinatarios apuntaba a la supuesta inviabilidad de excluir a priori a una persona determinada del universo de posibles destinatarios de una norma, dado que "los círculos de personas indicados cambian en su composición". ${ }^{266}$ Esta afirmación, sin embargo, descansa en la suposición, enteramente infundada, de que el respectivo "círculo de personas" tendría que ser determinado extensionalmente, y no, en cambio, intensionalmente. La factibilidad de ambos modos de determinación fue claramente demostrada por Ross, según quien el círculo de destinatarios de una norma cualquiera podría quedar definido o bien como una clase cerrada, a través de un criterio de pertenencia que identifique algún conjunto invariable de individuos, o bien como una clase abierta, a través de un criterio de pertenencia que se reduzca a la satisfacción (no especificada temporalmente) de una determinada descripción. ${ }^{267}$

Si a lo anterior se añade que, como acertadamente observara Langer, la especificación de lo que Kaufmann denominara el "sujeto de la norma" es eo ipso equivalente a la especificación del conjunto de individuos inmediatamente vinculados por ella, ${ }^{268}$ lo único que puede estar en juego en la resistencia de Kaufmann a validar la tesis de la restricción

\footnotetext{
${ }^{262}$ Para esta noción de ámbito de aplicabilidad interna, véase NAVARRO, Pablo; MORESO, José Juan, “Aplicabilidad y eficacia de las normas jurídicas", Isonomía 5, 1996, pp. 119-139, pp. 125 ss.; al respecto MAÑALICH, Juan Pablo, "El concurso aparente como herramienta de cuantificación penológica de hechos punibles", en: CÁRDENAS, Claudia; FERDMAN, Jorge (coords.), El derecho penal como teoría y práctica. Libro homenaje a Alfredo Etcheberry Orthusteguy, Santiago: La Ley/Thomson Reuters, 2016, pp. 501-548, pp. 505 ss., con referencias ulteriores.

${ }^{263}$ Véase KAUFMANN, Normentheorie, cit. nota $\mathrm{n}^{\circ}$ 16, pp. 133 s.; LANGER, Die Sonderstraftat, cit. nota $\mathrm{n}^{\mathrm{o}}$ 256, pp. 279 ss.

${ }^{264}$ BINDING, Die Normen, cit. nota $\mathrm{n}^{\circ} 11$, p. 127.

${ }^{265}$ KAUFMANN, Normentheorie, cit. nota $\mathrm{n}^{\circ} 16$, pp. 134.

${ }^{266}$ KAUFMANN, Normentheorie, cit. nota $\mathrm{n}^{\mathrm{o}} 16, \mathrm{p} .133$.

${ }^{267}$ ROSS, Alf, Directives and Norms, Nueva York: Humanities Press, 1968, pp. 108 ss.

${ }^{268}$ LANGER, Die Sonderstraftat, cit. nota $n^{\circ} 256$, p. 281.
} 
del círculo de destinatarios como marca de toda norma especial es justamente la explicación de la posibilidad de la participación de un extraneus en un delito especial. Pues del reconocimiento de esa posibilidad Kaufmann pretendía inferir, en efecto, que "también las normas especiales se dirigen a todos". ${ }^{269}$ Pero ya Nagler había demostrado que del hecho de que una norma especial se distinga por estar dirigida a un universo restringido de individuos no se sigue, en absoluto, que a un extraneus no pudiera resultar imputable su quebrantamiento a título de participación. ${ }^{270}$ Desde el punto de vista de la dogmática de las formas de intervención en el hecho punible, lo único que se sigue del carácter especial de la norma en cuestión es que sólo quienes cuentan como intranei puedan resultar responsables como autores del correspondiente delito. ${ }^{271} \mathrm{Y}$ esto se sigue, precisamente, de que sólo en cuanto comportamiento de un intraneus - o de dos o más intranei, tratándose de una coautoría - resulte antinormativo un comportamiento que exhibe las demás propiedades fundantes de la antinormatividad específicamente constitutiva del género del respectivo delito especial. Pero nada obsta a que uno o más extranei puedan hacerse accesoriamente responsables, "en segunda línea", del quebrantamiento de la norma especial imputable, "en primera línea", a uno o más intranei, precisamente porque, por esa vía, el respectivo bien jurídico se vuelve —indirectamente- accesible para aquéllos. ${ }^{272}$

Aquí es pertinente introducir dos observaciones acerca del argumento ofrecido por Nagler. En primer lugar, es crucial reparar en que, en lo tocante a lo que define la intervención de una persona a la cual el respectivo hecho punible pudiera resultar imputable a título de participación, no hay diferencia alguna en que se trate de un delito especial o bien de un delito común. Pues también tratándose del posible quebrantamiento de una norma general - esto es, de una norma respecto de la cual la distinción entre intranei y extranei resulta inaplicable - , la posición del eventual partícipe es la posición de alguien que por sí mismo no está en situación de quebrantar la norma. Pues sólo responde como autor la persona a la cual es imputable la no-omisión o la no-ejecución de una acción que bajo la norma de comportamiento en cuestión cuenta como principal, esto es, como una acción especificada bajo una descripción que la hace semánticamente autosuficiente para ejemplificar el tipo de acción sometido a prohibición o a requerimiento, según corresponda. ${ }^{273}$ En tal medida, es sólo en virtud de la función constitutiva que desempeña el principio de accesoriedad de la participación que puede resultar responsable, como partícipe, una persona a quien sólo es posible adscribir, directamente, la no-omisión o la no-ejecución de una acción auxiliar, esto es, de una acción cuya no-omisión o cuya no-ejecución ha posibilitado o favorecido el quebrantamiento de la norma imputable a quien funge como autor. ${ }^{274}$

En segundo lugar, cabe notar que el argumento de Nagler para sustentar la viabilidad de una responsabilidad secundaria, accesoriamente fundamentada, de un extraneus por el quebrantamiento de una norma especial, admite ser considerablemente esclarecido si se introduce una distinción, aportada por Gardner, entre el sentido en que una razón para la acción puede presentarse como una razón para hacer o no hacer algo determinado, por un

${ }^{269}$ KAUFMANN, Normentheorie, cit. nota $\mathrm{n}^{\mathrm{o}} 16$, p. 133.

${ }^{270}$ NAGLER, Die Teilnahme, cit. nota n ${ }^{\circ} 256$, pp. 83 ss., 89 ss., 113 ss.

${ }^{271}$ En detalle al respecto NAGLER, Die Teilnahme, cit. nota $\mathrm{n}^{\circ} 256$, pp. 39 ss., 47 ss.

${ }^{272}$ NAGLER, Die Teilnahme, cit. nota $\mathrm{n}^{\mathrm{o}} 256$, pp. $115 \mathrm{~s}$.

${ }^{273}$ Latamente al respecto MAÑALICH, Norma, cit. nota $n^{\circ} 23$, pp. 71 ss., con referencias ulteriores.

${ }^{274}$ MAÑALICH, Norma, cit. nota $n^{\circ} 23$, pp. 86 ss. 
lado, y el sentido en que esa misma razón puede presentarse como una razón para prestar atención a algo, por otro. ${ }^{275}$ Esta distinción, añade Gardner, provee la base para racionalizar la distinción entre títulos de responsabilidad principal y títulos de responsabilidad secundaria (o accesoria):

"I am responsible for what I do, and you are responsible for what you do. But on any credible view I need to give attention, in what I do, to what you will do in consequence. And you need to give attention, in what you do, to what I will do in consequence. [...] There is what I should do simpliciter, and then there is what I should do by way of contribution to what you do. If I fail in the first I am a principal. If I fail in the second I am an accomplice. The truism 'I am responsible for my actions' cannot mean that I am responsible for my actions, never mind your actions. For my own actions inevitably include my actions of contributing to your actions". 276

Justamente a partir de la distinción entre el sentido en que una norma puede fungir como una razón (externa) para hacer o no hacer algo simpliciter, por un lado, y el sentido en que una norma puede fungir como una razón (externa) para hacer o no hacer algo en contribución a lo que otro hace o no hace, por otro, es posible afirmar que una norma especial es siempre, en el primer sentido, sólo una razón para que uno o más intranei hagan o no hagan algo determinado, pero que al mismo tiempo ella es, en el segundo sentido, una razón para que cualquiera, sea intraneus o extraneus, preste atención a lo que pudiera llegar a estar en posición de hacer o no hacer un intraneus, y así no contribuir a que éste la quebrante por sí mismo. Pues en estos términos se vuelve más fácilmente comprensible la observación de Nagler en cuanto a que "los bienes jurídicos que por de pronto sólo son alcanzables para un círculo restringidos de los sometidos [a la autoridad de la ley] y que, correspondientemente, en su totalidad sólo pueden ser puestos en peligro o lesionados por éstos, demanden respeto en cuanto a su intangibilidad de parte de todos". ${ }^{277}$

\subsection{2. ¿Arbitrariedad de la distinción entre normas generales y normas especiales?}

La distinción recién sugerida provee un punto de partida para enfrentar el muy difícil problema de ofrecer una reconstrucción estructural de la formulación (linguística) de una norma especial en el sentido ya esclarecido. El problema se presenta por la irreductible posibilidad de que la especificación de la clase de individuos que conforma el universo de destinatarios de la norma pretendidamente especial sea reformulada como la especificación de un componente o aspecto del tipo de acción sometido a la norma. ${ }^{278}$ En la terminología

\footnotetext{
${ }^{275}$ GARDNER, John, “Complicity and Causality”, Criminal Law and Philosophy 1, 2007, pp. 127-141, pp. 131 s.; véase también GARDNER, John, "Relations of Responsibility", en: CRUF, Rowan; KRAMER, Mathew; REIFF, Mark (eds.), Crime, Punishment, and Responsibility. The Jurisprudence of Antony Duff, Oxford y Nueva York: Oxford University Press, 2011, pp. 87-102, p. 89.

${ }^{276}$ GARDNER, "Complicity", cit. nota no 275 , p. 132.

${ }^{277}$ NAGLER, Die Teilnahme, cit. nota n 256 , p. 115.

${ }^{278}$ Al respecto ya KAUFMANN, Normentheorie, cit. nota $\mathrm{n}^{\circ} 16$, pp. 137 s.; detalladamente KAUFMANN, Armin, "Rechtspflichtbegründung und Tatbestandseinschränkung", en: KOHLMANN, Günter, (coord.), Festschrift für Ulrich Klug zum 70. Geburtstag, tomo II, Colonia: Dr. Peter Deubner Verlag, 1983, pp. 277292, pp. 283 ss.; específicamente en relación con las normas cuyo quebrantamiento por parte de un garante puede ser constitutivo de un delito de omisión impropia, KAUFMANN, Armin, Die Dogmatik der Unterlassungsdelikte. Gotinga: Otto Schwarz \& Co, 1959, p. 305.
} 


\section{Polít. crim. Vol. 14, No 27 (Julio 2019), Art. 10, pp. 296-375. [http://politcrim.com/wp-content/uploads/2019/05/Vol14N27A10.pdf]}

favorecida por Von Wright, quien claramente advirtió el problema, éste consiste en la posibilidad de reformular la cláusula que especifica el "sujeto-norma" como una cláusula que especifica una "condición de aplicación" que se añada a la mera oportunidad para realizar o no realizar el respectivo "contenido-norma". ${ }^{279}$ Así por ejemplo, una prohibición, dirigida a todo quien ostente el estatus de juez (esto es, formulada con especificación del "sujeto-norma"), de pronunciar una sentencia manifiestamente injusta (y sin especificación de una ulterior condición de aplicación), podría ser sin más reformulada como una prohibición, dirigida a cualquiera persona (esto es, sin especificación del "sujeto-norma"), de pronunciar una sentencia manifiestamente injusta si se ostenta la posición de juez (esto es, formulada con especificación de una ulterior condición de aplicación).

Al respecto, ciertamente cabe dar razón a Ross en su detección de que, "para los propósitos del análisis lógico", la demarcación entre normas expresadas bajo una y otra formulación "tiene que ser trazada arbitrariamente". ${ }^{280}$ Pero que la demarcación en cuestión resulte lógicamente arbitraria sólo significa que la opción por favorecer una u otra formulación, para así dar cuenta de la estructura de la norma respectiva, no puede pretender fundarse en premisas puramente lógicas. De ello no se sigue que no haya premisas de índole alguna que puedan llevar, razonadamente, a privilegiar una u otra formulación.

En la senda de lo sugerido por Nagler, esas premisas no pueden más que concernir a la fisonomía y la fundamentación de las decisiones de criminalización que, en cuanto plasmadas en la formulación de las respectivas normas de sanción, sirven como criterio de reconocimiento de las normas de comportamiento reforzadas por ellas. A este respecto, Nagler proponía un catálogo de indicadores del carácter de tipo-de-delito-especial como dato de técnica legislativa, consistentes en la especificación de "propiedades especiales jurídicamente relevantes" en cuanto condiciones de tipicidad. ${ }^{281}$ El catálogo de tales indicadores quedaba conformado por las categorías siguientes: a) una posición al interior de un determinado estamento que lleve aparejados deberes públicos especiales, por ejemplo, la posición de funcionario público, o bien la de ministro de un culto; b) una posición de vinculación especial al interior de una relación de derecho público con el Estado, por ejemplo, la condición de perito, o bien la de obligado al servicio militar; c) una posición de vinculación especial con otro u otros individuos en el marco de determinadas relaciones de derecho privado, por ejemplo, la posición de empleador, o bien la de tutor o curador; d) una posición de vinculación especial en el marco de una relación entre un individuo y algún objeto corporal determinado, por ejemplo, la posición de capitán de un navío, o bien la de plantador de tabaco; y e) la condición de representante u órgano de alguna colectividad con capacidad jurídico-privada, por ejemplo, la posición de director de una sociedad, o bien la de liquidador de una compañía aseguradora. ${ }^{282}$

El recurso a una versión debidamente actualizada, y ajustada a las particularidades del ordenamiento jurídico de referencia, de un catálogo tal debería servir de base para la identificación de aquellos tipos-de-delito que se dejan reconstruir, parsimoniosamente,

\footnotetext{
${ }^{279}$ VON WRIGHT, Norm, cit. nota $\mathrm{n}^{\mathrm{o}} 125$, pp. 70 ss., $81 \mathrm{s.}$

${ }^{280}$ ROSS, Directives, cit. nota ${ }^{\circ} 267$, p. 108.

${ }^{281}$ NAGLER, Die Teilnahme, cit. nota n ${ }^{\circ} 256$, pp. 26 s.

${ }^{282}$ Latamente al respecto NAGLER, Die Teilnahme, cit. nota n ${ }^{\circ} 256$, pp. 27 ss.
} 
como tipos de delito especial. Como sostuviera Nagler, el catálogo así construido tendría que distinguirse por la "codificación" de categorías que especifiquen posiciones individuales al interior de relaciones jurídicas que hagan suficientemente plausible la conjetura de que quien ocupa la correspondiente posición habría de quedar vinculado a normas capaces de fundamentar deberes específicamente sensibles a la ostentación o desempeño de la posición en cuestión. ${ }^{283}$ Y un presupuesto mínimo para ello está constituido por la doble exigencia de que la posición en cuestión quede identificada con la satisfacción de una descripción que especifica propiedades positivas que habría de exhibir el individuo en cuestión, y que a su vez no puedan ser plausiblemente reducidas a propiedades que haya de exhibir el objeto de referencia del correspondiente tipo de acción.

Así por ejemplo, habría que descartar sin más que el tipo del hurto pudiera ser entendido como el tipo de un delito especial en razón de que para ser autor de hurto es necesario no ser propietario de la cosa de cuya apropiación se trata. ${ }^{284}$ Pues por una parte, la cualidad consistente en no ser propietario de la cosa en cuestión es una cualidad puramente negativa, esto es, una propiedad que alguien exhibe en cuanto no exhibe la propiedad positiva consistente en ser dueño de esa misma cosa. Y por otra parte, ciertamente no basta que X no sea dueño de una cosa de la cual $X$ se apropia mediante sustracción para que, por esa vía, $X$ se haga autor de un hurto respecto de esa misma cosa. Antes bien, la cosa en cuestión debe ser ajena para $X$, esto es, pertenecer en dominio a una persona distinta de X, lo cual muestra que la pretendida propiedad de no ser dueño de la cosa resulta enteramente reducible a la propiedad de ser ajena que debe exhibir la cosa.

Por otra parte, y según ya se anticipara, es necesario enfatizar que la posición cuya ocupación por una persona ha de convertir a ésta en integrante del universo (cualificado) de destinatarios de una norma especial debe distinguirse por definir el lugar de una relación con relevancia jurídica, tal que esa relación pueda ser entendida como un presupuesto de la posible fundamentación de un concreto deber de abstención o acción sobre la base de la norma en cuestión, en congruencia con la finalidad de protección atribuida a ésta. De esto se sigue, por ejemplo, que la prohibición cuyo quebrantamiento es constitutivo del delito de incesto no deba caracterizarse como una norma especial, sino como una norma general, esto es, dirigida a toda persona. ${ }^{285}$ Pues si bien X sólo puede quebrantar (perfectamente) la prohibición del incesto manteniendo un contacto sexual con $Y$, en la medida en que entre $X$ e Y se dé un vínculo de parentesco de una cierta clase, la exigencia de semejante vínculo es enteramente reducible a una propiedad que, en relación con $\mathrm{X}, \mathrm{Y}$ ha de exhibir en cuanto persona con la cual $\mathrm{X}$ mantiene el contacto sexual en cuestión. A ello se añade que la

\footnotetext{
${ }^{283}$ Esto justifica caracterizar las normas de requerimiento cuyo quebrantamiento puede ser constitutivo de un delito de omisión impropia como normas especiales "dirigidas-a-garantes"; véase al respecto, y en detalle, MAÑALICH, Juan Pablo, “Omisión del garante e intervención delictiva”, Revista de Derecho Universidad Católica del Norte 21, n 2, 2014, pp. 225-276, pp. 241 ss., con múltiples referencias ulteriores.

${ }^{284}$ Así, empero, argumenta JAKOBS, Strafrecht, cit. nota $\mathrm{n}^{\circ} 47,6 / 91$, al sugerir que la caracterización de un delito como especial, y no como común, sería arbitraria, en la medida en que ella quede asociada a la exigencia de que la persona del autor exhiba determinadas propiedades o se encuentre en una determinada posición. Acertadamente al respecto, ya STRATENWERTH, Günter, "Der Versuch des untauglichen Subjekts", en: FRISCH, Wolfgang; SCHMID, Werner (coords.), Festschrift für Hans-Jürgen Bruns zum 70. Geburtstag, Colonia, Berlín, Bonn y Múnich: Carl Heymanns Verlag, 1978, pp. 59-69, pp. 65 s.

${ }^{285}$ Así ya NAGLER, Die Teilnahme, cit. nota n ${ }^{\circ} 256$, pp. 12 s.
} 


\section{Polít. crim. Vol. 14, No 27 (Julio 2019), Art. 10, pp. 296-375. [http://politcrim.com/wp-content/uploads/2019/05/Vol14N27A10.pdf]}

finalidad de protección atribuida a esa misma prohibición no habla a favor de convertir esa propiedad relacional, consistente en ser pariente consanguíneo, en un determinado grado, de la persona con la cual se mantiene el respectivo contacto sexual, en un criterio de cualificación de la posición definitoria del correspondiente "sujeto-norma". ${ }^{286}$ En tal medida, la prohibición del incesto no tiene el carácter de una norma especial "dirigida-aparientes", sino el de una norma general dirigida a cualquiera, referida a un tipo de acción especificado por el involucramiento de alguna persona con quien se tenga un determinado vínculo de parentesco.

\subsection{La "tentativa subjetivamente inidónea" como delito putativo}

El argumento precedente ha meramente pretendido demostrar que, tratándose de la reconstrucción de determinadas normas de comportamiento cuyo quebrantamiento es delictivo, tiene pleno sentido privilegiar una formulación de ellas que las presente, estructuralmente, como normas especiales, esto es, como normas dirigidas a un universo cualificado de individuos, en cuanto individuos que satisfacen una descripción cuya satisfacción fundamenta una posición de vinculación especial. La determinación precisa del subconjunto de las normas de comportamiento jurídico-penalmente reforzadas bajo un determinado ordenamiento jurídico que tienen el carácter de normas especiales, en ese preciso sentido, no es algo que deba ser acometido en el presente contexto. Aquí sólo interesa, más bien, observar que es en consideración de aspectos concernientes a la legitimación de la respectivas normas de comportamiento que esa demarcación ha de tener lugar, lo cual al mismo tiempo basta para dar razón a Nagler en cuanto a la necesidad de conferir validez general a la presunción de que, por defecto, una norma de comportamiento cualquiera habría de ser reconstruida como una norma general, a menos que la restricción de su ámbito (interno) de validez "a los pertenecientes a un círculo vital especial se obtenga con suficiente determinación". 287

La consideración precedente es suficiente para dar cuenta de cómo el estatus de una norma como norma especial impacta la configuración de la fisonomía de su eventual quebrantamiento imperfecto, en la forma de una tentativa del correspondiente delito especial. Esta pregunta es especialmente virulenta tratándose de aquellos casos en los cuales la falta de consumación se explica por la "inidoneidad subjetiva" del agente, esto es, por la circunstancia de que éste objetivamente no satisface la descripción que convierte a alguien en destinatario de la respectiva norma especial, lo cual es, empero, desconocido por el agente. Como se intentará mostrar a continuación, estos últimos son casos en los cuales no se constituye una tentativa del delito especial en cuestión.

\footnotetext{
${ }^{286}$ Que además de tratarse de un delito común, el incesto tenga el carácter de un delito de propia mano, es enteramente independiente de ello, y resulta, antes bien, de que el tipo de acción sometido a prohibición quede aquí especificado por una descripción que lo convierte en un tipo de acción "ejecutivamente autoinvolucrante". Al respecto, véase MAÑALICH, Juan Pablo, "La violación como delito contra la indemnidad sexual bajo el derecho penal chileno", Ius et Praxis 20, nº 2, 2014, pp. 21-70, pp. 44 ss., con nota 95; más detalladamente MAÑALICH, Juan Pablo, "La violación como delito de propia mano", Revista de Ciencias Penales XLIII, $\mathrm{n}^{\circ}$ 4, 2016, pp. 39-50, pp. 41 ss.

${ }^{287}$ NAGLER, Die Teilnahme, cit. nota no 256 , p. 11.
} 
En el marco de la discusión alemana, el hito doctrinal decisivo en la progresiva consolidación de la tesis favorable a la punibilidad de la así llamada "tentativa subjetivamente inidónea" estuvo constituido por la aparición, en 1955, de un breve pero eficaz artículo de Bruns. ${ }^{288}$ En lo fundamental, el argumento de Bruns apunta a extraer las consecuencias que a su juicio se seguían de una concepción subjetivista de los presupuestos de punibilidad de la tentativa para el problema aquí considerado. Una contribución innegable del trabajo de Bruns consiste en una muy clarificadora redefinición de la tradicional distinción entre una concepción objetivista y una concepción subjetivista a este respecto. Pues el argumento de Bruns, fundado en la tesis de la "equivalencia de todos los elementos del tipo en el marco de la inferencia por inversión", ${ }^{289}$ descansa en su irrestricto compromiso con el ya referido axioma de la "sustituibilidad", sub specie constitución de una tentativa punible, de la satisfacción de cualquier presupuesto objetivo del carácter delictivo del comportamiento del potencial autor por su representación errónea de circunstancias cuya existencia conllevaría la satisfacción de ese mismo presupuesto, ${ }^{290}$ que es, en efecto, lo distintivo de una concepción subjetivista.

Ya se ha establecido, empero, que el así llamado "argumento de la inversión" resulta enteramente impotente para la determinación de las condiciones de punibilidad de la tentativa. $^{291}$ De ahí que la tesis de la punibilidad de la así llamada "tentativa subjetivamente idónea" se sostenga o se caiga, exclusivamente, con la tesis de la "equivalencia de todos los elementos del tipo" desde el punto de la sustituibilidad de su satisfacción por la correspondiente representación errónea del agente. Pues esto último es lo que está precisamente en juego en la afirmación de Bruns en cuanto a que "todos los casos de este error, esto es, del error invertido acerca de las circunstancias del hecho, han de ser tratados, jurídico-penalmente, de igual manera". ${ }^{292}$

Aquí es fundamental reparar en que la controversia se encuentra, en efecto, circunscrita a casos en los cuales el extraneus se representa como existentes circunstancias que, de ser existentes, lo convertirían en intraneus. En los términos ya introducidos más arriba, esto quiere decir que el error en cuestión ha de tener el carácter de un error-de-referencia. Precisamente esto no se daría en un caso como el siguiente:

(19) Tras haber ganado el concurso público para un cargo de profesor de una universidad del Estado, y creyendo erróneamente que al ser notificado del resultado del concurso tendría lugar su instalación en el cargo, $\mathrm{P}$ acepta recibir un incentivo económico de parte de una editorial para recomendar a sus estudiantes un manual para el curso que $\mathrm{P}$ deberá impartir el semestre inmediatamente siguiente.

\footnotetext{
${ }^{288}$ Sobre el impacto del trabajo de Bruns, véase sólo HARDWIG, Werner, "Der Versuch bei untauglichem Subjekt", Goltdammer's Archiv für Strafrecht, 1957, pp. 170-176, pp. 170 ss.; STRATENWERTH, "Der Versuch", cit. nota $n^{\circ} 284$, p. 59, con nota 2.

${ }^{289}$ BRUNS, Hans-Jürgen, Der untaugliche Täter im Strafrecht, Karlsruhe: C.F. Müller, 1955, pp. 10 ss., 16 ss.

${ }^{290}$ Véase supra, 4.1 .

${ }^{291}$ Supra, 4.2.

${ }^{292}$ BRUNS, Der untaugliche Täter, cit. nota n 289, p. 18.
} 


\section{Polít. crim. Vol. 14, No 27 (Julio 2019), Art. 10, pp. 296-375. [http://politcrim.com/wp-content/uploads/2019/05/Vol14N27A10.pdf]}

En este caso es claro que el error padecido por $\mathrm{P}$ es uno concerniente a las condiciones, fijadas en la respectiva regla constitutiva, cuya satisfacción efectivamente determina que una persona pase a exhibir el estatus institucional de funcionario público. En tal medida, el solo hecho de que en (19) $\mathrm{P}$ se represente como existente una regla constitutiva inexistente, esto es, distinta de aquella validada por el respectivo régimen de derecho administrativo, es suficiente para sostener que una (errónea) consciencia de la ilicitud que $\mathrm{P}$ pudiese llegar a formarse en referencia a su comportamiento no podría sino corresponderse con un delito putativo. ${ }^{293} \mathrm{Y}$ esto es algo que un partidario de la tesis de la "equivalencia de todos los elementos del tipo", como Bruns, tendría que aceptar sin más.

Con ello, la pregunta aquí relevante necesita ser precisada como sigue: ¿puede resultar responsable como autor de la tentativa de un delito especial un extraneus que erróneamente tiene por existentes circunstancias cuya existencia lo convertirían en intraneus y que, bajo ese error, ejecuta u omite una acción cuya ejecución u omisión habría, ceteris paribus, de realizar el tipo en cuestión, de resultar imputable a un intraneus? Para ilustrar el punto, considérese ahora el caso siguiente:

(20) Tras haber ganado el concurso público para un cargo de profesor de una universidad del Estado, y creyendo erróneamente que su nombramiento en el cargo ya habría tenido lugar, $\mathrm{P}$ acepta recibir un incentivo económico de parte de una editorial para recomendar a sus estudiantes un manual para el curso que $\mathrm{P}$ deberá impartir el semestre inmediatamente siguiente.

Ante un caso como éste, entonces, la pregunta pasa a ser si, bajo la tipificación del cohecho plasmada en los arts. 248 y siguientes del Código Penal chileno, $\mathrm{P}$ podría resultar responsable como autor de una tentativa de cohecho.

Desde luego, la respuesta que se sigue de la tesis defendida por Bruns es afirmativa. Pero aquí es crucial reparar en la definición del concepto de delito especial que subyace a esa misma respuesta afirmativa, y que Bruns mismo sintetizara en la fórmula según la cual "la esencia de los delitos especiales [...] no radica en la exención de terceros del deber de obediencia, sino meramente en que sólo las personas designadas en la ley pueden perpetrar estos delitos en el estadio de la consumación". ${ }^{294}$ Como acertadamente observara Stratenwerth, semejante reformulación llevaría a suprimir toda posible particularidad de la estructura típica de los delitos especiales frente a la de los delitos comunes, de manera tal que, consistentemente aplicada, ella tendría que llevar a afirmar la posibilidad constructiva de que un extraneus responda como coautor de un delito (pretendidamente) especial, siempre que a su lado figure a lo menos un intraneus como coautor. ${ }^{295}$

En su defensa de la tesis de la "equivalencia de todos los elementos del tipo", Bruns intentó refutar la propuesta de una distinción, al interior de la categoría de los "elementos de la norma", entre los "elementos-de-acción" (Handlungsmerkmale) y los "elementos-de-autor" (Tätermerkmale), ${ }^{296}$ pormenorizadamente desarrollada por Armin Kaufmann y conducente

\footnotetext{
${ }^{293}$ Véase supra, 6.3.

${ }^{294}$ BRUNS, Der untaugliche Täter, cit. nota $\mathrm{n}^{\circ} 289$, p. 31.

${ }^{295}$ STRATENWERTH, "Der Versuch", cit. nota n' 284, p. 69.

${ }^{296}$ BRUNS, Der untaugliche Täter, cit. nota ${ }^{\circ} 289$, pp. 32 ss.
} 
a la solución de la imposibilidad de la constitución de una tentativa de delito especial en casos de "inidoneidad subjetiva" del agente. ${ }^{297}$ Mediante tal distinción, Kaufmann pretendía sustentar la tesis de que las circunstancias realizadoras de elementos-de-autor, en cuanto puros "elementos del deber jurídico" (Rechtspflichtmerkmale), no formarían parte del objeto de referencia del dolo. ${ }^{298}$ Pero como Kaufmann mismo llegara a advertirlo más tarde, tal disociación resulta imposible de compatibilizar con la consideración de que las cláusulas de los tipos-de-delito-especial que especifican el correspondiente "sujeto-norma" son, inequívocamente, elementos del tipo en cuestión, de lo cual se sigue que las circunstancias de cuya existencia depende que el agente satisfaga la correspondiente descripción deben formar parte del objeto de referencia del dolo. ${ }^{299}$

Pero de esto último no se sigue que la representación errónea de esas mismas circunstancias sea suficiente, todo lo demás siendo igual, para que a un extraneus resulte imputable una tentativa del respectivo delito especial. ${ }^{300}$ Pues lo contrario supondría desconocer que la particularidad de todo delito especial consiste en que se trata, en el sentido ya explicado, del quebrantamiento de una norma cuyo universo de destinatarios se ve restringido a una clase (abierta) de individuos que satisfacen una descripción que resulta fundante, desde el punto de vista de la legitimación de la norma, de una relación de vinculación especial. ${ }^{301} \mathrm{Y}$ desde esta perspectiva, la posición de un extraneus es la posición de alguien a quien no se encuentra dirigida la norma en cuanto razón inmediata para la omisión o la ejecución de acciones que ejemplifican el correspondiente tipo-de-acción, y así la posición de alguien que, por sí mismo, no puede quebrantar tal norma, tampoco imperfectamente. Pues aceptar lo contrario sería validar la proposición de que un agente que objetivamente no puede resultar obligado por la norma respectiva podría, no obstante, quedar solipsistamente obligado en virtud de una creencia errónea de su parte. ${ }^{302}$

De esto se sigue que la efectiva satisfacción del elemento del tipo de un delito especial que especifica las propiedades "fundantes-de-autoría" no es subjetivamente reemplazable por la representación errónea, por parte de un extraneus, de las circunstancias que lo realizarían objetivamente. ${ }^{303}$ En tal medida, la designación "tentativa subjetivamente inidónea" expresa una contradicción en los términos. Quien objetivamente no cuenta como destinatario de una norma no puede quebrantarla, sea en la forma de un delito consumado, sea en la forma de una tentativa, de manera tal que a su respecto la pregunta por una eventual adscripción de dolo no pueda llegar a ser planteada. La constelación así identificada se corresponde, en tal

\footnotetext{
${ }^{297}$ KAUFMANN, Normentheorie, cit. nota no 16, pp. 134 ss., 141 s., 148 ss., 155 s. Más recientemente, en la misma dirección, BLOY, René, "Die Bedeutung des Irrtums über die Täterrolle", Zeitschrift für die gesamte Strafrechtswissenschaft 117, 2005, pp. 3-36, pp. 31 ss., 33 ss.

${ }^{298}$ KAUFMANN, Normentheorie, cit. nota $\mathrm{n}^{\circ}$ 16, pp. 149 ss.; coincidentemente BLOY, "Die Bedeutung”, cit. nota $\mathrm{n}^{\circ} 297$, p. 32.

${ }^{299}$ KAUFMANN, "Rechtspflichtbegründung”, cit. nota $\mathrm{n}^{\circ} 278$, pp. 283 ss.

300 Así empero RENZIKOWSKI, "Wahnkausalität”, cit. nota no 55, pp. 319 s.

${ }^{301}$ Supra, 7.2.2.

302 Acertadamente en esta dirección ya HARDWIG, "Der Versuch", cit. nota no 288, p. 172; STRATENWERTH, "Der Versuch", cit. nota n ${ }^{\circ} 284$, pp. 68 s.; LANGER, Die Sonderstraftat, cit. nota $n^{\circ}$ 256, pp. 438 ss.

${ }^{303}$ KAUFMANN, "Rechtspflichtbegründung”, cit. nota n 278, pp. 283 ss.
} 


\section{Polít. crim. Vol. 14, No 27 (Julio 2019), Art. 10, pp. 296-375. [http://politcrim.com/wp-content/uploads/2019/05/Vol14N27A10.pdf]}

medida, con una constelación paradigmática de delito putativo, esto es, de un delito inexistente.

\section{Colofón: la heterogeneidad categorial del "delito putativo"}

Es posible poner término a la presente indagación echando un vistazo a la muy heterogénea muestra de instancias de delito putativo que han sido descubiertas en el esfuerzo por demarcar los contornos de la noción de tentativa de delito a través de su puesta en relación con el problema de la exclusión y la fundamentación del dolo en virtud de errores (negativa o positivamente) referidos a las circunstancias de cuya existencia depende o dependería que un comportamiento exhiba las respectivas propiedades fundantes-de-antinormatividad.

Que en casos estructuralmente tan dispares como los que involucran la constatación de una "tentativa irreal (o supersticiosa)", o bien la constatación de un error-de-sentido invertido acerca del alcance de un elemento normativo del tipo en cuestión, o bien un desconocimiento por el agente de su "inidoneidad subjetiva" bajo el tipo de un determinado delito especial, quepa postular la existencia de un delito putativo, está lejos de ser una casualidad. Pues como ya observara Struensee, "el delito putativo no es un fenómeno autosuficiente" y tampoco necesitaría recibir una "determinación conceptual segura", en cuanto la expresión en cuestión se comporta, más bien, como una "designación aglutinadora no cerradamente fijada", ${ }^{304}$ esto es, como la designación de un género nominal. ${ }^{305} \mathrm{Y}$ esto se comprueba en el hecho de que, como lo ha enfatizado Kindhäuser, "en el juzgamiento jurídico-penal de un comportamiento no se presenta ocasión alguna para la comprobación de un delito putativo", puesto que "una norma que no existe tampoco tiene un supuesto de hecho (objetivo) bajo el cual la descripción [concreta] de un comportamiento pudiera ser subsumida". ${ }^{306}$

${ }^{304}$ STRUENSEE, "Verursachungsvorsatz", cit. nota no 122, pp. $41 \mathrm{~s}$.

305 Sobre esto, véase MOORE, Michael, Placing Blame. A Theory of the Criminal Law, Oxford y Nueva York: Oxford University Press, 1997, p. 19, quien observa: "A nominal kind is simply a set of individual things that shares no nature save a common name used to refer collectively to the class". Agradezco a Javier Contesse por la sugerencia de esta categorización.

${ }^{306}$ KINDHÄUSER, "Versuch", cit. nota n ${ }^{\text {0 } 7, ~ p . ~} 325$. 


\section{Bibliografía}

ALCÁCER, Rafael, La tentativa inidónea, Granada: Editorial Comares, 2000.

ALWART, Heiner, Strafwürdiges Versuchen, Berlín: Duncker \& Humblot, 1982.

ARMSTRONG, David, A World of States of Affairs, Cambridge: Cambridge University Press, 1997.

AUDI, Robert, Epistemology. A contemporary introduction to the theory of knowledge, $2^{\mathrm{a}}$ ed., Nueva York y Londres: Routledge, 2003.

BINDING, Karl, Handbuch des Strafrechts, Léipzig: Felix Meiner, 1885.

BINDING, Karl, Die Normen und ihre Übertretung, tomo II-1, 2a ed., Léipzig: Felix Meiner, 1914.

BINDING, Karl, Strafrechtliche und strafprozessuale Abhandlungen, tomo I, Múnich y Léipzig: Duncker \& Humblot, 1915.

BINDING, Karl, Die Normen und ihre Übertretung, tomo III, Léipzig: Felix Meiner, 1918.

BINDING, Karl, Die Normen und ihre Übertretung, tomo I, $4^{\mathrm{a}}$ ed., Léipzig: Felix Meiner, 1922.

BINDING, Karl, La culpabilidad en el derecho penal, Trad. CANCIO, Manuel, Buenos Aires y Montevideo: BdF, 2009.

BLOY, René, "Unrechtsgehalt und Strafbarkeit des grob unverständigen Versuchs", Zeitschrift für die gesamte Strafrechtswissenschaft 113, 2001, pp. 76-111.

BLOY, René, "Die Bedeutung des Irrtums über die Täterrolle", Zeitschrift für die gesamte Strafrechtswissenschaft 117, 2005, pp. 3-36.

BRUNS, Hans-Jürgen, Der untaugliche Täter im Strafrecht, Karlsruhe: C.F. Müller, 1955.

BURKHARDT, Björn, "Rechtsirrtum und Wahndelikt", Juristenzeitung, 1981, pp. 681688.

BURKHARDT, Björn, "Nachschlag zum Wahndelikt", Goltdammer's Archiv für Strafrecht, 2013, pp. 346-359.

COHEN, Morris; NAGEL, Ernest, Introducción a la Lógica y al Método Científico, tomo I, Trad. MIGUEL, Nestor, Buenos Aires: Amorrortu editores, 1968.

CURY, Enrique, Tentativa y delito frustrado, Santiago: Editorial Jurídica de Chile, 1977.

DAVIDSON, Donald, Truth and Predication, Cambridge (Mass.) y Londres: The Belknap Press, 2005.

DUFF, Antony, Criminal Attempts, Oxford: Clarendon Press, 1996.

ENGISCH, Karl, "Der ,umgekehrte Irrtum' und das ,Umkehrprinzip“", en: LÜTTGER, Hans (coord.), Festschrift für Ernst Heinitz zum 70. Geburtstag, Berlín: Walter de Gruyter, 1972, pp. 185-205.

FAKHOURI, Yamila, El objeto del dolo en derecho penal, Bogotá: Universidad Externado de Colombia, 2012.

FARRÉ TREPAT, Elena, La tentativa de delito, $2^{\mathrm{a}}$ ed., Madrid, Montevideo y Buenos Aires: Edisofer y BdF, 2011.

FIEDLER, Herbert, Vorhaben und Versuch im Strafrecht, Baden-Baden: Nomos, 1967.

FREGE, Gottlob, Logische Untersuchungen, Gotinga: Vandenhoeck \& Ruprecht, 1966.

GARDNER, John, "Complicity and Causality", Criminal Law and Philosophy 1, 2007, pp. 127-141. 
Polít. crim. Vol. 14, No 27 (Julio 2019), Art. 10, pp. 296-375.

[http://politcrim.com/wp-content/uploads/2019/05/Vol14N27A10.pdf]

GARDNER, John, "Relations of Responsibility", en: CRUF, Rowan; KRAMER, Mathew; REIFF, Mark (eds.), Crime, Punishment, and Responsibility. The Jurisprudence of Antony Duff, Oxford y Nueva York: Oxford University Press, 2011, pp. 87-102.

GARRIDO, Mario, Etapas de ejecución del delito. Autoría y participación, Santiago: Editorial Jurídica de Chile, 1984.

GASKING, Douglas, "Causation and Recipes", Mind 64, 1955, pp. 479-487.

GETTIER, Eduard, "Is Justified True Belief Knowledge?", Analysis 23, nº 6, 1963, pp. 121-123.

GÓMEZ MARTIN, Víctor, Los delitos especiales, Madrid, Montevideo y Buenos Aires: Edisofer y BdF, 2006.

GONZÁLEZ LAGIER, Daniel, Acción y norma en G.H. von Wright, Madrid: Centro de Estudios Constitucionales, 1995.

HAAS, Volker, "Die strafrechtliche Lehre von der objektiven Zurechnung - eine Grundsatzkritik", en: KAUFMANN, Matthias; RENZIKOWSKI, Joachim. (coords.), Zurechnung als Operationalisierung von Verantwortung, Fráncfort del Meno: Peter Lang, 2004, pp. 193-224.

HAAS, Volker, "Zum Rechtsgrund von Versuch und Rücktritt", Zeitschrift für die gesamte Strafrechtswissenschaft 123, 2011, pp. 226-259.

HACKER, P.M.S., The Intellectual Powers. A Study of Human Nature, Malden (Mass.), Oxford y Chichester (West Sussex): Wiley-Blackwell, 2013.

HÄLSCHNER, Hugo, Das Gemeine Deutsche Strafrecht, vol. I., Bonn: Adolph Marcus, 1881.

HARDWIG, Werner, "Der Versuch bei untauglichem Subjekt", Goltdammer's Archiv für Strafrecht, 1957, pp. 170-176.

HART, H.L.A, "The House of Lords on Attempting the Impossible", Oxford Journal of Legal Studies 1, 1981, pp. 149-166.

HART, H.L.A., The Concept of Law, $3^{\mathrm{a}}$ ed., Oxford: Oxford University Press, 2012.

HEMPEL, Carl, Philosophy of Natural Science, Upper Saddle River (N.J.): Prentice-Hall, 1966.

HEMPEL, Carl, The Philosophy of Carl. G. Hempel, Oxford: Oxford University Press, 2001.

HRUSCHKA, Joachim, Strukturen der Zurechnung, Berlín y Nueva York: Walter de Guyter, 1976.

HRUSCHKA, Joachim, Strafrecht nach logisch-analytischer Methode, $2^{\mathrm{a}}$ ed, Berlín: Walter de Gruyter, 1988.

JAKOBS, Günther, "Tätervorstellung und objektive Zurechnung", en: DORNSEIFER, Gerhard et al. (coords.), Gedächtnisschrift für Armin Kaufmann, Colonia, Berlín, Bonn y Múnich: Carl Heymanns Verlag, 1989, pp. 271-288.

JAKOBS, Günther, Strafrecht Allgemeiner Teil, 2a ed., Berlín: Walter de Gruyter, 1991.

JAKOBS, Günther, La imputación objetiva en derecho penal, Trad. CANCIO, Manuel, Buenos Aires: Ad-Hoc, 1996.

JAKOBS, Günther, "Altes und Neues zum strafrechtlichen Vorsatzbegriff", Rechtswissenschaft, 2010, pp. 283-315.

JIMÉNEZ DE ASÚA, Luis, Tratado de Derecho Penal, tomo VII, $3^{\mathrm{a}}$ ed., Buenos Aires: Losada, 1985. 


\section{distinción entre tentativa y delito putativo".}

JOERDEN, Jan, "Wesentliche und unwesentliche Abweichungen zurechnungsrelevanter Urteile des Täters von denen des Richters", Jahrbuch für Recht und Ethik 2, 1994, pp. 307-325.

KAUFMANN, Armin, Lebendiges und Totes in Bindings Normentheorie, Gotinga: Otto Schwarz \& Co, 1954.

KAUFMANN, Armin, Die Dogmatik der Unterlassungsdelikte. Gotinga: Otto Schwarz \& Co, 1959.

KAUFMANN, Armin, "Rechtspflichtbegründung und Tatbestandseinschränkung", en: KOHLMANN, Günter (coord.), Festschrift für Ulrich Klug zum 70. Geburtstag, tomo II, Colonia: Dr. Peter Deubner Verlag, 1983, pp. 277-292.

KIM, Jaegwon, Mind in a Physical World, Cambridge (Mass.): The MIT Press, 1998.

KIM, Jaegwon, Physicalism, or Something Near Enough, Princeton y Oxford: Princeton University Press, 2005.

KIM, Jaegwon, Essays in the Metaphysics of Mind, Oxford: Oxford University Press, 2010.

KINDHÄUSER, Urs, Intentionale Handlung, Berlín: Duncker \& Humblot, 1980.

KINDHÄUSER, Urs, "Der Vorsatz als Zurechnungskriterium”, Zeitschrift für die gesamte Strafrechtswissenschaft 96, 1984, pp. 1-35.

KINDHÄUSER, Urs, "Rohe Tatsachen und normative Tatbestandsmerkmale", Jura, 1984, pp. 465-478.

KINDHÄUSER, Urs, Gefährdung als Straftat, Fráncfort del Meno: Vittorio Klostermann, 1989.

KINDHÄUSER, Urs, “Zur Unterscheidung von Tat- und Rechtsirrtum”, Goltdammer's Archiv für Strafrecht, 1990, pp. 407-423.

KINDHÄUSER, Urs, "Objektive und subjektive Zurechnung beim Vorsatzdelikt", en: BYRD, Sharon; JOERDEN, Jan (coords.), Philosophia Practica Universalis. Festschrift für Joachim Hruschka, Berlín: Duncker \& Humblot, 2005, pp. 527-542.

KINDHÄUSER, Urs, "Der subjektive Tatbestand im Verbrechensaufbau. Zugleich eine Kritik der Lehre von der objektiven Zurechnung", Goltdammer's Archiv für Strafrecht, 2007, pp. 447-468.

KINDHÄUSER, Urs, "Risikoerhöhung und Risikoverringerung", Zeitschrift für die gesamte Strafrechtswissenschaft 120, 2008, pp. 481-503.

KINDHÄUSER, Urs, Strafgesetzbuch. Lehr- und Praxiskommentar, $4^{\mathrm{a}} \mathrm{ed}, 2010$.

KINDHÄUSER, Urs, "Versuch und Wahn. Zum Irrtum über Rechtstatsachen", en: SAFFERLING, Christoph et al. (coords.), Festschrift für Franz. Streng zum 70. Geburtstag, Heidelberg: C.F. Müller, 2017, pp. 325-342.

KINDHÄUSER, Urs, "Zur ,Drittwirkung' strafrechtlicher Verhaltensnormen”, en: SALIGER, Frank et al. (coords.), Rechtsstaatliches Strafrecht. Festschrift für Ulfrid Neumann zum 70. Geburtstag, Heidelberg: C.F. Müller, 2017, pp. 917-930.

KÜHL, Kristian, Strafrecht Allgemeiner Teil, 4ª ed., Múnich: Verlag Vahlen, 2002.

LANGER, Winrich, Die Sonderstraftat, 2a ed., Berlín: Duncker \& Humblot, 2007.

MACKIE, J.L., The Cement of the Universe, Oxford: Clarendon Press, 1980.

MAIER, Thomas, Die Objektivierung des Versuchsunrechts, Berlín: Duncker \& Humblot, 2005.

MAÑALICH, Juan Pablo, Nötigung und Verantwortung, Baden-Baden: Nomos, 2009.

MAÑALICH, Juan Pablo, "La estructura de la autoría mediata", Revista de Derecho de la Pontificia Universidad Católica de Valparaíso 34, 2010, pp. 385-414. 
Polít. crim. Vol. 14, No 27 (Julio 2019), Art. 10, pp. 296-375.

[http://politcrim.com/wp-content/uploads/2019/05/Vol14N27A10.pdf]

MAÑALICH, Juan Pablo, "El delito como injusto culpable. Sobre la conexión funcional entre el dolo y la consciencia de la antijuridicidad", Revista de Derecho de la Universidad Austral de Chile 24, 2011, pp. 87-115.

MAÑALICH, Juan Pablo, "Determinismo, autonomía y responsabilidad penal", en: KINDHÄUSER, Urs; MAÑALICH, Juan Pablo, Pena y culpabilidad en el Estado democrático de derecho, $2^{\mathrm{a}}$ ed., Montevideo y Buenos Aires: BdF, 2011, pp. 181210.

MAÑALICH, Juan Pablo, "El concepto de acción y el lenguaje de la imputación”, DOXA 35, 2012, pp. 663-690.

MAÑALICH, Juan Pablo, "La malversación de caudales públicos y el fraude al fisco como delitos especiales", Política Criminal 7, n $\mathrm{n}^{\circ}$ 14, 2012, pp. 357-377.

MAÑALICH, Juan Pablo, Norma, causalidad y acción, Madrid, Barcelona, Buenos Aires y San Pablo: Marcial Pons, 2014.

MAÑALICH, Juan Pablo, "Normas permisivas y deberes de tolerancia", Revista Chilena de Derecho 41, nº 2, 2014, pp. 473-522.

MAÑALICH, Juan Pablo, "Omisión del garante e intervención delictiva", Revista de Derecho Universidad Católica del Norte 21, $\mathrm{n}^{\circ}$ 2, 2014, pp. 225-276.

MAÑALICH, Juan Pablo, "La violación como delito contra la indemnidad sexual bajo el derecho penal chileno", Ius et Praxis 20, nº 2, 2014, pp. 21-70.

MAÑALICH, Juan Pablo, "La imprudencia como estructura de imputación", Revista de Ciencias Penales XLII, $\mathrm{n}^{\circ}$ 3, 2015, pp. 13-35.

MAÑALICH, Juan Pablo, "El concurso aparente como herramienta de cuantificación penológica de hechos punibles", en: CÁRDENAS, Claudia; FERDMAN, Jorge (coords.), El derecho penal como teoría y práctica. Libro homenaje a Alfredo Etcheberry Orthusteguy, Santiago: La Ley/Thomson Reuters, 2016, pp. 501-548.

MAÑALICH, Juan Pablo, "La violación como delito de propia mano", Revista de Ciencias Penales XLIII, ${ }^{\circ}$ 4, 2016, pp. 39-50.

MAÑALICH, Juan Pablo, "La tentativa como hecho punible. Una aproximación analítica", Revista Chilena de Derecho 44, nº 2, 2017, pp. 461-493.

MAÑALICH, Juan Pablo, “¿Incompatibilidad entre frustración y dolo eventual?”, Revista de Estudios de la Justicia 27, 2017, pp. 171-182.

MEZGER, Edmund, Tratado de Derecho Penal, tomo II, Trad. RODRÍGUEZ, José, $3^{\text {a }}$ ed., Madrid: Editorial Revista de Derecho Privado, 1957.

MITSCH, Wolfgang, "§ 23 Abs. 3 StGB: grob unverständiges Strafrecht”, Zeitschrift für internationale Strafrechtsdogmatik 6, 2016, pp. 352-365.

MONTIEL, Juan Pablo; RAMÍREZ, Lorena, "De camareros estudiantes de biología a jueces biólogos. A propósito de la sentencia del BGH sobre los hongos alucinógenos y la deferencia a los expertos en el ámbito penal", InDret 1, 2010, en: [http://www.indret.com/pdf/691.pdf].

MOORE, Michael, "The Semantics of Judging", Southern California Law Review 54, 1981, pp. 151-294.

MOORE, Michael, "A Natural Law Theory of Interpretation", Southern California Law Review 58, 1985, pp. 277-398.

MOORE, Michael, Placing Blame. A Theory of the Criminal Law, Oxford y Nueva York: Oxford University Press, 1997. 


\section{distinción entre tentativa y delito putativo".}

MORENO-TORRES, $\mathrm{M}^{\mathrm{a}}$ Rosa, Tentativa de delito y delito irreal, Valencia: Tirant lo Blanch, 1999.

NAGLER, Johannes, Die Teilnahme am Sonderverbrechen, Léipzig: Wilhelm Engelmann, 1903.

NAVARRO, Pablo; MORESO, José Juan, “Aplicabilidad y eficacia de las normas jurídicas", Isonomía 5, 1996, pp. 119-139.

NEUMANN, Ulfrid, "Normtheorie und strafrechtliche Zurechnung", Goltdammer's Archiv für Strafrecht, 1985, pp. 389-401.

NEUMANN, Ulfrid, "Regel und Sachverhalt in der strafrechtlichen Irrtumsdogmatik", en: PAEFFGEN, Hans-Ullrich et al. (coords.), Strafrechtswissenschaft als Analyse und Konstruktion. Festschrift für Ingeborg Puppe zum 70. Geburtstag, Berlín: Duncker \& Humblot, 2011, pp. 171-187.

NEUMANN, Ulfrid, "Normlogik, Argumentationstheorie und das Problem der negativen Tatbestandsmerkmale", en: KARDA, Piotr, et al. (coords.), Państwo prawa i prawo karne. Księga Jubileuszowa Profesora Andrzeja Zolla, tomo II, Varsovia: Wolters Kluwer, 2012, pp. 417-432.

NOVOA, Eduardo, "Algunas consideraciones acerca de la tentativa", Revista de Ciencias Penales XX, n $1,3^{\mathrm{a}}$ época, 1961, pp. 3-32.

NOZICK, Robert, Philosophical Explanations, Cambridge (Mass.): The Belknap Press, 1981.

OLAVE, Alejandra, "El delito de hurto como tipo de delito de resultado", Política Criminal 13, no 25, 2018, pp. 175-207.

PARDO, Michael; PATERSON, Dennis, Minds, Brains, and Law, Oxford y Nueva York: Oxford University Press, 2013.

POLITOFF, Sergio, Los actos preparatorios del delito. Tentativa y frustración, Santiago: Editorial Jurídica de Chile, 1999.

PUPPE, Ingeborg, Strafrechtsdogmatische Analyse, Gotinga: Vandenhoeck \& Ruprecht, 2006.

PUPPE, Ingeborg, Kleine Schule des juristischen Denkens, $2^{\mathrm{a}}$ ed., Gotinga: Vandenhoeck \& Ruprecht, 2011.

PUPPE, Ingeborg, "Der Umkehrschluss", Zeitschrift für die gesamte Strafrechtswissenschaft 128, 2016, pp. 301-315.

PUPPE, Ingeborg, "Die Zurechnung des Erfolgs zum Vorsatz", Zeitschrift für die gesamte Strafrechtswissenschaft 129, 2017, pp. 1-19.

PUTNAM, Hilary, Mind, Language and Reality, Cambridge: Cambridge University Press, 1975.

RAGUÉS, Ramón, El dolo y su prueba en el proceso penal, Barcelona: Bosch, 1999.

RENZIKOWSKI, Joachim, "Wahnkausalität und Wahndelikt — zur Strafbarkeit des untauglichen Versuchs", KAUFMANN, Matthias (coord.), Wahn und Wirklichkeit Multiple Realitäten, Fráncfort del Meno: Peter Lang, 2003, pp. 309-322.

RESCHER, Nicholas, Epistemology. An Introduction to the Theory of Knowledge, Nueva York: Universidad del Estado de Nueva York, 2003.

REYES, Yesid, El delito de tentativa, Montevideo y Buenos Aires: BdF, 2016.

ROSS, Alf, Directives and Norms, Nueva York: Humanities Press, 1968.

RYLE, Gilbert, The Concept of Mind, Chicago: The University of Chicago Press, 1949. 
Polít. crim. Vol. 14, No 27 (Julio 2019), Art. 10, pp. 296-375.

[http://politcrim.com/wp-content/uploads/2019/05/Vol14N27A10.pdf]

SANCINETTI, Marcelo, Fundamentación subjetiva del ilícito y desistimiento de la tentativa, Bogotá: Temis, 1995.

SAX, Walter, "Zum logischen und sachlichen Gehalt des sogen. Umkehrschlusses aus § 59 StGB”, Juristenzeitung, 1964, pp. 241-245.

SEARLE, John, Intentionality, Cambridge: Cambridge University Press, 1983.

SEARLE, John, The Construction of Social Reality, Nueva York: The Free Press, 1995.

SEARLE, John, Mind. A Brief Introduction, Oxford y Nueva York: Oxford University Press, 2004.

SEARLE, John, Making the Social World, Oxford y Nueva York: Oxford University Press, 2010.

SEARLE, John; VANDERVEKEN, Daniel, Foundations of illocutionary logic, Cambridge: Cambridge University Press, 1985.

SEMINARA, Sergio, Il delitto tentato, Milán: Giuffrè Editore, 2012.

SOLA RECHE, Esteban, La llamada «tentativa inidónea» de delito. Aspectos básicos, Granada: Comares, 1996.

SCHRÖDER, Jürgen, Einführung in die Philosophie des Geistes, Fráncfort del Meno: Suhrkamp, 2004.

SPENDEL, Günter, "Der sogenannte Umkehrschluß aus $§ 59$ StGB nach der subjektiven Versuchstheorie", Zeitschrift für die gesamte Strafrechtswissenschaft 69, 1957, pp. 441-459.

SPENDEL, Günter, "Kritik der subjektiven Versuchstheorie", Neue Juristische Wochenschrift, 1965, pp. 1881-1888.

STARK, Findlay, Culpable Carelessness. Recklessness and Negligence in the Criminal Law, Cambridge: Cambridge University Press, 2016.

STRATENWERTH, Günter, "Der Versuch des untauglichen Subjekts", en: FRISCH, Wolfgang; SCHMID, Werner (coords.), Festschrift für Hans-Jürgen Bruns zum 70. Geburtstag, Colonia, Berlín, Bonn y Múnich: Carl Heymanns Verlag, 1978, pp. 5969.

STRENG, Franz, "Der Irrtum beim Versuch - ein Irrtum?", Zeitschrift für die gesamte Strafrechtswissenschaft 109, 1997, pp. 862-899.

STRUENSEE, Eberhard, "Verursachungsvorsatz und Wahnkausalität", Zeitschrift für die gesamte Strafrechtswissenschaft 102, 1990, pp. 21-50.

TOEPEL, Friedrich, "Zur Abgrenzung von untauglichem Versuch und Wahndelikt", Zeitschrift für internationale Strafrechtsdogmatik 10, 2017, pp. 606-611.

VILLAR, Mario, Suerte penal. Un estudio acerca de la interferencia de la suerte en los sistemas de imputación, Buenos Aires: ediciones Didot, 2016.

VON BURI, Maximilian, Abhandlungen aus dem Strafrecht, Gießen: Ferber'sche Universitäts-Buchhandlung, 1862.

VON BURI, Maximilian, "Zur Lehre vom Versuche”, Der Gerichtssaal 19, 1867, pp. 6080.

VON BURI, Maximilian, "Der Versuch des Verbrechens mit untauglichen Mitteln oder an einem untrüglichen Object", Der Gerichtssaal 20, 1868, pp. 325-335.

VON BURI, Maximilian, "Versuch und Kausalität", Der Gerichtssaal 32, 1880, pp. 321389.

VON BURI, Maximilian, “Über die sog. untauglichen Versuchshandlungen”, Zeitschrift für die gesamte Strafrechtswissenschaft 1, 1881, pp. 185-210. 


\section{distinción entre tentativa y delito putativo".}

VON WRIGHT, Georg Henrik, Norm and Action, Londres: Routledge \& Kegan Paul, 1963.

VON WRIGHT, Georg Henrik, The Varieties of Goodness, Londres: Routledge \& Kegan Paul, 1963.

VON WRIGHT, Georg Henrik, Explanation and Understanding, Londres: Routledge \& Kegan Paul, 1971.

VON WRIGHT, Georg Henrik, Practical Reason. Philosophical Papers I, Oxford: Basil Blackwell, 1983.

WACHTER, Matthias, Das Unrecht der versuchten Tat, Friburgo: Mohr Siebeck, 2015.

WRIGHT, Richard, "Causation, Responsibility, Risk, Probability, Naked Statistics, and Proof: Pruning the Bramble Bush by Clarifying the Concepts", Iowa Law Review 73, 1988, pp. 1001-1077.

YAFFE, Gideon, Attempts in the Philosophy of Action and in the Criminal Law, Oxford: Oxford University Press, 2010.

ZACZYK, Rainer, "§ 22” y “\$ 23”, en: KINDHÄUSER, Urs; NEUMANN, Ulfrid; PAEFFGEN, Hans-Ullrich (coords.), Strafgesetzbuch. NomosKommentar, $5^{\mathrm{a}}$ ed., tomo I, 2017, pp. 1036-1084.

ZIMMERMAN, Michael, Living with Uncertainty. The Moral Significance of Ignorance, Cambridge: Cambridge University Press, 2008. 